\title{
Mechanisms of vasodilatation in early pregnancy : studies in instrumented conscious rats and isolated rat arteries
}

Citation for published version (APA):

van Eijndhoven, H. W. F. (2009). Mechanisms of vasodilatation in early pregnancy : studies in instrumented conscious rats and isolated rat arteries. [Doctoral Thesis, Maastricht University]. Maastricht University. https://doi.org/10.26481/dis.20091211he

Document status and date:

Published: 01/01/2009

DOI:

10.26481/dis.20091211he

Document Version:

Publisher's PDF, also known as Version of record

Please check the document version of this publication:

- A submitted manuscript is the version of the article upon submission and before peer-review. There can be important differences between the submitted version and the official published version of record.

People interested in the research are advised to contact the author for the final version of the publication, or visit the DOI to the publisher's website.

- The final author version and the galley proof are versions of the publication after peer review.

- The final published version features the final layout of the paper including the volume, issue and page numbers.

Link to publication

\footnotetext{
General rights rights.

- You may freely distribute the URL identifying the publication in the public portal. please follow below link for the End User Agreement:

www.umlib.nl/taverne-license

Take down policy

If you believe that this document breaches copyright please contact us at:

repository@maastrichtuniversity.nl

providing details and we will investigate your claim.
}

Copyright and moral rights for the publications made accessible in the public portal are retained by the authors and/or other copyright owners and it is a condition of accessing publications that users recognise and abide by the legal requirements associated with these

- Users may download and print one copy of any publication from the public portal for the purpose of private study or research.

- You may not further distribute the material or use it for any profit-making activity or commercial gain

If the publication is distributed under the terms of Article $25 \mathrm{fa}$ of the Dutch Copyright Act, indicated by the "Taverne" license above, 


\section{MECHANISMS OF VASODILATATION IN EARLY PREGNANCY}

Studies in instrumented conscious rats and isolated rat arteries

H.W.F. van Eijndhoven 
(C) van Eijndhoven, H.W.F.

All rights reserved. No part of this book may be reproduced, stored in a retrieval system, or transmitted, in any form or by any means, electronic, mechanical, photocopying, recording or otherwise, without the prior written permission of the copyright holder.

ISBN / EAN: 9789090248424

Cover design: Hugo van Eijndhoven

Lay-out: Thea Schenk

Printer: $\quad$ Gildeprint, Enschede 


\title{
MECHANISMS OF VASODILATATION IN EARLY PREGNANCY
}

Studies in instrumented conscious rats and isolated rat arteries

\author{
proefschrift
}

Ter verkrijging van de graad van doctor

aan de Universiteit Maastricht,

op gezag van de Rector Magnificus,

Prof. mr. G.P.M.F. Mols

volgens het besluit van het College van Decanen,

in het openbaar te verdedigen

op vrijdag 11 december 2009 om 12:00 uur

door

Hugo Willem Frans van Eijndhoven

geboren op 30 januari 1967 te Delft 


\section{Promotores}

Prof. dr. J. de Haan

Prof. dr. J.G.R. De Mey

\section{Copromotor}

Dr. L.L.H. Peeters

Beoordelingscommissie

Prof. dr. G.G.M. Essed (voorzitter)

Prof. dr. J. Glatz

Prof. dr. P.W. de Leeuw

Prof. dr. H.A.J. Struijker Boudier 


\section{Contents}

Abbreviations

vii

CHAPTER 1 General introduction

1

CHAPTER 2 Hemodynamic changes in pseudopregnancy in chronically instrumented, conscious rats are preserved after hysterectomy

CHAPTER 3 Vasodilator reactivity to calcitonin gene-related peptide is increased in mesenteric arteries of rats during early pregnancy

CHAPTER 4 Mechanisms leading to increased vasodilator responses to calcitonin gene-related peptide in mesenteric resistance arteries of early pregnant rats

CHAPTER 5 Pregnancy enhances the prejunctional vasodilator response to adrenomedullin in selective regions of the arterial bed of Wistar rats

CHAPTER 6 Mechanisms of vasodilatation in early pregnancy: role of nitric oxide and vascular remodeling in blunted vasoconstrictor responses

CHAPTER 7 General discussion and summary 91

CHAPTER 8 Nederlandse samenvatting .... 103

Dankwoord 109

Curriculum Vitae 113 



\section{Abbreviations}

$\begin{array}{ll}\text { ADM } & \text { adrenomedullin } \\ \text { AT } & \text { angiotensin } \\ \text { AVP } & \text { arginine vasopressin } \\ \text { cAMP } & \text { cyclic adenosine monophosphate } \\ \text { cGMP } & \text { cyclic guanosine monophosphate } \\ \text { CGRP } & \text { calcitonin gene-related peptide } \\ \text { CO } & \text { cardiac output } \\ \text { CRLR } & \text { calcitonin receptor-like receptor } \\ \text { CSA } & \text { media cross-sectional area } \\ \text { E2 } & \text { 17ß-estradiol } \\ \text { EFS } & \text { electric field stimulation } \\ \text { ET } & \text { endothelin } \\ \text { KRB } & \text { Krebs } \\ \text { L-NAME } & \text { N } \text {-Nitro-L-arginine methyl ester } \\ \text { MAP } & \text { mean arterial pressure } \\ \text { MMP } & \text { matrix metalloproteinase } \\ \text { Mt } & \text { media thickness } \\ \text { NO } & \text { nitric oxide } \\ \text { NOS } & \text { nitric oxide synthase } \\ \text { RAMP } & \text { receptor activity modifying protein } \\ \text { RAS } & \text { renin-angiotensin system } \\ \text { RCP } & \text { receptor component protein } \\ \text { SV } & \text { stroke volume } \\ \text { SW } & \text { stroke work } \\ \text { TPR } & \text { total peripheral resistance } \\ \text { VIP } & \text { vasoactive intestinal peptide } \\ & \end{array}$





\section{CHAPTER 1}

GENERAL INTRODUCTION 



\section{CHAPTER 1}

Pregnancy induces marked changes in the maternal organism, many of them related to the cardiovascular and renal functions. The hemodynamic adaptation to pregnancy results in the institution of a high flow and low resistance circulation. This so-called 'hyperdynamic circulation' is characterized by a rise in cardiac output (CO) - mainly by a rise in stroke volume (SV) - and a fall in total systemic vascular resistance without concomitant rise in oxidative metabolism [1]. The observed changes appear to be secondary to an initial, pregnancy-specific, systemic vascular relaxation, which not only leads to the development of this hyperdynamic circulation, but also enhances sodium and water retention so as to raise plasma volume [2-5]. Although the functional meaning of these changes is still obscure, their importance for a normal course of pregnancy is emphasized by the epidemiological observation that hypertensive complications of pregnancy such as preeclampsia, the HELLP syndrome and placental insufficiency, are often preceded by the defective development of this adaptive response to pregnancy [6-7].

Almost 6-8\% of all pregnancies are complicated by hypertensive disorders [8] and these complications in turn, are major contributors to maternal mortality in developing countries [9]. Unfortunately, management of hypertensive disorders in pregnancy is still limited to symptomatic treatment and, in case of inadequate response, to (often preterm) termination of pregnancy.

Today, there is compelling evidence for all discernable hemodynamic changes in pregnancy to be triggered by an initial systemic vasorelaxation [2-5]. Unraveling the underlying mechanism of this phenomenon is expected to improve our insight in the pathophysiology of maladaptation to pregnancy as frequently seen in the subclinical phase of hypertensive disorders in pregnancy [10]. Systemic vasodilatation along with its induced hemodynamic compensations is already detectable in the $5^{\text {th }}$ week of human pregnancy [2] and is also observed at a correspondingly early stage of pregnancy in other mammals such as sheep [11] and rat [12]. The latter animal is a suitable research model for the study of pregnancy-related hemodynamic changes as these resemble closely those observed in human pregnancy [12].

Vasodilatation can be induced by neural, hormonal and neurohormonal stimuli or mechanically, by a rise in blood flow. These stimuli in turn, may employ different signaltransduction pathways to trigger the vascular response. So far, it seems unlikely that the fall in systemic vascular tone in early pregnancy is induced by some unique pregnancy-specific factor or change in signal-transduction pathway. In the search for such an overall mechanism, several candidate contributors have been identified without a single one being really dominant. These contributors will be discussed one by one in the following paragraphs. 


\subsection{STEROIDS AND RELAXIN}

\section{7ק-estradiol}

The vasodilator properties of $17 \beta$-estradiol have been studied extensively in various different mammals. In these studies administration of $17 \beta$-estradiol always induced regional vasodilatation in the uterus and other reproductive tissues [11,13-16], accompanied by systemic vasodilatation in ewes [15,17], guinea pigs [18] and male transsexuals [19]. Although chronic i.v. administration of $17 \beta$-estradiol in sheep raised CO and SV without concomitant change in mean arterial pressure (MAP) [11,13], the initial marked rise in uterine blood flow diminishes gradually in spite of ongoing infusion [11]. Part of the vasodilator effect of $17 \beta$ estradiol results from stimulation of endothelial nitric oxide synthase [NOS] [20-24]. This vasodilator response is dependent on shear stress and therefore, is considered 'flow-induced vasorelaxation' [25]. After binding to specific 'non-genomic' membrane-bound estrogen receptors, $17 \beta$-estradiol has also been found to trigger a NO-independent vasodilator response [26-27], probably mediated by activation of large conductance calcium-dependent potassium channels [28].

\section{Progesterone}

Administration of progesterone elicits acute endothelium-independent vasodilatation, probably through the cyclic AMP pathway, in $1^{\text {st }}$ and $2^{\text {nd }}$ order human umbilical arteries and veins [29] and in human omental arteries [26]. In rat mesenteric arteries, progesterone also induces both endothelium-dependent and -independent relaxation [30]. Chronic administration of progesterone to rat results in a state of 'pseudopregnancy' [31], resembling the hormonal changes of pregnancy. During pseudopregnancy in rat, the cardiac output is raised and the peripheral vascular resistance reduced [32] resembling the hemodynamic changes of normal rat pregnancy [12]. The underlying mechanism of this progesterone-related effect is unclear. However, the similar circulatory changes in pseudopregnancy as in normal pregnancy support the view that the trophoblast plays a negligible role in the induction of the initial vasorelaxation of pregnancy.

\section{Relaxin}

Relaxin is a hormone of the insulin family of peptides produced and - during pregnancy - secreted by the corpus luteum in mice, rat and human [33]. It regulates growth and remodeling of reproductive tissues during advanced pregnancy but also during decidualization [34]. It is involved in the pregnancy-induced renal vasodilatation as suggested by the rapid onset of this effect after administration [35] and by the disappearance of this effect after the 


\section{CHAPTER 1}

administration of neutralizing antibodies or after ovariectomy in midpregnant rat [36]. However, the midpregnancy fall in blood pressure is neither inhibited in ovariectomized, steroidsupplemented rats [37] nor attenuated in response to relaxin-neutralizing antibodies [36]. The administration of the latter antibodies to pregnant rat reduces cardiac output to the nonpregnant level without altering heart rate, mean arterial pressure and structure of the arteries [38]. Although, the exact mechanism of the vasodilator properties of relaxin is still unclear, it partly seems to induce vasodilatation by converting endothelin in inactive fragments [39] and by activation of so called $\mathrm{ET}_{\mathrm{B}}$ receptors that have been proposed to stimulate the release of $\mathrm{NO}$ by the endothelium $[40,41]$.

\subsection{VASODILATOR PEPTIDES: CALCITONIN GENE-RELATED PEPTIDE, ADRENOMEDULLIN, NITRIC OXIDE AND RELATED AGENTS}

\section{Calcitonin gene-related peptide}

Calcitonin Gene-Related Peptide (CGRP) is a 37-amino-acid vasoactive neuropeptide that is mainly expressed in the dorsal-root ganglia. It is the most potent endogenous vasodilator and is released from the sensory-motor nerves, which are distributed throughout the cardiovascular system [42]. The classical mechanism leading to release of CGRP is by stimulation of the sensory-motor nerves by capsaicin, a vanilloid pungent [43]. Substances considered to act via the same vanilloid receptors on sensory-motor nerves include kinins and prostaglandins $[44,45]$ and NO [46]. Other substances, such as histamine, neuropeptide $\mathrm{Y}$ and vasoactive intestinal polypeptide modulate CGRP release through their own specific receptors located on sensory nerves [42]. Stimulation of $\alpha_{2}$-adrenoreceptors, located presynaptically on sensory-motor nerves was demonstrated to inhibit CGRP release [47]. Both in women taking contraceptive pills [48] and postmenopausal women receiving hormonal replacement therapy [49] circulating levels of CGRP are increased, suggesting a modulating effect of steroid hormones on CGRP release. Indeed, in rat, pregnancy and steroids induce a rise in circulating CGRP concentration [50] probably due stimulation of the sensory-motor nerves by nerve growth factor [51]. In women, increasing CGRP levels are demonstrated from the third month of gestation, with a sharp decline to normal on the fifth day after delivery [52,53]. The administration of steroids enhances the vasodilator properties of CGRP [54,55]. In advanced pregnancy the sensitivity to CGRP is enhanced in both the vasculature $[55,56]$ and the myometrium [57]. Finally, the administration of $\mathrm{N}^{\mathrm{G}}$-nitro-L-arginine methyl ester during pregnancy induces a rise in blood pressure, which is reversed by CGRP [58,59], suggesting a compensatory role in this experimental preeclampsia model. 


\section{Adrenomedullin}

Adrenomedullin (ADM) was originally extracted from human pheochromocytoma [60], but is now known to be present in many organs. ADM is a 52 -amino-acid peptide sharing structural homology with CGRP. Together with amylin and calcitonin, ADM and CGRP are considered to belong to the same superfamily of peptides. Although less potent than CGRP, ADM has also vasodilator and hypotensive properties $[61,62]$. The circulating ADM plasma levels are elevated in human [63-66] and rat pregnancy [67]. Both progesterone and estradiol play a role in the regulation of mRNA expression of ADM [68,69] and its receptor components [70] in the pregnant uterus. In rat the administration of ADM has a stronger hypotensive effect in pregnancy than in the nonpregnant state [71]. Furthermore, ADM resembles CGRP in attenuating the $\mathrm{N}^{\mathrm{G}}$-nitro-L-arginine methyl ester-induced rise in blood pressure in late-pregnant rat [71]. In early rat pregnancy ADM gene expression is raised in aorta, renal artery and kidney [72]. Finally, because of deviant plasma levels in preeclampsia relative to uneventful pregnancy, it has been suggested that ADM plays a role in the pathogenesis of this disorder. This role, though, ought to be complex as in preeclampsia both higher [73-75] and lower circulating levels of ADM [76] have been reported to occur. Nevertheless, it has been observed that a normally functioning ADM system is a prerequisite for normal fetal and placental growth [77,78].

Nitric oxide, acetylcholine, sodium nitroprusside, vasoactive intestinal peptide, substance $P$

The enzyme NO synthase (NOS) catalyzes the formation of NO from the amino acid L-arginine. One of the isoforms of this enzyme - eNOS - is located in the endothelium and is involved in the regulation of the cardiovascular system [79]. In sheep [80], rat [81] and human [82] uterine artery eNOS expression and NO release are upregulated by pregnancy. $\mathrm{NO}$ is an important second messenger in the vasculature and therefore, contributes indirectly to the hemodynamic and volume adaptation to pregnancy. Inhibition of NOS during rat pregnancy induces a fall in glomerular filtration rate and plasma volume [83-89]. However, NOS inhibition did only partly abolish the difference between pregnant and nonpregnant rats in mean blood pressure, mesenteric perfusion pressure, and renal perfusion pressure [90,91]. Furthermore, prolonged inhibition of NOS in pregnant rat led to hypertension, proteinuria, thrombocytopenia, reduced plasma volume and fetal growth restriction $[83,85]$. Data about the contribution of $\mathrm{NO}$ to the blunted pressor and enhanced vasodilator responses in the vasculature during pregnancy are conflicting and in general limited to advanced pregnancy. The difference between pregnant and nonpregnant rats in pressor responses to phenylephrine persisted during NOS inhibition in thoracic aorta [92], but disappeared completely in uterine arteries [93]. Although NOS blockage led to a stronger renal vasoconstrictor response to angiotensin II in both pregnant and nonpregnant rats, the lower angiotensin II response in 


\section{CHAPTER 1}

pregnancy was preserved [90,91]. In advanced rat pregnancy $\mathrm{NO}$ also attenuated the pressor response of interlobar renal arteries to phenylephrine [94]. Inhibition of NOS reduced the vasoconstrictor response to electrical field stimulation (EFS) of mesenteric arteries in latepregnant rat [95]. However, the reduced responses to vasopressin and endothelin were endothelium-independent [95]. During guinea pig pregnancy, renal and mesenteric arteries were found to be more sensitive to the vasodilator properties of acetylcholine. NOS blockade abolished this effect in the renal - [96] but not in the uterine arteries [97]. Finally, pregnancy in women did not alter the endothelium-dependent relaxing response of small subcutaneous arteries to acetylcholine [98]. On the other hand, pregnancy enhances the acetylcholineinduced vasodilatation of uterine arteries, a difference probably mediated by NO [99]. In myometrial arteries from pregnant women, flow-induced shear stress modulates vascular tone by NO and endothelin [100,101]. Interestingly, NOS blockade did neither abolish this effect on resting nor on stimulated forearm vascular resistance [102]. In conclusion, in advanced rat pregnancy NO is involved in renal and uterine vasodilatation. In human pregnancy, $\mathrm{NO}$ seems to contribute to the pregnancy-specific vasodilatation by its enhanced shear-stress dependent release in certain regions of the vascular bed. Therefore, it is more likely that NO is involved in maintaining rather than in inducing the pregnancy-related vasorelaxation.

Acetylcholine is widely accepted to act as an endothelium-dependent vasodilator involving, among others, endothelium-derived NO. Sodium nitroprusside, on the other hand, is frequently used as an NO-donor substance. Data on vasoactivity of acetylcholine and sodium nitroprusside in pregnancy are inconsistent. There is neither evidence for pregnancy altering the vasodilator properties of acetylcholine [22,95,103] and sodium nitroprusside [95] in rat mesenteric arteries, nor for pregnancy modulating the relaxation of human subcutaneous fat resistance arteries in response to these agonists [98]. On the other hand, uterine artery $[99,104,105]$ and thoracic aortic rings in late-pregnant rat did respond stronger to acetylcholine than in the nonpregnant state [106], an effect not accompanied by a change in the response to sodium nitroprusside [93]. Also, pregnancy was found to enhance the relaxing response of guinea-pig mesenteric arteries to acetylcholine [96]. These data support the concept that pregnancy may alter the vascular response to acetylcholine in selective regions of the vasculature.

Little is known about the role of vasodilators as vasoactive intestinal peptide (VIP) and substance $\mathrm{P}$ in pregnancy. In one study VIP was found to induce uterine vasodilatation [107], whereas in another study the postmenopausal hypo-estrogenic state was found to correlate with a reduced content of both VIP and substance P in the uterine artery wall [108]. Whether, and if so, how changes in sex steroids during pregnancy modulate the activity of these vasodilators is unknown. 


\subsection{VASOCONSTRICTOR NERVES AND PEPTIDES: SYMPATHETIC NERVES, NORADRENALINE, ANGIOTENSIN, ARGININE VASOPRESSIN}

\section{Sympathetic nerves and noradrenaline}

The uterus was the first organ to be explored for changes in sympathetic innervation during pregnancy. It was shown that pregnancy induced both degenerative [109-112] and regenerative changes [113] in sympathetic innervation of this organ. Later the role of steroids in the decrease of uterine arterial sympathetic activity was established in pig [114] and sheep [15]. More recently also in women, pregnancy was reported to lower the sympathetic response of uterine arteries to electrical field stimulation [115]. Meanwhile, in mesenteric veins of pregnant rat, transmural sympathetic nerve stimulation induced a smaller response, whereas exogenous noradrenaline triggered a larger response [116] suggesting hypersensitivity secondary to reduced sympathetic innervation. In rat pregnancy, arterial pressor responsiveness to noradrenaline has been reported to be either blunted [90,117-119] or unchanged [95,120]. Moreover, these pregnancy-dependent changes show a profound regional variation with blunted responses in the mesenteric artery and unchanged responses in the arcuate [121] and renal [91] arteries. It is important to emphasize that these studies were all performed in late-pregnant rat. Finally, in normal human pregnancy peripheral sympathetic activity appears to be raised [122], a condition that seems to evolve into sympathetic hyperactivity in pregnancy-induced hypertension and preeclampsia $[123,124]$.

\section{Angiotensin II}

In rat, pregnancy has been found to blunt the systemic arterial response to angiotensin II, in vitro - in mesenteric $[90,117]$ and uterine $[104,105]$ arteries - as well as in vivo - in a perfused renal preparation [91]. In both normal and spontaneously-hypertensive pregnant rats, inhibition of NOS did not abolish this Angiotensin II-mediated effect [91,125], suggesting that these blunted responses are NO-independent. It has been suggested that the activation of the renin-angiotensin system (RAS) in pregnancy contributes to the down regulation of ATreceptors [126]. Interestingly, the higher RAS activity in pregnancy [1,3] coincides with the onset of early-pregnancy vasorelaxation. It is unclear, whether these two early changes are causally related.

\section{Arginine vasopressin (AVP)}

Information on the effect of pregnancy on AVP activity is scarce. Although late-pregnant rat mesenteric arteries elicit a lower response to AVP than nonpregnant mesenteric arteries 


\section{CHAPTER 1}

[90,95], this difference was not found in small omental arteries of late-pregnant women with an uneventful pregnancy $[127,128]$.

All the factors summarized in the introduction seem to play a role in the vascular adaptation to pregnancy. It is obvious that we have only limited insight in the complex sequence of events and interdependence of the effects induced by these factors, which culminates into systemic vasorelaxation. Most of the experimental data from the animal studies mentioned in the introduction were obtained in late pregnancy. Therefore, it is unclear if they are really involved in the initiation of early-pregnancy vasorelaxation. To further explore the mechanism that leads to this phenomenon of systemic vasodilatation in early pregnancy, we have tried to answer the following questions:

- Is the hormonal environment created by steroids of luteal origin the sole prerequisite for the induction of early-pregnancy vasorelaxation?

- If so, are the potent vasodilators CGRP and ADM, known to be mediated by the sex steroids, involved in early pregnancy vasorelaxation?

- Are the pregnancy-dependent blunted vasoconstrictive responses typical for late pregnancy also found in early pregnancy? And are they mediated by the second messenger NO?

This thesis consists of five independent studies designed to explore mechanisms leading to early-pregnancy vasorelaxation:

1. The first study (chapter 2) was designed to explore the possible uterine and trophoblastic contributions to early-pregnancy vasorelaxation and also intended to confirm the importance of steroids in this process.

2. The second study (chapter 3) focuses on the vascular reactivity to CGRP in early pregnancy, in particular, on the role of elevated circulating potassium levels on sensorymotor nerves and the possibility of pregnancy-related changes in CGRP availability from the vascular wall.

3. The objective of the third study (chapter 4) was to unravel the underlying mechanism of the raised vasodilator reactivity to CGRP in pregnancy relative to the nonpregnant state. We intended to generate experimental evidence for one of the following three possible explanations: diminished degradation of CGRP by matrix metalloproteinase-2, a rise in CGRP-receptor density, or effect-augmenting changes in the post-receptor CGRP-signaltransduction pathway.

4. ADM belongs to the same family of peptides as CGRP. Therefore, the fourth study (chapter 5) was designed to explore (1) the vascular reactivity of ADM in early preg- 
nancy; (2) the modulating effect of ADM on sympathetic and sensory-motor nerves and (3) the interaction between CGRP and ADM receptors.

5. The fifth study of this thesis (chapter 6) elaborates on the pregnancy-dependent attenuated vascular response to sympathetic stimuli, noradrenaline, vasopressin and angiotensin II. The emphasis of this study is on how NO and vascular remodeling impacts the vasoconstrictive reactivity in pregnancy.

6. The general discussion is presented in chapter 7 and intends to integrate all observations and data reported in the literature in a unifying concept explaining our current ideas about the mechanism of early-pregnancy vasorelaxation. 


\section{CHAPTER 1}

\section{REFERENCES}

1. Spaanderman MEA, Meertens M, van Bussel M, Ekhart THA, Peeters LLH: Cardiac output increases independently of basal metabolic rate in early human pregnancy. Am J Physiol Heart Circ Physiol 2000; 278(5):1585-1588.

2. Duvekot JJ, Cheriex EC, Pieters FAA, Menheere PPCA, Peeters LLH: Early pregnancy changes in hemodynamics and volume homeostasis are consecutive adjustments triggered by a primary fall in systemic vascular tone. Am J Obstet Gynecol 1993;169:1382-1392.

3. Chapman AB, S. Zamudio, Woodmansee W, Merouani A, Osorio F, Johnson A, Moore LG, Dahms T, Coffin C, Abraham WT, Schrier RW: Systemic and renal hemodynamic changes in the luteal phase of the menstrual cycle mimic early pregnancy. Am J Physiol Renal Physiol 1997;273(42):F777-F782

4. Chapman AB, Abraham WT, Zamudio S, Coffin C, Merouani A, Young D, Johnson A, Osorio F, Goldberg C, Moore LG, Dahms T, Schrier RW: Temporal relationships between hormonal and hemodynamic changes in early human pregnancy. Kidney Int 1998;54(6):2056-63.

5. Spaanderman MEA, willekes C, Hoeks APG, Ekhart THA, Peeters LLH: The effect of pregnancy on the compliance of large arteries and veins in normal parous controls and formerly preeclamptics. Am J Obstet Gynecol 2000;183:1278-1286.

6. Duvekot JJ, Cheriex EC, Pieters FAA, Menheere PPCA, Schouten HJA, Peeters LLH: Maternal volume homeostasis in early pregnancy in relation to fetal growth restriction. Obstet Gynecol 1995;85:361-367.

7. Spaanderman MEA, Willekes C, Hoeks AP, Ekhart THA, Aardenburg R, Courtar DA, van Eijndhoven HWF, Peeters LLH: Maternal nonpregnant vascular function correlates with subsequent fetal growth. Am J Obstet Gynecol 2005;192(2):504-512.

8. Report of the National High Blood Pressure Education Program Working Group on High Blood Pressure in Pregnancy. Am J Obstet Gynecol 2000;183(1):S1-S22.

9. Khan KS, Wojdyla D, Say L, Gülmezoglu AM, van Look PF: WHO analysis of maternal death: a systemic review. Lancet 2006;367(9516):1066-1074.

10. Spaanderman MEA, Ekhart THA, van Eyck J, de Leeuw P, Peeters LLH: Preeclampsia and maladaptation to pregnancy: a role for atrial natriuretic peptide? Kidney Int 2001;60(4):1397-1406.

11. Magness RR, Rosenfeld CR: Local and systemic estradiol-17ß: effects on uterine and systemic vasodilation. Am J Physiol 1989;E536-E542.

12. Slangen BFM, Out ICM, Verkeste CM, Peeters LLH: (1996) Hemodynamic changes in early pregnancy in chronically instrumented conscious rats. Am J Physiol Heart Circ Physiol 1996;270(39):H1779H1784.

13. Rosenfeld CR, Morriss FH, Battaglia FC, Makowski EL, Meschia G: Effect of estradiol-17ß on blood flow to reproductive and nonreproductive tissues in pregnant ewes. Am J Obstet Gynecol 1976;124: 618-629.

14. Rosenfeld CR: Responses of reproductive and nonreproductive tissues to 17 beta-estradiol during ovine puerperium. Am J Physiol 1980;239(5):E333-E339.

15. Naden RP, Rosenfeld CR: Systemic and uterine responses to angiotensin II and norepinephrine in estrogen-treated nonpregnant sheep. Am J Obstet Gynecol 1985;153(4):417-425.

16. Davis LE, Hohimer AR, Giraud GD, Paul MS, Morton MJ : Vascular pressor-volume relationships in pregnant and estrogen-treated guinea pigs. Am J Physiol 1989;257:R1205-1211.

17. Magness RR, Parker CR, Rosenfeld CR: Systemic and uterine responses to chronic infusion of estradiol-17ß. Am J Physiol 1993;265:E690-698.

18. Hart MV, Hosenpud JD, Hohimer AR, Morton MJ: Hemodynamics during pregnancy and sex steroid administration in guinea pigs. Am J Physiol 1985;249:R179-R185.

19. Slater AJ, Gude N, Clark IJ, Walters WA: Haemodynamic changes and left ventricular performance during high-dose oestrogen administration to male transsexuals. Br J Obstet Gynaecol 1986;93(6):532538. 


\section{GENERAL INTRODUCTION}

20. Goetz RM, Morano I, Calovini T, Studer R, Holtz J: Increased expression of endothelial constitutive nitric oxide synthase in rat aorta during pregnancy. Biochem Biophys Res Commun 1994;205:905-910.

21. Weiner CP, Lizasoain I, Baylis SA, Knowles RG, Charles IG, Moncada S: Induction of calciumdependent nitric oxide synthases by sex hormones. Proc Natl Acad Sci USA 1994;91:5212-5216.

22. Learmont JG, Cockell AP, Knock GA, Poston L: Myogenic and flow-mediated responses in isolated mesenteric small arteries from pregnant and nonpregnant rats. Am J Obstet Gynecol 1996;174:16311636 .

23. Rosenfeld CR, Cox BE, Roy T, Magness RR: Nitric oxide contributes to estrogen-induced vasodilation of the ovine uterine circulation. J Clin Invest 1996;98(9):2158-2166.

24. Chen DB, Bird IM, Zheng J, Magness RR: Membrane estrogen receptor-dependent extracellular signalregulated kinase pathway mediates acute activation of endothelial nitric oxide synthase by estrogen in uterine artery endothelial cells. Endocrinology 2004;145(1):113-125.

25. Cockell AP, Poston L: 17Beta-estradiol stimulates flow-induced vasodilatation in isolated small mesenteric arteries from prepubertal female rats. Am J Obstet Gynecol 1997;177(6):1432-1438.

26. Belfort MA, Saade GR, Wen TS, Vedernikov YP: The direct action of 17beta-estradiol in isolated omental artery from nonpregnant and pregnant women is related to calcium antagonism. Am J Obstet Gynecol 1996:175(5):1163-1172.

27. Magness RR, Phernetton TM, Gibson TC, Chen DB: Uterine blood flow responses to ICI 182780 in ovariectomized oestradiol-17beta-treated, intact follicular and pregnant sheep. J Physiol 2005;565:7183.

28. Rosenfeld CR, Cornfield DN, Roy $\mathrm{T}$ : $\mathrm{Ca}^{2+}$-activated $\mathrm{K}^{+}$channels modulate basal and $\mathrm{E}_{2}$ beta-induced rises in uterine blood flow in ovine pregnancy. Am J Physiol 2001;281(1):H422-H431.

29. Omar HA, Ramirez R, Gibson M: Properties of a progesterone-induced relaxation in human placental arteries and veins. J Clin Endocrinol Metab 1995;80(2):370-373.

30. Chan HY, Yao X, Tsang SY, Chan FL, Lau CW, Huang Y: Different role of endothelium/nitric oxide in 17beta-estradiol- and progesterone-induced relaxation in rat arteries, Life Sci 2001;69(14):1609-1617.

31. De Greef WJ, Dullaart J, Zeilmaker GH: Serum concentrations of progesterone, luteinizing hormone, follicle stimulating hormone and prolactin in pseudopregnant rats: effect of decidualization. Endocrinology 1977;101:1054-1063.

32. Slangen BFM, Out ICM, Verkeste CM, Smits JFM, Peeters LLH: Hemodynamic changes in pseudopregnancy in chronically instrumented conscious rats. Am J Physiol 1997;272(41):H695-H700.

33. Sherwood OD: Relaxin's physiological roles and other divers actions. Endocr Rev 2004;25(2):205-234

34. Telgmann R, Gellersen B: Marker genes of decidualization:activation of the decidual prolactin gene. Hum Reprod Update 1998;4(5):472-479.

35. Danielson LA, Conrad KP: Time course of relaxin-mediated renal vasodilation, hyperfiltration, and changes in plasma osmolality in conscious rats. J Appl Physiol 2003;95(4):1509-1514.

36. Novak J, Danielson LA, Kerchner LJ, Sherwood OD, Ramirez RJ, Moalli PA, Conrad KP: relaxin is essential for renal vasodilation during pregnancy in conscious rats. J Clin Invest 2001;107(11):14691475 .

37. Ahokas RA, Sibai BM, Anderson GD: Lack of evidence of a vasodepressor role for relaxin in spontaneously hypertensive and normotensive pregnant rats. Am J Obstet Gynecol 1989;161(3):618-622.

38. Debrah DO, Novak J, Matthews JE Ramirez RJ, Shroff SG, Conrad KP: Relaxin is essential for systemic vasodilation and increased global arterial compliance during early pregnancy in conscious rats. Endocrinology 2006;147(11):1526-1531.

39. Conrad KP: Mechanisms of renal vasodilation and hyperfiltration during pregnancy. J Soc Gynecol Investig 2004;11(7):438-448.

40. Novak J, Ramirez RJ, Gandley RE, Sherwood OD, Conrad KP: Myogenic reactivity is reduced in small renal arteries isolated from relaxin-treated rats. Am J Physiol Regul Integr Comp Physiol 2002;283(2): R349-355. 


\section{CHAPTER 1}

41. Jeyabalan A, Novak J, Danielson LA, Kerchner LJ, Opett SL, Conrad KP: Essential role for vascular gelatinase activity in relaxin-induced renal vasodilation, hyperfiltration, and reduced myogenic reactivity of small arteries. Circ Res 2003;93(12):1249-1257.

42. Brain SD, Grant AD: Vascular actions of calcitonin gene-related peptide and adrenomedullin. Physiol Rev 2004;84:903-934.

43. Szallassi A, Blumberg PM: Vanilloid (capsaicin) receptors and mechanisms. Pharmacol Rev 1999;51: 159-211.

44. Andreeva L, Rang HP: Effect of bradykinin and prostaglandins on the release of calcitonin gene-related peptide-like immunoreactivity from the rat spinal cord in vitro. Br J Pharmacol 1993;108(1):185-190.

45. Jenkins DW, Freniuk W, Humphrey PP: Characterization of the prostanoid receptor types involved in mediating calcitonin gene-related peptide release from cultured rat trigeminal neurones. $\mathrm{Br} \mathrm{J}$ Pharmacol 2001;134(6):1296-1302.

46. Booth BP, Tabrizi-Fard MA, Fung H: Calcitonin gene-related peptide-dependent vascular relaxation of rat aorta. An additional mechanism for nitroglycerin. Biochem Pharmacol 2000;59(12):1603-1609.

47. Kawasaki H, Nuki C, Saito A, Takasaki K: Adrenergic modulation of calcitonin gene-related peptide (CGRP)-containing nerve-mediated vasodilation in the rat mesenteric resistance vessel. Brain Res 1990; 506:287-290

48. Valdemarsson S, Edvinsson L, Hedner P, Ekman R: Hormonal influence on calcitonin gene-related peptide in man: effects of sex difference and contraceptive pills. Scand J Clin Lab Invest 1990;50(4): 385-388.

49. Spinetti A, Margutti A, Bertolini S, Bernardi F, BiFulco G, degli Uberti EC, Petraglia F, Genazzani AR: Hormonal replacement therapy affects calcitonin gene-related peptide and atrial natriuretic peptide secretion in postmenopausal women. Eur J Endocrinol 1997;137(6):664-669.

50. Gangula PRR, Wimalawansa SJ, Yallampalli C: Pregnancy and sex steroids enhance circulating calcitonin gene-related peptide concentrations in rats. Hum Reprod 2000;15:949-953.

51. Gangula PR, Lanlua P, Wimalawansa S, Supowit S, DiPette D, Yallampalli C: Regulation of calcitonin gene-related peptide expression in dorsal root ganglia of rats by female sex steroid hormones. Biol Reprod 2000;62(4):1033-1039.

52 Sagesse G, Belloni S, Barocelli GI, Pelletti A, Benedetti U: Evaluation of a peptide family encoded by the calcitonin gene in selected healthy pregnant women. A longitudinal study. Horm Res 1990;34:240244

53. Stevenson JC, MacDonald DWR, Warren RC: Increased concentration of calcitonin gene-related peptide during normal human pregnancy. Br Med J 1986;293:1329-1330.

54. Gangula PRR, Zhao H, Supowit SC, Wimalawansa S, Dipette D, Yallampalli C: Pregnancy and steroid hormones enhance the vasodilatation responses to CGRP in rats. Am J Physiol Heart Circ Physiol 1999; 276:H284-288.

55. Grewal M, Cuevas J, Chaudhuri G, Nathan L: Effects of calcitonin gene-related peptide on vascular resistance in rats: role of sex steroids. Am J Physiol Heart Circ Physiol 1999;276:H2063-H2068.

56. Gangula PR, Zhao H, Wimalawansa S, Supowit SC Dipette DJ, Yallampalli C: Pregnancy and steroid hormones enhance the systemic and regional hemodynamic effects of calcitonin gene-related peptide in rats. Biol Reprod 2001;64(6):1776-178

57. Yallampalli C, Gangula PRR, Kondapaka S, Fang L, Wimalawansa S: Regulation of calcitonin generelated peptide receptors in the rat uterus during pregnancy and labor and by progesterone. Biol Reprod 1999;61(4):1023-1030.

58. Yallampalli C, Dong Y, Wimalawansa SJ: Calcitonin gene-related peptide reverses the hypertension and significantly decreases the fetal mortality in pre-eclampsia rats induced by NG-nitro-L-arginine methyl ester. Hum Reprod 1996;11:895-899. 
59. Gangula PRR, Supowit SC, Wimalawansa SJ, Zhao H, Hallman DM, DiPette DJ, Yallampalli C: Calcitonin gene-related peptide is a depressor in NG-nitro-L-arginine methyl ester-induced hypertension during pregnancy. Hypertension 1997;29:248-253.

60. Kitamura K, Kangawa K, Kawamoto M, Ichiki Y, Nakamura S, Matsuo H, Eto T: Adrenomedullin: a novel hypotensive peptide isolated from human pheochromocytoma. Biochem Biophys Res Commun 1993;192:553-560.

61. Hall JM, Siney L, Lippton H, Hyman A, Kang-Chang J, Brain SD: Interaction of human adrenomedullin 13-52 with calcitonin gene-related peptide receptors in the microvasculature of the rat and hamster. $\mathrm{Br} \mathrm{J}$ Pharmacol 1995;114(3):592-597.

62. Chu DQ, Choy W, Foster P, Cao T, Brain SD: A comparative study of the ability of calcitonin generelated peptide and adrenomedullin(13-52) to modulate microvascular but not thermal hyperalgesia responses. Br J Pharmacol 2000;130(7):1589-1596.

63. Di Iorio R, Marinoni E, Scavo D, Letizia C, Cosmi EV: Adrenomedullin in pregnancy. Lancet 1997; 349(9048): 328.

64. Di Iorio R, Marinoni E, Letizia C, Villacio B, Alberini A, Cosmi E: Adrenomedullin production is increased in normal human pregnancy. Eur J Endocrinol 1999;140:201-206.

65. Kobayashi K, Kubota T, Aso T, Hirata Y, Imai T, Marumo F: Immunoreactive adrenomedullin (AM) concentration in maternal plasma during human pregnancy and AM expression in placenta. Eur $\mathrm{J}$ Endocrinol 2000;142:683-687.

66. Hoshimoto $\mathrm{K}$, Hayashi M, Ohkura $\mathrm{T}$ : Mature adrenomedullin concentrations in plasma during pregnancy. J Matern Fetal Neonatal Med 2002;11:126-129.

67. Jerat S, Kaufman S: Effects of pregnancy and steroid hormones on plasma adrenomedullin levels in the rat. Can J Physiol Pharmacol 1998;76:463-466.

68. Ikeda K, Arao Y, Otsuka H, Kikuchi A, Kayama F: Estrogen and phytoestrogen regulate the mRNA expression of adrenomedullin and adrenomedullin receptor components in the rat uterus. Mol Cell Endocrinol 2004;223(1-2):27-34.

69. Thota C, Yallampalli C: Progesterone upregulates calcitonin gene-related peptide and adrenomedullin receptor components and cyclic adenosine 3',5'-monophosphate generation in Eker rat uterine smooth muscle cell line. Biol Reprod 2005;72(2):416-422.

70. Thota C, Gangula PR, Dong YL, Yallampalli C : Changes in the expression of calcitonin receptor-like receptor, receptor activity-modifying protein (RAMP) 1, RAMP2, and RAMP3 in rat uterus during pregnancy, labor, and by steroid hormone treatments. Biol Reprod 2003;69(4):1432-1437.

71. Makino I, Shibata K, Makino Y, Kangawa K, Kawarabayashi T: Adrenomedullin attenuates the hypertension in hypertensive pregnant rats induced by $\mathrm{N}^{\mathrm{G}}$-nitro-L-arginine methyl ester. Eur $\mathrm{J}$ Pharmacol 1999;371:159-167.

72. van der Heijden OW, Essers YP, van Eyndhoven HW, Spaanderman ME, Aardenburg R, van Eys GJ, Peeters LL: Vascular expression of adrenomedullin is increased in Wistar rats during early pregnancy. Eur J Obstet Gynecol Reprod Biol 2005;123(1):35-40.

73. Di Iorio R, Marinoni E, Cosmi EV: Adrenomedullin in pre-eclampsia. Lancet 1998;350(9091):1600.

74. Di Iorio R, Marinoni E, Letizia C, Alò P, Villaccio B, Cosmi EV: Adrenomedullin, a new vasoactive peptide, is increased in preeclampsia. Hypertension 1998;32(4):758-763.

75. Lauria MR, Standley CA, Sorokin Y, Yelian FD, Cotton DB: Adrenomedullin levels in normal and preeclamptic pregnancy at term. J Soc Gynecol Investig 1999;6(6):318-321.

76. Hata T, Miyazaki K, Matsui K: Decreased circulating adrenomedullin in pre-eclampsia. Lancet 1998; 351(9103):676-677.

77. Witlin AG, Li ZY, Wimalawansa SJ, Grady JJ, Grafe MR, Yallampalli C: Placental and fetal growth and development in late rat gestation is dependent on adrenomedullin. Biol Reprod 2002;67(3):10251031. 


\section{CHAPTER 1}

78. Penchalaneni J, Wimalawansa SJ, Yallampalli C: Adrenomedullin antagonist treatment during early gestation in rats causes fetoplacental growth restriction through apoptosis. Biol Reprod 2004;71(5): $1475-1483$.

79. Moncada S, Higgs A: The L-arginine-nitric oxide pathway. N Engl J Med 1993;329(27):2002-2012.

80. Magness RR, Sullivan JA, Li Y, Phernetton TM, Bird IM: Endothelial vasodilator production by uterine and systemic arteries. VI. Ovarian and pregnancy effects on eNOS and NO(x). Am J Physiol 2001; 280(4): H1692-H1698.

81. Scott PA, Tremblay A, Brochu M, St-Louis J: Vasorelaxant action of 17ß-estradiol in rat uterine arteries: role of nitric oxide synthases and estrogen receptors. Am J Physiol 2007;293(6):H3713-3719.

82. Nelson SH, Steinsland OS, Wang Y, Yallampalli C, Dong YL, Sanchez JM : Increased nitric oxide synthase activity and expression in the human uterine artery during pregnancy. Circ Res 2000; 87(5):406-411.

83. Baylis C, Mitruka B, Deng A: Chronic blockade of nitric oxide synthesis in the rat produces systemic hypertension and glomerular damage. J Clin Investig 1992;90(1):278-281.

84. Molnár M, Hertelendy F: N $\omega$-Nitro-L-arginine, an inhibitor of nitric oxide synthesis, increases blood pressure in rats and reverses the pregnancy-induced refractoriness to vasopressor agents. Am J Obstet Gynecol 1992;166:1560-1567.

85. Molnár M, Sütö T, Tóth T, Hertelendy F: Prolonged blockade of nitric oxide synthesis in gravid rats produces sustained hypertension, proteinuria, trombocytopenia and intrauterine growth retardation. Am J Obstet Gynecol 1994;170:1458-1466.

86. Danielson LA, Conrad KP: Acute blockade of nitric oxide synthase inhibits renal vasodilation and hyperfiltration during pregnancy in chronically instrumented conscious rats. J Clin Investig 1995;96: 482-490.

87. Pascoal IF, Lindheimer MD, Nalbantian-Brandt C, Umans JG: Contraction and endothelium-dependent relaxation in mesenteric microvessels from pregnant rats. Am J Physiol 1995;269:H1899-H1904.

88. Conrad KP, Gandley RE, Ogawa T, Nakanishi S, Danielson LA: Endothelin mediates renal vasodilation and hyperfiltration during pregnancy in chronically instrumented conscious rats. Am J Physiol 1999; 276(5):F767-F776.

89. Cadnapaphornchai MA, Ohara M, Morris KG Jr, Knotek M, Rogachev B, Ladtkow T, Carter EP, Schrier RW: Chronic NOS inhibition reverses systemic vasodilation and glomerular hyperfiltration in pregnancy. Am J Physiol 2001;280(4):F592-598.

90. Chu ZM, Beilin LJ: Mechanisms of vasodilatation in pregnancy: studies of the role of prostaglandins and nitric-oxide in changes of vascular reactivity in the in situ blood perfused mesentery of pregnant rats. Br J Pharmacol 1993;109(2):322-329.

91. Chu ZM, Beilin LJ: Demonstration of the existence of nitric oxide-independent as well as nitric oxidedependent vasodilator mechanisms in the in situ renal circulation in near term pregnant rats. $\mathrm{Br} \mathrm{J}$ Pharmacol 1997;122(2):307-315.

92. St-Louis J, Sicotte B: Prostaglandin- or endothelium-mediated vasodilation is not involved in the blunted responses of blood vessels to vasoconstrictors in pregnant rats. Am J Obstet Gynecol 1992; 166(2):684-692.

93. Ni Y, Meyer M, Osol G: Gestation increases nitric oxide-mediated vasodilation in rat uterine arteries Am J Obstet Gynecol 1997;176(4):856-864.

94. Griggs KC, Conrad KP, Mackey K, McLaughlin MK: Endothelial modulation of renal interlobar arteries from pregnant rats. Am J Physiol 1993;265(2):F309-F315.

95. Ralevic V, Burnstock G: Mesenteric arterial function in the rat in pregnancy: role of sympathetic and sensory-motor perivascular nerves, endothelium, smooth muscle, nitric oxide and prostaglandins. Br J Pharmacol 1996;117:1463-1470.

96. Kim TH, Weiner CP, Thompson LP: Effect of pregnancy on contraction and endothelium-mediated relaxation of renal and mesenteric arteries. Am J Physiol 1994;267(1):H41-H47. 


\section{GENERAL INTRODUCTION}

97. Jovanović A, Jovanović S, Grbović L: Endothelium-dependent relaxation in response to acetylcholine in pregnant guinea-pig uterine artery. Hum Reprod 1997;12(8):1805-1809.

98. McCarthy AL, Taylor P, Graves J, Raju SK, Poston L: Endothelium-dependent relaxation of human resistance arteries in pregnancy. Am J Obstet Gynecol 1994;171(5):1309-1315.

99. Nelson SH, Steinsland OS, Suresh MS, Lee NM: Pregnancy augments nitric oxide-dependent dilator response to acetylcholine in the human uterine artery. Hum Reprod 1998;13(5):1361-1367.

100. Kublickiene KR, Cockell AP, Nisell H, Poston L: Role of nitric oxide in the regulation of vascular tone in pressurized and perfused resistance myometrial arteries from term pregnant women. Am J Obstet Gynecol 1997;177(5):1263-1269.

101. Kublickiene KR, Nisell H, Poston L, Krüger K, Lindblom B: Modulation of vascular tone by nitric oxide and endothelin 1 in myometrial resistance arteries from pregnant women at term. Am J Obstet Gynecol 2000;182(1):87-93.

102. Langenfeld MR, Simmons LA, McCrohon JA, Raitakari OT, Lattimore JD, Hennessy A, Celermajer DS: Nitric oxide does not mediate the vasodilation of early human pregnancy. Heart Lung Circ 2003; 12(3):142-148

103. Ballejo G, Barbosa TA, Coelho EB, Antoniali C, Salgado MC: Pregnancy-associated increase in rat systemic arteries endothelial nitric oxide production diminishes vasoconstrictor but does not enhance vasodilator responses. Life Sci 2002;70(26):3131-3142.

104. Alsip NL, Hornung JW, Henzel MK, Asher EF: Pregnancy-induced alterations of uterine arteriolar reactivity in the rat: observations with a new in vivo microcirculatory preparation. Am J Obstet Gynecol 2000;183(3):621-626.

105. Wight E, Küng CF, Moreau P, Takase H, Bersinger NA, Lüscher TF: Aging, serum estradiol levels, and pregnancy differentially affect vascular reactivity of the rat uterine artery. J Soc Gynecol Investig 2000; $7(2): 106-113$.

106. Bobadilla RA, Henkel CC, Henkel EC, Escalante B, Hong E: Possible involvement of endotheliumderived hyperpolarizing factor in vascular responses of abdominal aorta from pregnant rats. Hypertension 1997;30(3):596-602.

107. Clark KE, Mills EG, Stys SJ, Seeds AE: Effects of vasoactive polypeptides on the uterine vasculature. Am J Obstet Gynecol 1981;139(2):182-188.

108. Di Carlo C, Di Spiezio Sardo A, Bifulco G, Tommaselli GA, Guerra G, Rippa E, Mandato VD, Nappi C: Postmenopausal hypoestrogenism increases vasoconstrictor neuropeptides and decreases vasodilator neuropeptides content in arterial-wall autonomic terminations. Fertil Steril 2007;88(1):95-99.

109. Thorbert G, Alm P, Björklund AB, Owman C, Sjöberg NO: Adrenergic innervation of the human uterus. Disappearance of the transmitter and transmitter-forming enzymes during pregnancy. Am J Obstet Gynecol 1979;135(2):223-226.

110. Marshall JM: Effects of ovarian steroids and pregnancy on adrenergic nerves of uterus and oviduct. Am J Physiol 1981;240(5):C165-C174.

111. Zuspan FP, O'Shaughnessy RW, Vinsel J, Zuspan M: Adrenergic innervation of uterine vasculature in human term pregnancy. Am J Obstet Gynecol 1981;139(6):678-680.

112. Klukovits A, Gáspár R, Sántha P, Jancsó G, Falkay G: Functional and histochemical characterization of a uterine adrenergic denervation process in pregnant rats. Biol Reprod 2002;67(3):113-117.

113. Owman C: Pregnancy induces degenerative and regenerative changes in the autonomic innervation of the female reproductive tract. Ciba Found Symp 1981;83:252-279.

114. Ford SP, Reynolds LP, Farley DB, Bhatnagar RK, Van Orden DE: Interaction of ovarian steroids and periarterial alpha 1-adrenergic receptors in altering uterine blood flow during the estrous cycle of gilts. Am J Obstet Gynecol 1984;150(5):480-484.

115. Nelson SH, Steinsland OS, Johnson RL, Suresh MS, Gifford A, Ehardt JS: Pregnancy-induced alterations of neurogenic constriction and dilation of human uterine artery. Am J Physiol 1995;268(4): H1694-H1701. 


\section{CHAPTER 1}

116. Hohmann M, Keve TM, Osol G, McLaughlin MK: Norepinephrine sensitivity of mesenteric veins in pregnant rats. Am J Physiol 1990;259(4):R753-R759.

117. Paller MS: Mechanism of decreased pressor responsiveness to ANG II, NE, and vasopressin in pregnant rats. Am J Physiol 1984;247(1):H100-H108.

118. Massicotte G, St-Louis J, Parent A, Schiffrin EL: Decreased in vitro responses to vasoconstrictors during gestation in normotensive and spontaneously hypertensive rats. Can J Physiol Pharmacol 1987; 65(12):2466-2471

119. Parent A, Schiffrin EL, St-Louis J: Role of the endothelium in adrenergic responses of mesenteric artery rings of pregnant rats. Am J Obstet Gynecol 1990;163(1):229-234.

120. Hart JL, Freas W, Muldoon SM: Neurovascular function in the rat during pregnancy. Am J Physiol 1986;251(5):H1000-H1008.

121. D'Angelo G, Osol G: Regional variation in resistance artery diameter responses to alpha-adrenergic stimulation during pregnancy. Am J Physiol 1993;264(1):H78-H85.

122. Greenwood JP, Scott EM, Stoker JB, Walker JJ, Mary DA: Sympathetic neural mechanisms in normal and hypertensive pregnancy in humans. Ciculation 2001;104(18):2200-2204.

123. Schobel HP, Fischer T, Heuszer K, Geiger H, Schmieder RE: Preeclampsia - a state of sympathetic overactivity. N Engl J Med 1996;335(20):1480-1485.

124. Greenwood JP, Stoker JB, Walker JJ, Mary DA: Sympathetic nerve discharge in normal pregnancy and pregnancy-induced hypertension. J Hypertens 1998;16(5):617-624.

125. Chu ZM, Beilin LJ: Nitric oxide-mediated changes in vascular reactivity in pregnancy in spontaneously hypertensive rats. Br J Pharmacol 1993;110(3):1184-1188.

126. Conrad KP, Morganelli PM, Brinck-Johnsen T, Colpoys MC: The renin-angiotensin system during pregnancy in chronically instrumented, conscious rats. Am J Obstet Gynecol 1989;161(4):1065-1072.

127. Pascoal IF, Lindheimer MD, Nalbantian-Brandt C, Umans JG: Preeclampsia selectively impairs endothelium-dependent relaxation and leads to oscillatory activity in small omental arteries. J Clin Invest 1998;101(2):464-470.

128. Ashworth JR, Warren AY, Baker PN, Johnson IR: A comparison of endothelium-dependent relaxation in omental and myometrial resistance arteries in pregnant and nonpregnant women. Am J Obstet Gynecol 1996;175(5):1307-1312. 



\section{CHAPTER 2}

\section{HEMODYNAMIC CHANGES IN PSEUDOPREGNANCY IN CHRONICALLY INSTRUMENTED, CONSCIOUS RATS ARE PRESERVED AFTER HYSTERECTOMY}

Hugo W.F. van Eijndhoven, Brigitte F.M. Slangen, Olivier W.H. van der Heijden, Robert Aardenburg, Marc E.A. Spaanderman, Louis L.H. Peeters 



\section{ABSTRACT}

Hemodynamic changes in early pregnant and pseudopregnant rats are comparable, indicating that the trophoblast does not contribute to these changes. It is unclear whether the presence of the uterus is needed for the normal early-pregnancy hemodynamic adaptation. In this study we tested the hypothesis that uterine factors do not contribute to the systemic hemodynamic changes in early pseudopregnancy. To this end, we studied systemic hemodynamics in conscious pseudopregnant rats subjected to a hysterectomy, and compared these results with those obtained in a control group of pseudopregnant rats. The animals were studied on days 4, 8, 12 and 19 postmating.

On day 8 of pseudopregnancy, cardiac output has increased by $23 \pm 7 \%$ in the hysterectomized group and $15 \pm 5 \%$ in the control group. In both groups this rise in cardiac output was entirely accomplished by a rise in stroke volume, by $28 \pm 8 \%$ and $19 \pm 5 \%$, respectively. Mean arterial pressure did not change appreciably. Therefore, total peripheral resistance also decreased in both groups $(17 \pm 6 \%)$ by day 8 . After day 12 the hemodynamic parameters returned to baseline.

We conclude that systemic hemodynamic changes in hysterectomized pseudopregnant rats closely resemble those in intact pseudopregnant rats. Therefore, the uterus does not seem to play a role in these changes. This supports the hypothesis that only hormones from ovarian origin trigger the initial hemodynamic adaptation to early pregnancy.

\section{INTRODUCTION}

Hemodynamic changes in the pregnant woman can already be observed by the 5 th week of human pregnancy $[4,12]$. These changes include a rise in cardiac output by approx. $20 \%$ above the nonpregnant value, mostly as a result of a rise in stroke volume $[9,16]$. A fall in mean arterial pressure and a rise in plasma volume [4] accompany the rise in cardiac output. The pregnancy-associated rise in cardiac output seems to develop in response to a fall in peripheral vascular resistance which in turn, results from systemic vasodilatation $[4,5,9]$. The functional contribution of these changes to pregnancy is still obscure. However, their importance is emphasized by the fact that the defective development of these adaptive changes in early pregnancy has been found to precede complications of pregnancy, such as fetal growth restriction and preeclampsia [10]. The underlying mechanisms as well as the factors that trigger these changes are obscure. In human pregnancy, the endocrine changes in the period between implantation and luteo-placental shift are orchestrated by the interplay 
between corpus luteum and trophoblast. The synchronicity of the latter changes and those in hemodynamics suggests a causal relationship. However, neither the independent contribution of the two endocrine systems nor the mechanism by which they may trigger the institution of the high flow/low resistance circulation of pregnancy is understood [3,5].

Changes in systemic hemodynamics [18] and the hormones 17 $\beta$-estradiol (E2), progesterone and prolactin $[11,15,21]$ in early rat pregnancy are comparable with those in early human pregnancy. Meanwhile, in the rat the state of pseudopregnancy mimics early pregnancy in many aspects. Pseudopregnancy in the rat is a condition characterized by persistence of the endocrine function of the corpus luteum and lasts for a period of up to 1214 days [1,7]. During the first 9-10 days of this period, the patterns of change in the circulating levels of the sex steroids and prolactin $[1,8,11,21]$ on the one hand, and those in hemodynamics on the other hand [14,19] are comparable with those in normal early rat pregnancy. This observation supports the view that, at least in the rat, the trophoblast plays a negligible role in this particular adaptation. However, this does not exclude the possibility that the luteal hormones trigger the typical pregnancy-like hemodynamic changes by acting in concert with an unknown factor of endometrial or myometrial origin. That is to say, does the uterus by releasing some vasoactive factor contribute to the induction of the hemodynamic changes of (pseudo)pregnancy? This possibility is plausible, knowing that the secretory endometrium is a production site of prolactin, relaxin and insulin-like growth factor-binding protein [17], all substances with vasoactive properties. If the latter possibility can be rejected, it is highly likely, that the early-pregnancy institution of a high flow / low resistance circulation is entirely orchestrated by ovarian hormones only.

Rats become readily pseudopregnant, even after hysterectomy. The latter induces a state of prolonged pseudopregnancy, in which the hormonal changes do not differ appreciably from those observed in normal pregnancy as well as from those in pseudopregnancy $[7,15]$. The present study was designed to test the hypothesis that the hemodynamic changes in early pseudopregnancy develop exclusively in response to changes in the circulating levels of ovarian hormones. To this end, we determined the pattern in systemic hemodynamic changes in conscious hysterectomized pseudopregnant rats and compared the data with that in intact conscious pseudopregnant rats. 


\section{METHODS}

\section{Animal preparation}

This study was performed in female Wistar rats at the age of 3-4 months. After arrival from the external supplier (Charles River, Sulzfeld, Germany) the animals were allowed to acclimatize to our laboratory facility for at least 1 week before surgery. They were kept on a $12 \mathrm{~h} / 12 \mathrm{~h}$ light/dark cycle with free access to standard chow (Hope Farms, Woerden) and tap water. The animals were subdivided into two groups, with one group being subjected to hysterectomy (study group, $\mathrm{n}=7$ ) and the other to a sham procedure (control group, $n=6$ ). Surgery was performed aseptically under general anesthesia, induced by ketamine $(40 \mathrm{mg} / \mathrm{kg})$ with xylazine $(4 \mathrm{mg} / \mathrm{kg})$. The rats allocated to the study group underwent a bilateral hysterectomy by exposing the uterus through a mid-line abdominal incision. The uterus was dissected by ligation just proximal to the cervix and at the uterotubal junction. The rats in the control group underwent a sham procedure, which consisted of an abdominal incision only. After the surgical procedure the animals were housed in individual cages and allowed to recover from surgery for a period of at least two estrus cycles. Then pseudopregnancy was induced by allowing them to mate with a vasectomized male.

The presence of a vaginal sperm plug was considered as day 1 of pseudopregnancy. The latter state was subsequently confirmed by the cessation of the estrus cycle (assessed by the persistence of the leucocytic vaginal smear). The instrumentation was performed on day 1 of pseudopregnancy. After the induction of anesthesia we performed a right-side thoracotomy under positive pressure respiration entering the thorax via the third intercostal space. After separating the ascending aorta from its surrounding tissue, we fitted an electromagnetic flow probe (2.3 mm Skalar, Delft, The Netherlands) around the aorta approx. 3-4 mm above the aortic valves as detailed previously [18,22]. Then, a polyethylene catheter $(0.28 \mathrm{~mm} \mathrm{ID,} 0.61$ $\mathrm{mm}$ OD) was advanced into the abdominal aorta from one of the femoral arteries. Both probe cable and catheter tip were tunneled subcutaneously and exteriorized from the neck, where they both were also sutured to the skin.

The interruption of estrus cycle typical for pseudopregnancy was confirmed by daily vaginal smears. All measurements were performed on day 4, 8, 12 and 19 of pseudopregnancy. The Ethical Board of the University of Maastricht approved all facilities and procedures.

\section{Experimental measurements}

To avoid the influence of diurnal variation on hemodynamics [13], we studied all animals at the same time of the day (between 10:00 and 15:00 h). Before data acquisition blood pres- 
sure transducer (Statham pressure transducer, Oxnard, CA, USA) and electromagnetic flow meter (Skalar instruments, Delft, The Netherlands) were calibrated. For the measurement of aortic flow, we assumed end-diastolic aortic flow to be zero at the site of the flow probe, since the latter was located just above the heart. After connecting the arterial catheter and the flow probe to the measurement devices, the animals were allowed to adjust to the experimental setup for $60 \mathrm{~min}$. After this data were recorded for 90-120 min. Mean values were stored on hard disk every $30 \mathrm{~s}$ after on-line analysis by a real-time data system. From the flow signal, cardiac output (minus coronary flow, $\mathrm{ml} / \mathrm{min}$ ), heart rate $(\mathrm{bpm})$ and stroke volume $(\mathrm{ml})$ were derived. Systolic pressure, diastolic pressure and mean arterial pressure $(\mathrm{mmHg})$ were recorded from the arterial pressure signal. From these indices total peripheral vascular resistance $\left(\mathrm{mmHg} \cdot \mathrm{ml}^{-1} \cdot \mathrm{min}\right)$ and stroke work $(\mathrm{mmHg} \cdot \mathrm{ml})$, an indictor of the energetic expense of blood imposed by the left ventricle per stroke were calculated. Catheter obliteration interfered with the blood pressure recording in some rats on days 12 and 19 of pseudopregnancy.

\section{Statistical analysis}

Data on day 4 were defined as baseline, as previous studies showed that on that particular day the hemodynamic function in pregnant and pseudopregnant rats does not differ appreciably from that in nonpregnant rats $[18,19]$. Furthermore, hemodynamics between the control and study group was not statistically different on that day (Mann-Whitney $U$-test). The longitudinal pattern in the various parameters throughout the measurement period in the two groups was analyzed by two-way analysis of variance by ranks (Friedman Test). In addition, we compared the absolute data and the percentage change relative to the 4th day, between the two groups on days 8, 12 and 19 using Mann-Whitney $U$-test with BonferroniHochberg correction. Intra-group differences between the observations on days 8, 12 and 19 on the one hand, and day 4 of pseudopregnancy on the other hand, were analyzed by Wilcoxon Signed Rank-Test with Bonferroni-Hochberg correction. Data are expressed as means \pm SE unless stated otherwise.

\section{RESULTS}

Mean body weight at the onset of pseudopregnancy was $230 \pm 21 \mathrm{~g}$ and $236 \pm 25 \mathrm{~g}$ (means $\pm \mathrm{SD}$ ) in the control and study group, respectively. Post-surgical weight loss was always less than 5\%. Duration of pseudopregnancy assessed by the persistence of a leucocytic vaginal smear was $12 \pm 2$ days in control and $17 \pm 1$ (means $\pm \mathrm{SD}$ ) days in hysterectomized rats. 
The hemodynamic data in the two groups are listed in table 1, whereas patterns of change in cardiac output, stroke volume, total peripheral vascular resistance and stroke work are illustrated in figures 1 and 2. On pseudopregnancy day 8 , cardiac output had increased by $15 \pm 5 \%$ (control) and $23 \pm 7 \%$ (study) above the reference value of day 4 ( $<<0.05$; figure 1 ).

This rise in cardiac output resulted entirely from a rise in stroke volume $(\mathrm{p}<0.05$; figure 1) by $19 \pm 5 \%$ (control) and $28 \pm 8 \%$ (study), respectively, since the concomitantly measured heart rate had not changed appreciably (day 8). In both groups, the raised cardiac output on day 8 persisted until day 12 , to return gradually to baseline afterwards, together with the other hemodynamic indices. In both groups we noticed a gradual decrease in heart rate after day 8 .

Table 1. Cardiovascular observations in control - and hysterectomized pseudopregnant rats

\begin{tabular}{lccccc}
\hline Pseudopregnancy & & Day 4 & Day 8 & Day 12 & Day 19 \\
\hline \hline CO $(\mathrm{ml} / \mathrm{min})$ & $\mathrm{C}$ & $67 \pm 5$ & $76 \pm 8^{*}$ & $74 \pm 5^{*}$ & $61 \pm 6$ \\
& $\mathrm{~S}$ & $66 \pm 7$ & $80 \pm 9^{*}$ & $76 \pm 7^{*}$ & $69 \pm 3$ \\
$\mathrm{HR}(\mathrm{beats} / \mathrm{min})$ & $\mathrm{C}$ & $433 \pm 26$ & $423 \pm 16$ & $382 \pm 17^{*}$ & $361 \pm 23^{*}$ \\
& $\mathrm{~S}$ & $444 \pm 27$ & $426 \pm 22^{*}$ & $393 \pm 11^{*}$ & $370 \pm 8^{*}$ \\
$\mathrm{SV}(\mathrm{ml})$ & $\mathrm{C}$ & $152 \pm 9$ & $180 \pm 16^{*}$ & $194 \pm 5^{*}$ & $169 \pm 8$ \\
& $\mathrm{~S}$ & $147 \pm 23$ & $190 \pm 27^{*}$ & $194 \pm 17^{*}$ & $184 \pm 10$ \\
$\mathrm{n}$ & $\mathrm{C}$ & 6 & 6 & 6 & 5 \\
& $\mathrm{~S}$ & 7 & 7 & 7 & 5 \\
$\mathrm{MAP}(\mathrm{mmHg})$ & $\mathrm{C}$ & $102 \pm 7$ & $97 \pm 4$ & $105 \pm 4$ & - \\
& $\mathrm{S}$ & $96 \pm 8$ & $96 \pm 6$ & $104 \pm 7$ & - \\
$\mathrm{TPR}\left(\mathrm{mmHg} \cdot \mathrm{ml}^{-1} \cdot \mathrm{min}\right)$ & $\mathrm{C}$ & $1.53 \pm 0.23$ & $1.25 \pm 0.06$ & $1.36 \pm 0.09$ & - \\
& $\mathrm{S}$ & $1.50 \pm 0.17$ & $1.23 \pm 0.20$ & $1.38 \pm 0.19$ & - \\
$\mathrm{SW}\left(\mathrm{mmHg} \cdot \mathrm{ml}^{*}\right)$ & $\mathrm{C}$ & $14.3 \pm 3.5$ & $18.2 \pm 3.5$ & $20.0 \pm 1.4^{*}$ & - \\
& $\mathrm{S}$ & $15.7 \pm 0.8$ & $18.0 \pm 1.9 *$ & $20.2 \pm 0.8 *$ & - \\
$\mathrm{n}$ & $\mathrm{C}$ & 5 & 5 & 5 & - \\
& $\mathrm{S}$ & 5 & 5 & 5 & - \\
\hline
\end{tabular}

Values are means \pm SD. n, number of rats; HR, heart rate; CO, cardiac output; SV, stroke volume; MAP, mean arterial pressure; TPR, total peripheral vascular resistance; SW, stroke work.

Each variable was subjected to two-way analysis of variance by ranks (Friedman test).

Pseudopregnant sham group (control group; $\mathrm{C}$ ): $\mathrm{p}<0.01$ for HR; $\mathrm{p}<0.05$ for CO, SV, TPR and SW.

Pseudopregnant hysterectomized group (study group; $\mathrm{S}$ ): $\mathrm{p}<0.01$ for $\mathrm{HR}$ and $\mathrm{SV} ; \mathrm{p}<0.05$ for $\mathrm{CO}$ and $\mathrm{SW}$.

$* \mathrm{P}<0.05$ compared with day 4 by Wilcoxon's signed rank test. 

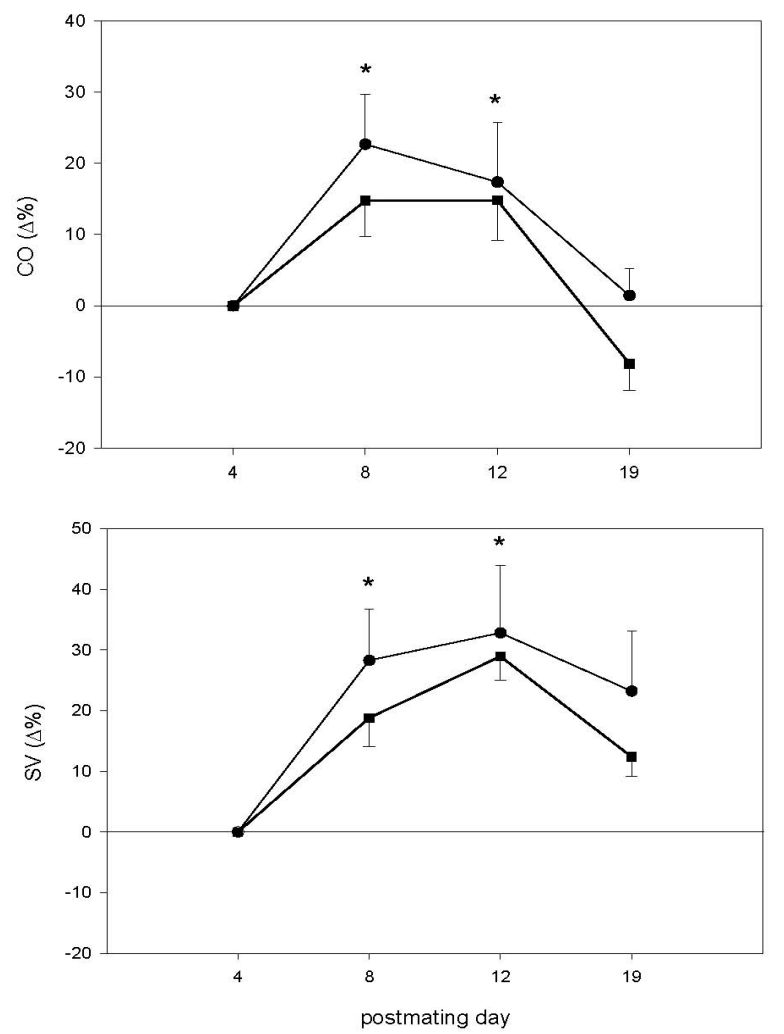

Fig. 1. Percent changes relative to day 4 in cardiac output (CO) and stroke volume (SV) in intact (control group; $\mathbf{\square}$ ) and hysterectomized pseudopregnant rats (study group; $\bullet$ ). Values are given as means \pm SE. An asterix $(*)$ indicates that in both groups the observations at days 8 and 12 had changed significantly relative to day $4(\mathrm{p}<0.05)$.

Since mean arterial pressure did not change consistently throughout the measurement period, the rise in cardiac output on days 8 and 12 was accompanied by a $17 \pm 6 \%$ fall in, total peripheral vascular resistance in both groups (figure 2). Figure 2 also depicts the percentage change in stroke work. In both groups this variable had increased relative to day 4 . Throughout pseudopregnancy none of these variables differed between the control and study groups. 


\section{CHAPTER 2}
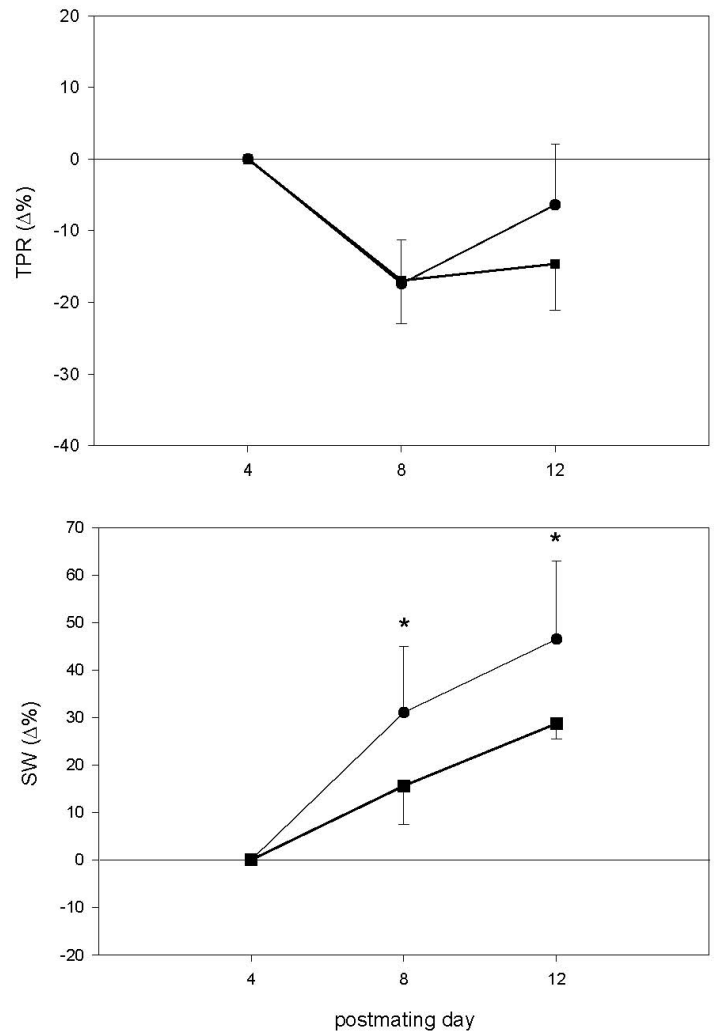

Fig. 2. Percent changes relative to day 4 in total peripheral vascular resistance (TPR) and stroke work $(\mathrm{SW})$ in intact - (control group; $\mathbf{\square}$ ) and hysterectomized pseudopregnant rats (study group; ${ }^{\bullet}$ ). Values are given as means \pm SE. An asterix $(*)$ indicates that in both groups the observations at days 8 and 12 had changed significantly relative to day $4(\mathrm{p}<0.05)$. (At day 8 the $\mathrm{SW}$ had changed significantly only in the control group.)

\section{DISCUSSION}

Changes in hemodynamics, renal function and volume homeostasis as well as endocrine changes do not differ appreciably between early pseudo - and early normal rat pregnancy $[1,2,7,15,18,20,21]$. Therefore, the pseudopregnant rat seems to be an attractive model to explore the mechanism of early-pregnancy vasodilatation. Our previously reported finding 
[19] that pseudopregnant and normal pregnant rat show a comparable systemic vasodilatation, supports a negligible role of the throphoblast in the development of this particular effect. However, this observation does not rule out the possibility, that luteal hormones induce their hemodynamic effects indirectly or in concert with some concomitantly released vasoactive substance from the myometrium or endometrium.

Obviously, comparable hemodynamic changes in pseudopregnant and normal pregnant rat do not imply that the throphoblast is entirely irrelevant for the development of these changes. Firstly, only pseudopregnancy is self-limiting after approx. 10-12 days. Secondly, the rat does not have a luteo-placental shift. In contrast to human pregnancy, removal of the corpus luteum at any time in rat pregnancy is followed by abortion. These differences between human and rat pregnancy indicate that the mechanism of vasodilatation in the pseudopregnant rat model does not have to be exactly similar to that in human pregnancy. In the present study we found that the hemodynamic changes in pseudopregnancy were preserved after hysterectomy. In both groups cardiac output had increased by day 8 of pseudopregnancy, by a comparable selective rise in stroke volume. Although the data suggest a slower return to baseline of at least the stroke volume in the study group, we did not find any intergroup differences before day 12 of pseudopregnancy. The limited number of observations in our study after day 12 makes it difficult to interpret the influence of prolonged pseudopregnancy on hemodynamics. Others $[7,15]$ have also reported the prolongation of pseudopregnancy by almost a week in hysterectomized rats. However, the lack of differences between the two groups in the first 12 days of pseudopregnancy makes it unlikely that the uterus has an appreciable influence on the presumed endocrine stimulus for the hemodynamic changes typical for this period. This is also supported by reports on progesterone levels during the first 10 days in intact and hysterectomized pseudopregnant rats [7,15].

In our study, the animals in both groups showed a gradual decline in heart rate in the course of the study period. In previous studies with identical instrumentation and measurement procedures, we observed a similar pattern in heart rate in pregnant, pseudopregnant and control rats $[18,19]$. In this context, it is important to emphasize that the initial heart rate in the present study as well as in our previous studies was higher than corresponding values reported by others, using less extensive or no instrumentation. Most likely the initially higher heart rate in the present study reflects a higher sympathetic tone in the post-surgical recovery period as a consequence of our extensive instrumentation. The decline in heart rate over the subsequent days in all studies mentioned can be considered a combination of recovery and habituation to our experimental protocol. Although it is possible that a change in heart rate induced by pseudopregnancy was not identified because of the experiment-related tachycardia, the latter did not seem to have interfered with the changes in cardiac output and blood pressure in early pseudopregnancy. The fact that the comparable fall 
in heart rate without concomitant fall in cardiac output was also observed in nonpregnant animals after the same extensive instrumentation [18] supports our view that the rise in cardiac output in pseudopregnancy is primarily due to a rise in stroke volume.

Our results in intact and hysterectomized pseudopregnant rats indicate that neither the trophoblast nor the uterus is needed for the development of the vasodilatory response. Therefore, these results support our hypothesis that only hormones from ovarian origin trigger the systemic vasodilatation. Obviously, to explore the mechanism responsible for the hemodynamic changes in early pregnancy, it is important to know the exact contribution of the independent ovarian hormones to these changes. To this end, the pseudopregnant rat may prove to be an attractive model in which hormonal and hemodynamic data can be studied at the same time.

In summary, the present data suggest that, until day 12 post-mating, there is no difference in hemodynamic changes between intact and hysterectomized pseudopregnant rats. These hemodynamic changes are similar to the ones observed in early pregnancy and include peripheral vasodilatation, a rise in cardiac output by a selective rise in stroke volume and stroke work. Therefore, neither conceptus nor uterus seems to play a critical role in the induction of the initial hemodynamic adaptation to early pregnancy. The change in ovarian function resulting in a rise in sex steroids is the most likely mechanism responsible for this adaptation. How the sex steroids and possibly other ovarian hormones such as relaxin [6] initiate systemic vasodilatation remains to be elucidated. 


\section{HEMODYNAMIC CHANGES IN PSEUDOPREGNANCY AFTER HYSTERECTOMY}

\section{REFERENCES}

1. Atherton JC, Bu'lock D, Pirie SC: The effect of pseudopregnancy on glomerular filtration rate and salt and water reabsorption in the rat. J Physiol Lond 1982;324:11-20.

2. Baylis C: Glomerular ultrafiltration in the pseudopregnant rat. Am J Physiol 1982;234(3):F300-F305.

3. van Beek E, Houben AJ, van Es PN, Willekes C, Korten EC, de Leeuw PW, Peeters LLH: Peripheral haemodynamics and renal function in relation to the menstrual cycle. Clin Sci 1996;91:163-168.

4. Chapman AB, Abraham WT, Zamudio S, Coffin C, Merouani A, Young D, Johnson A, Osorio F, Goldberg C, Moore LG, Dahms T, Schrier RW: Temporal relationships between hormonal and hemodynamic changes in early human pregnancy. Kidney Int 1998;54(6):2056-63.

5. Chapman AB, S. Zamudio, Woodmansee W, Merouani A, Osorio F, Johnson A, Moore LG, Dahms T, Coffin C, Abraham WT, Schrier RW: (1997) Systemic and renal hemodynamic changes in the luteal phase of the menstrual cycle mimic early pregnancy. Am J Physiol 1997;273(42):F777-F782.

6. Danielson LA, Sherwood OD, Conrad KP: Relaxin is a potent renal vasodilator in conscious rats. J Clin Invest 1999;103:525-533.

7. De Greef WJ, Dullaart J, Zeilmaker GH: Effect of hysterectomy on serum luteinizing hormone concentrations and on corpus luteum function in the rat. Endocrinology 1976;98:1228-1234.

8. De Greef WJ, Dullaart J, Zeilmaker GH: Serum concentrations of progesterone, luteinizing hormone, follicle stimulating hormone and prolactin in pseudopregnant rats: effect of decidualization. Endocrinology 1977;101:1054-1063.

9. Duvekot JJ, Cheriex EC, Pieters FAA, Menheere PPCA, Peeters LLH: Early pregnancy changes in hemodynamics and volume homeostasis are consecutive adjustments triggered by a primary fall in systemic vascular tone. Am J Obstet Gynecol 1993;169:1382-1392.

10. Duvekot JJ, Cheriex EC, Pieters FAA, Menheere PPCA, Schouten HJA, Peeters LLH: Maternal volume homeostasis in early pregnancy in relation to fetal growth restriction. Obstet Gynecol 1995;85:361-367.

11. Garland HO, Atherton JC, Baylis C, Morgan MRA, Milne CM: Hormone profiles for progesterone, estradiol, prolactin, plasma renin activity, aldosterone and corticosterone in two strains of rats: correlation with renal studies. J Endocrinol 1987;113:435-444.

12. La Sala GB, Gaddi O, Bruno G, Brandi L, Cantarelli M, Salvatore V, Torelli MG, Dall'Asta D: Noninvasive evaluation of cardiovascular hemodynamics during multiple follicular stimulation, late luteal phase and early pregnancy. Fertil Steril 1989;51:796-802.

13. Montani J, Mizelle HL, van Vliet BN, Adair TH: Advantages of continuous measurement of cardiac output 24 hours a day. Am J Physiol 1995;269(38):H696-H703.

14. Paller MS, Gregorini G, Ferris TF: Pressor responsiveness in pseudopregnant and pregnant rats: role of maternal factors. Am J Physiol 1989;257(26):R866-R871.

15. Pepe GJ, Rothchild I: A comparative study of serum progesterone levels in pregnancy and in various types of pseudopregnancy in the rat. Endocrinology 1974;95:275-279.

16. Robson SC, Hunter S, Boys RJ, Dunlop W: (1989) Serial study of factors influencing changes in cardiac output during human pregnancy. Am J Physiol 1989;256(25):H1060-H1065.

17. Seppala M, Tiitinen A: Endometrial responses to corpus luteum products in cycles with induced ovulation: theoretical and practical considerations. Hum Reprod 1995;10:67-76. 


\section{CHAPTER 2}

18. Slangen BFM, Out ICM, Verkeste CM, Peeters LLH: Hemodynamic changes in early pregnancy in chronically instrumented conscious rats. Am J Physiol 1996;270(39):H1779-H1784.

19. Slangen BFM, Out ICM, Verkeste CM, Smits JFM, Peeters LLH: Hemodynamic changes in pseudopregnancy in chronically instrumented conscious rats. Am J Physiol 1997;272(41):H695-H700.

20. Smith MS, Freeman ME, Neill JD: The control of progesterone secretion during the estrous cycle and early pseudopregnancy in the rat: prolactin, gonadotropin and steroid levels associated with rescue of the corpus luteum of pseudopregnancy. Endocrinology 1975;96:219-226.

21. Smith MS, Neill JD: Termination at midpregnancy of two daily surges of plasma prolactin initiated by mating in the rat. Endocrinology 1976;98:696-701.

22. Smits JFM, Coleman TG, Smith, Kasbergen CM, van Essen H, Struyker-Boudier HAJ: Antihypertensive effect of propanolol in conscious spontaneously hypertensive rats: central haemodynamics, plasma volume, and renal function during ß-blockade with propanolol. J Cardiovasc Pharmacol 1982;4:903-914. 



\section{CHAPTER 3}

\section{VASODILATOR REACTIVITY TO CALCITONIN GENE-RELATED PEPTIDE IS INCREASED IN MESENTERIC ARTERIES OF RATS DURING EARLY PREGNANCY}

Hugo W.F. van Eijndhoven, Olivier W.H. van der Heijden,

Gregorio E. Fazzi, Robert Aardenburg, Marc E.A. Spaanderman, Louis L.H. Peeters, Jo G.R. De Mey 



\title{
CHAPTER 3
}

\begin{abstract}
The objective of the present study was to determine the effect of early pregnancy on the sensitivity to, and endogenous production of Calcitonin Gene-Related Peptide (CGRP). Contractile responses of arteries of 10-day pregnant and nonpregnant rats were studied in myographs. During contractions induced by $40 \mathrm{mmol} / 1 \mathrm{~K}^{+}$, exogenous CGRP elicited in pregnancy an approx. 30\% stronger relaxation in mesenteric arteries, an effect not seen in renal and uterine arteries. Capsaicin treatment during $\mathrm{K}^{+}$-induced contractions caused a persistent potentiation of the contractile response in mesenteric arteries indicating that $\mathrm{K}^{+}$ stimulates the endogenous release of CGRP. This potentiation was similar in the pregnant and nonpregnant state $(+81 \pm 23 \%$ and $+82 \pm 23 \%$, respectively), suggesting no effect of pregnancy on the endogenous CGRP release. The latter was paralleled by comparable CGRP content in the arteries of both groups indicating similar tissue CGRP availability.

The results of this study support the concept that early pregnancy is associated with a rise in the vascular sensitivity to CGRP in selected areas of the vascular bed without concomitant increase in the vascular CGRP production and release.
\end{abstract}

\section{INTRODUCTION}

Early pregnancy is associated with marked hemodynamic changes, which include a rise in cardiac output and plasma volume, a fall in peripheral systemic vascular resistance and hemodilution. These changes seem to represent compensations for a primary fall in systemic vascular tone. The latter phenomenon is observed not only in human - [1,2], but also in rat [3] and sheep pregnancy [4]. Although the functional meaning of the systemic vasorelaxation in pregnancy is still obscure, its importance for pregnancy is emphasized by the epidemiological observation that hypertensive complications of pregnancy such as preeclampsia and fetal growth restriction (IUGR) are preceded by the defective development of this adaptive vascular response to pregnancy [5]. Therefore, we expect that exploration of the mechanism responsible for the early-pregnancy vasorelaxation will improve our understanding of the pathogenesis of hypertensive complications in pregnancy.

Calcitonin Gene-Related Peptide (CGRP) is a 37-amino-acid vasoactive neuropeptide that is mainly expressed in the dorsal root ganglia. It is the most potent endogenous vasodilator and is released from the sensory-motor nerves, which are distributed throughout the cardiovascular system. In the rat [6,7] the hypotensive effect of CGRP is enhanced in late pregnancy possibly as a result of a higher vascular sensitivity to CGRP. Whether CGRP con- 
tributes to the vasorelaxation in early pregnancy is unknown. Elevated peripheral CGRP levels in both rat - [8] and human pregnancy $[9,10]$ support the view that CGRP is involved in the regulation of vascular tone in pregnancy.

The objective of this study was to test the hypothesis that the vasorelaxation in early pregnancy is also caused by an increased vascular sensitivity to CGRP. To this end, we studied in a myograph the vasodilator effects of exogenous CGRP on $\mathrm{K}^{+}$-induced contractions in different types of rat arteries. By using capsaicin [11], a vanilloid pungent, that initially stimulates and subsequently desensitizes and destroys the sensory-motor nerves, we also determined the vasorelaxant response of endogenous CGRP released from perivascular sensory-motor nerves.

\section{MATERIAL AND METHODS}

\section{Preparation}

The present study was carried out on arteries of 3-4-month-old female Wistar rats (Iffa Credo, Someren, The Netherlands). We subdivided the animals $(\mathrm{n}=20)$ into equal-sized groups of pregnant and nonpregnant rats. To establish pregnancy, we allowed the animals in the pregnant group to mate with a male rat. We defined retrieval of a sperm plug from the cage as confirmation of day 1 of pregnancy. On day 10 of pregnancy we sacrificed the rats by cervical dislocation and isolated a renal -, a uterine -, and a branch of the superior mesenteric artery. Segments (1.5-2 mm long) of these arteries were mounted on two stainless wires (diameter: $40 \mu \mathrm{m}$ ) in an isometric myograph (JP, Trading, Aarhus, Denmark) between an isometric force transducer (Kistler Morse, DSC6, Seattle, WA, USA) and a displacement device. The organ chamber $(10 \mathrm{ml})$ of the myograph was filled with Krebs-Ringer bicarbonate solution (KRB, composition in $\mathrm{mM}: \mathrm{NaCl} 118.3, \mathrm{KCl} 4.7, \mathrm{CaCl}_{2} 2.5, \mathrm{MgSO}_{4} \cdot \mathrm{H}_{2} \mathrm{O}$ 1.2, $\mathrm{KH}_{2} \mathrm{PO}_{4} 1.2, \mathrm{NaHCO}_{3} 25.0$ and glucose 5.5) which was maintained at $37^{\circ} \mathrm{C}$ and aerated with $95 \% \mathrm{O}_{2} / 5 \% \mathrm{CO}_{2}$. Subsequently all arteries were distended to their individual optimal diameter, which was determined by increasing the lumen diameter by $50 \mu \mathrm{m}$ (mesenteric and uterine artery) or $100 \mu \mathrm{m}$ (renal artery) increments. Intermittently, contractile responses to maximal depolarization were induced by exposing the preparations to high potassium solution (K-KRB, KRB in which all $\mathrm{NaCl}$ was replaced by an equimolar amount of $\mathrm{KCl}$ ). The diameter at which a maximal contractile response was obtained was considered to be the optimal diameter. All experiments were performed at this diameter. The same procedure was applied to arteries of nonpregnant female rats serving as control group. 


\section{CHAPTER 3}

\section{Experimental protocol}

During a steady-state contraction induced by $40 \mathrm{mmol} / \mathrm{l} \mathrm{K} \mathrm{K}^{+}$we tested the response to exogenously applied human CGRP (0.1 to $100 \mathrm{nmol}$; Natick, MA, USA). Subsequently and during $\mathrm{K}^{+}$-induced contraction, we incubated the arteries with $1 \mu \mathrm{mol} / 1$ capsaicin (Sigma Chemical Co., St. Louis, MO, USA) during at least $20 \mathrm{~min}$, in order to desensitize the sensory-motor nerves [11]. The neuro-excitatory effect of the vanilloid during this period was recorded. After this treatment the dose-response curve with CGRP was repeated. Between the different parts of the protocol the arteries were allowed to return to their basal tone by rinsing the drugs (figure 1). As we have reported previously [12], capsaicin neither influences basal tone nor does the induced desensitization of sensory-motor nerves result in a loss of postjunctional responses to exogenous CGRP.

\section{Immunohistochemistry}

The presence of sensory-motor nerves was demonstrated by staining arteries with rabbit anti-rat CGRP antibodies. The mounted arteries were fixed overnight in the myograph organ bath in phosphate-buffered $(\mathrm{pH}$ 7.4) formaldehyde (4\%) at room temperature, followed by storage in $70 \%$ ethanol. Blockade of endogenous peroxidase activity was achieved by incubation at room temperature in $0.3 \% \mathrm{H}_{2} \mathrm{O}_{2}$ for $2 \mathrm{~h}$. Subsequently, the preparations were washed with 70\% ethanol and then treated with Triton X-100 (0.2\% in PBS), before overnight incubation with 1:3000 diluted primary antibody (Amersham) at room temperature. Then, the preparations were rewashed with Triton X-100 for $1 \mathrm{~h}$, incubated with the secondary antibody (swine anti-rabbit peroxidase, 1:200; DAKO Immunoglobulins, Glostrup, Denmark) and washed once more with Triton X-100. Finally, preparations were incubated with $1.2 \mathrm{mmol} / \mathrm{l}$ diaminobenzidine and $0.03 \% \mathrm{H}_{2} \mathrm{O}_{2}$ for $15 \mathrm{~min}$ at room temperature, dehydrated to xylene (30 min), embedded in Entellan and finally examined and photographed using a Zeiss axioscope.

\section{CGRP-content}

After isolation the arteries are kept for $15 \mathrm{~min}$ in $1 \mathrm{ml}$ boiling $0.5 \mathrm{M} \mathrm{HCl}$. After removing the arteries CGRP is extracted and determined from this solution, using a CGRP RIA-kit (Peninsula). The arteries are placed in $200 \mu \mathrm{l} \mathrm{M} \mathrm{KOH}$ for $48 \mathrm{~h}$ at room temperature. This solution is used for DNA determination according to the Hoechst 33258-method [13]. CGRP content of the arteries is expressed as $\mathrm{pg} / \mu \mathrm{g}$ DNA.

\section{Statistics}

Vascular reactivity was expressed as percent change of the maximal steady-state $\mathrm{K}^{+}$induced contraction. Sensitivity (given as the negative logarithm of $\mathrm{EC}_{50}=\mathrm{pD}_{2}$ ) and maximal response $\left(\mathrm{E}_{\max }\right)$ to $\mathrm{CGRP}$ were calculated by a square sigmoidal curve fit of the response 


\section{VASODILATOR REACTIVITY TO CGRP IN EARLY PREGNANCY}

curves. Data are expressed as means \pm SEM. We evaluated differences between the pregnant and nonpregnant groups by Student's $t$-test. A p-value of less than 0.05 was considered to indicate statistical significance.

\section{RESULTS}

\section{Reactivity}

The mesenteric-, uterine- and renal arteries responded similarly to the application of 40 $\mathrm{mmol} \mathrm{K}^{+}$: an initial transient phase (figure 1) passing into a steady-state contraction persisting for at least $20 \mathrm{~min}$. Exogenous CGRP during this steady-state contraction caused concentration-dependent relaxation in the mesenteric and uterine arteries. Concentrationresponse analysis of the mesenteric artery disclosed a higher sensitivity $\left(\mathrm{pD}_{2}\right)$ and a higher maximal response $\left(\mathrm{E}_{\max }\right)$ to exogenous CGRP in early pregnancy than in the nonpregnant state (table 1 and figure 2). This difference was not observed in the uterine artery (table 1). The renal artery did not respond to exogenous CGRP in either pregnancy or the nonpregnant state (data not shown). Initially capsaicin $(1 \mu \mathrm{mol} / \mathrm{l})$ diminished the $\mathrm{K}^{+}$induced contraction in mesenteric arteries (-61 $\pm 7 \%$ pregnant group; $-54 \pm 8 \%$ nonpregnant group) and in the uterine arteries (-39 $\pm 7 \%$ pregnant group; $-52 \pm 9 \%$ nonregnant group). After approximately 5 min this relaxing effect faded and the $\mathrm{K}^{+}$induced contraction stabilized between 10 to $20 \mathrm{~min}$ as sign of complete desensitization of sensory-motor nerves (figure 1). Contractile responses to 40

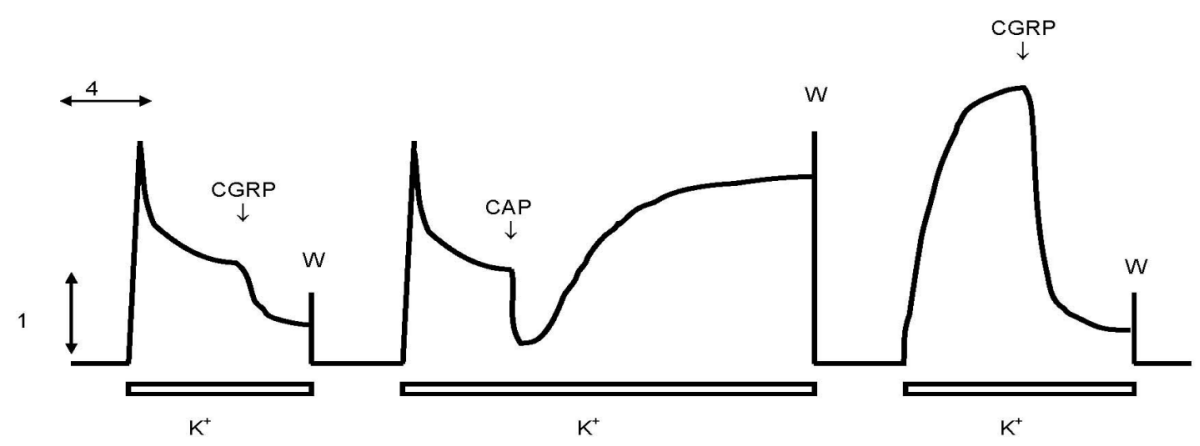

Fig. 1. Typical tracing of the effects on isometric tension development in isolated rat mesenteric artery (pregnant and nonpregnant) of $40 \mathrm{mmol} / 1 \mathrm{~K}^{+}$(horizontal bar), exogenous CGRP and capsaicin $(1 \mu \mathrm{mol} / \mathrm{l}$, CAP). At washout (W) the tissue was incubated in drug-free Krebs solution. 
mmol K $\mathrm{K}^{+}$after the capsaicin pretreatment (figure 1) were significantly higher in mesenteric $(+81 \pm 23 \%$ pregnant group; $+82 \pm 23 \%$ nonpregnant group $)$ and uterine arteries $(+81 \pm 41 \%$ pregnant group; $+101 \pm 37 \%$ nonpregnant group) compared to the responses before capsaicin pretreatment. These higher responses were not significantly different between the pregnant and nonpregnant group for both arteries. Renal arteries did not respond to capsaicin and the contractile response to $\mathrm{K}^{+}$was not modified after treatment with the pungent. After capsaicin pretreatment, sensitivity and maximal response to exogenous CGRP were still higher in the mesenteric artery of the pregnant group than in the nonpregnant group (table 1 and figure 2).

Table 1. Vascular reactivity to CGRP before and after capsaicin treatment.

\begin{tabular}{llcllll}
\hline & & \multicolumn{2}{c}{ Mesenteric artery } & & Uterine artery \\
& $\mathrm{N}$ & $\mathrm{pD}_{2}$ & $\mathrm{E}_{\max }$ & & $\mathrm{pD}_{2}$ & $\mathrm{E}_{\max }$ \\
\hline \hline Nonpregnant & 10 & $8.45 \pm 0.21$ & $40 \pm 6$ & & $8.73 \pm 0.17$ & $70 \pm 7$ \\
Pregnant & 10 & $11.03 \pm 0.91^{*}$ & $75 \pm 4^{*}$ & & $8.67 \pm 0.29$ & $78 \pm 3$ \\
& \multicolumn{2}{c}{ Capsaicin treatment } & & & \\
Nonpregnant & 10 & $8.95 \pm 0.14$ & $76 \pm 2$ & & $8.84 \pm 0.12$ & $90 \pm 1$ \\
Pregnant & 10 & $10.97 \pm 0.78^{*}$ & $82 \pm 2^{*}$ & & $9.28 \pm 0.26$ & $90 \pm 2$ \\
\hline
\end{tabular}

$\mathrm{pD}_{2}$ values (-Log Molar $\left[\mathrm{EC}_{50}\right]$ ) and $\mathrm{E}_{\max }$ for the response to exogenous CGRP before and after capsaicin pretreatment for mesenteric and uterine arteries.

Data are shown as mean \pm SEM. ${ }^{*} \mathrm{p}<0.05$ with Student's $t$-test.
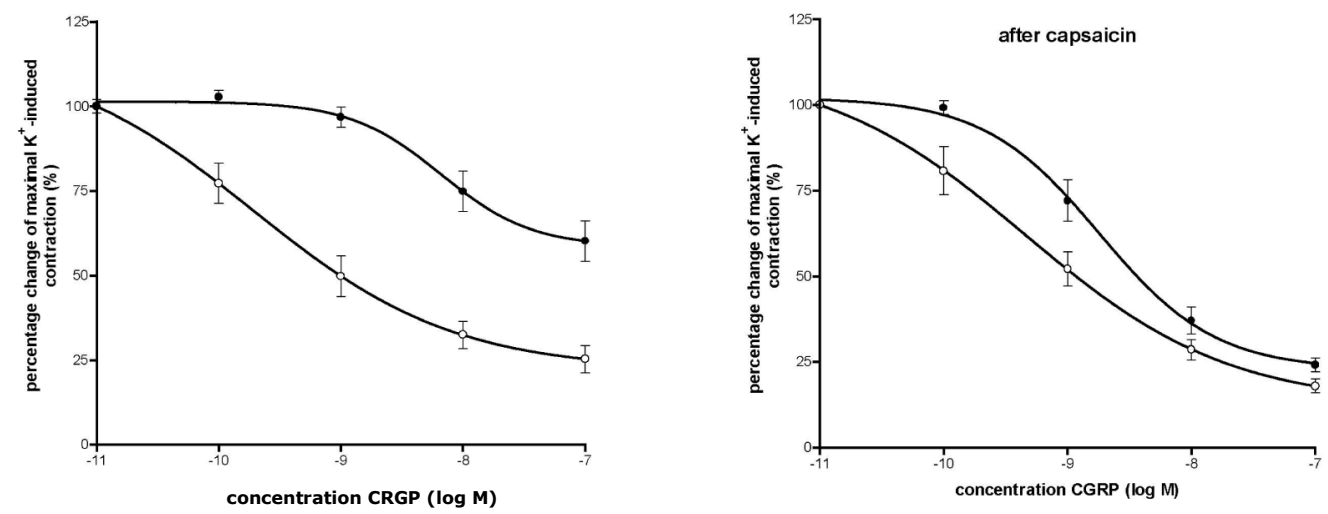

Fig. 2. Relaxing responses to exogenous CGRP (0.1 to $100 \mathrm{nmol} / \mathrm{l})$ during $\mathrm{K}^{+}$-induced contraction (40 $\mathrm{mmol} / \mathrm{l})$ before and after pretreatment with capsaicin $(1 \mu \mathrm{mol} / \mathrm{l})$ in mesenteric arteries of pregnant (open circle) and non-pregnant (closed circle) Wistar rats. 

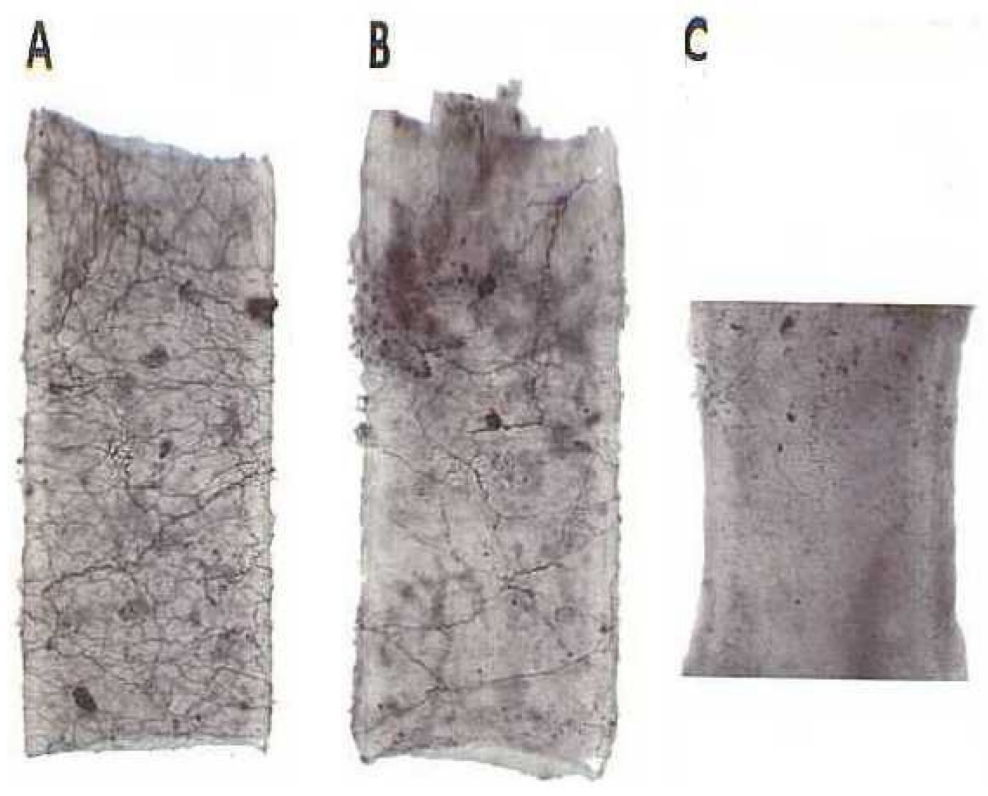

Fig. 3. Anti-CGRP immunohistochemistry in whole mount preparations of a mesenteric (A), uterine (B) and renal $(\mathrm{C})$ artery of a 10-day pregnant Wistar rat. Note the absence anti-CGRP staining in the renal artery.

However, the difference in maximal response to exogenous CGRP diminished after this pretreatment (table 1 and figure 2). After capsaicin pretreatment there was still no difference in uterine vasodilator response to exogenous CGRP between the pregnant and nonpregnant group (table 1). Also, after exposure to capsaicin, renal arteries failed to respond to exogenous CGRP.

\section{Immunohistochemistry}

The density of CGRP-immunoreactive sensory-motor nerves was higher in the mesenteric and uterine arteries than in the renal artery (figure 3) with no appreciable change in pregnancy.

\section{CGRP content}

Table 2 illustrates the CGRP content of the three types of arteries. Early pregnancy did not seem to have altered the arterial CGRP content. 


\section{CHAPTER 3}

Table 2. CGRP-content of rat arteries

\begin{tabular}{llll}
\hline & Mesenteric artery & Uterine artery & Renal artery \\
& CGRP $(\mathrm{pg} / \mu \mathrm{g}$ DNA) & CGRP $(\mathrm{pg} / \mu \mathrm{g}$ DNA) & CGRP $(\mathrm{pg} / \mu \mathrm{g}$ DNA) \\
\hline \hline Nonpregnant & $32.6 \pm 2.50$ & $18.7 \pm 1.54$ & $9.8 \pm 1.85$ \\
Pregnant & $30.1 \pm 1.89$ & $16.5 \pm 1.05$ & $11.5 \pm 1.77$ \\
\hline
\end{tabular}

CGRP content expressed as $\mathrm{pg} / \mu \mathrm{g}$ DNA. The data are shown as mean \pm SEM. Control group ( $\mathrm{n}=6$ for all three types of arteries), pregnant group ( $\mathrm{n}=6$ for all three types of arteries).

\section{DISCUSSION}

Our results clearly indicate that mesenteric arteries are more sensitive to exogenous CGRP at day 10 of pregnancy than in the nonpregnant state. We also demonstrated that $\mathrm{K}^{+}$induced contractile responses of arteries equipped with a dense network of CGRP-containing sensory-motor nerves, such as the mesenteric and uterine arteries, are effected by endogenously released CGRP. Several lines of evidence support this finding. First, in mesenteric and uterine arteries the sensory-motor nerve stimulating and desensitizing agent capsaicin [11] initially reduces and then potentiates the contractile response to $\mathrm{K}^{+}$. Second, relaxing responses to exogenous CGRP in mesenteric and uterine arteries are increased after capsaicin treatment. Therefore, it is likely that the observed $\mathrm{K}^{+}$-induced contraction before capsaicin is the combined response to $\mathrm{K}^{+}$and to endogenously released CGRP. After capsaicin treatment endogenous CGRP is no longer released by the depolarizing stimulus and exogenous CGRP can gain access to its receptors on the arterial smooth muscle cells without competition by endogenous released neuropeptide. Third, neither the relaxing nor the potentiating effects of capsaicin are seen in arteries with sparse perivascular sensory-motor nerve density such as the renal artery (this study) and the superior epigastric artery [14]. Fourth, a CGRP-receptor antagonist such as $\mathrm{CGRP}_{8-37}$ increases contractile responses to $\mathrm{K}^{+}$in arteries densely innervated with perivascular sensory-motor nerves such as the mesentery [12].

The increased sensitivity to exogenous CGRP in the mesenteric arteries of the pregnant group was preserved after desensitization of the sensory-motor nerves by capsaicin. The difference in maximal dilatation between the pregnant and nonpregnant groups also persisted after pretreatment with capsaicin. These findings suggest that the difference between the pregnant and nonpregnant state cannot be explained by a difference at a prejunctional level, e.g. a higher density or CGRP-content of the perivascular sensory-motor nerves in pregnancy. This 


\section{VASODILATOR REACTIVITY TO CGRP IN EARLY PREGNANCY}

conclusion is consistent with our data of the immunohistochemical and CGRP-content studies, which revealed no pregnancy-related change in sensory-motor nerve density or CGRP-content in the mesenteric arteries.

Pregnancy and the sex steroids are known to raise peripheral CGRP levels in the human [9] and rat [8]. From the reported data it is not possible to discern whether these higher circulating levels of CGRP are to be explained by accelerated synthesis and/or excretion into the circulation by perivascular sensory-motor nerves or of diminished metabolization of CGRP. The equally potentiated response to $\mathrm{K}^{+}$after capsaicin pretreatment in the pregnant and nonpregnant mesenteric artery $(+81 \pm 23 \%$ and $+82 \pm 23 \%$, respectively) supports the concept that higher circulating levels of CGRP are probably secondary to attenuated clearance or as recently reported [15], increased release of CGRP by the nerve terminal. Obviously, it is also possible that capsaicin and $\mathrm{K}^{+}$act via different pathways in releasing endogenous CGRP from the sensory-motor nerve endings but further detailed studies are required to explore this mechanism.

We observed marked regional differences in sensitivity to the vasodilator effects of exogenous CGRP and its modulation by pregnancy. In contrast to the mesenteric artery, contractile and relaxing responses to $\mathrm{K}^{+}$, exogenous CGRP and capsaicin in the uterine arteries did not change in early pregnancy relative to the nonpregnant state. The renal arteries display only sparse perivascular sensory-motor innervation and did not respond to exogenous CGRP or capsaicin at all. The differences between these arteries and the mesenteric arteries could be explained by the fact that they are conduit and not resistance arteries. Although speculative, the different function and size of the latter could be associated with a difference in CGRP-receptor density or coupling. Therefore, one cannot exclude the possibility that further downstream the vascular beds of the kidney and the uterus the same pregnancy-related increase in sensitivity to exogenous CGRP could be obtained. At least in humans at term, sensitivity to CGRP of segments of the uterine arteries was increased [16]. Furthermore, there is evidence that sex steroid supplementation in ovariectomized rats increases the fall in uterine perfusion pressure in response to CGRP [7].

There is compelling evidence that CGRP is involved in the hemodynamic adaptation to pregnancy. The decrease in mean arterial pressure in response to CGRP is larger in pregnancy than in the nonpregnant state [6]. This response was also enhanced in ovariectomized rats treated with progesterone or estradiol. Induction of hypertension by inhibition of nitric oxide production (L-NAME) in pregnant rats could be reversed by infusion of CGRP [17] and again this effect seemed to be progesterone dependent [18]. These studies suggest an altered effect of CGRP on vascular resistance in pregnancy, that is to say an increase in sensitivity to CGRP. However, all these data were obtained in rats at a gestational age of 19 days, while systemic vasorelaxation leading to the pregnancy-related hemodynamic changes takes place 


\section{CHAPTER 3}

in early pregnancy. Therefore, it is difficult to extrapolate the results of these earlier studies to the regulation of vascular tone in early pregnancy. In rat pregnancy, cardiac output increases by approx. $20 \%$ by the 10th day of pregnancy, without any change in vascular structure [19]. This means that our results, suggesting a higher sensitivity to CGRP in mesenteric arteries by 10 days pregnancy, are not paralleled by the confounding influence of vascular remodeling.

The mechanism by which pregnancy modulates the effect of CGRP on vascular tone is unknown. The vasodilator effect of CGRP involves the endothelium, activation of $\mathrm{K}^{+}$channels in the arterial smooth muscle and activation of adenylate cyclase [20]. Unpublished data of our group reveal that the relaxing effects of exogenous CGRP in rat mesenteric arteries were not modified by the removal of endothelium and thus they appear to be nitric oxide independent. This is in agreement with previous findings [16,21] and the fact that CGRP completely reversed L-NAME induced hypertension in pregnant rats [17,18]. We studied the relaxing responses of CGRP in the presence of $40 \mathrm{mmol} \mathrm{K}^{+}$. This excludes the possibility that the difference in response between the pregnant and nonpregnant groups is due to a difference in sarcolemmal $\mathrm{K}^{+}$channels. Activation of adenylate cyclase takes place through G-protein coupled CGRP receptors. Increased concentration or affinity of these receptors may be involved in the mechanism leading to an increased sensitivity to CGRP in pregnancy. Recent studies demonstrating the up-regulation of CGRP receptor concentration and binding in human and rat uterus in pregnancy [22,23] support this hypothesis. Progesterone is thought to play a crucial role in this process [23]. Whether or not CGRP receptor concentration or the coupling of CGRP receptors to adenylate cyclase is changed in resistant arteries in early pregnancy remains to be elucidated.

In summary, our results confirm the hypothesis that resistance artery sensitivity to CGRP in pregnancy is increased. This change can already be detected in 10-day pregnant rats, and is regionally selective. Further, our results indicate that early pregnancy is not associated with a change in perivascular density of sensory-motor nerves or CGRP-content. Thus, CGRP may play a role in the early-pregnancy vasorelaxation and hemodynamic adaptation during pregnancy. The mechanism responsible for the increased vasodilator response of CGRP in pregnancy and the assumed role of the sex steroids in this process remains to be established. Our data support the view that the latter effect could be secondary to a higher density and/or function of postjunctional receptors. 


\section{VASODILATOR REACTIVITY TO CGRP IN EARLY PREGNANCY}

\section{REFERENCES}

1. Duvekot JJ, Cheriex EC, Pieters FAA, Menheere PPCA, Peeters LLH: Early pregnancy changes in hemodynamics and volume homeostasis are consecutive adjustments triggered by a primary fall in systemic vascular tone. Am J Obstet Gynecol 1993;169:1382-1392.

2. Chapman AB, Abraham WT, Zamudio S, Coffin C, Merouani A, Young D, Johnson A, Osorio F, Goldberg C, Moore LG, Dahms T, Schrier RW: Temporal relationships between hormonal and hemodynamic changes in early human pregnancy. Kidney Int 1998;54(6):2056-63.

3. Slangen BFM, Out ICM, Verkeste CM, Peeters LLH: Hemodynamic changes in early pregnancy in chronically instrumented conscious rats. Am J Physiol Heart Circ Physiol 1996;270:H1779-1784.

4. Magness RR, Rosenfeld CR: Local and systemic estradiol-17ß: effects on uterine and systemic vasodilatation. Am J Physiol 1989;256:E536-E542.

5. Duvekot JJ, Cheriex EC, Pieters FAA, Menheere PPCA, Schouten HJA, Peeters LLH: Maternal volume homeostasis in early pregnancy in relation to fetal growth restriction. Obstet Gynecol 1995;85:361-367.

6. Gangula PRR, Zhao H, Supowit SC, Wimalawansa S, Dipette D, Yallampalli C: Pregnancy and steroid hormones enhance the vasodilatation responses to CGRP in rats. Am J Physiol Heart Circ Physiol 1999; 276:H284-288.

7. Grewal M, Cuevas J, Chaudhuri G, Nathan L: Effects of calcitonin gene-related peptide on vascular resistance in rats: role of sex steroids. Am J Physiol Heart Circ Physiol 1999;276:H2063-H2068.

8. Gangula PRR, Wimalawansa SJ, Yallampalli C: Pregnancy and sex steroids enhance circulating calcitonin gene-related peptide concentrations in rats. Hum Reprod 2000;15:949-953.

9. Stevenson JC, MacDonald DWR, Warren RC: Increased concentration of calcitonin gene-related peptide during normal human pregnancy. Br Med J 1986;293:1329-1330.

10. Sagesse G, Belloni S, Barocelli GI, Pelletti A, Benedetti U: Evaluation of a peptide family encoded by the calcitonin gene in selected healthy pregnant women. A longitudinal study. Horm Res 1990;34:240244

11. Szallasi A, Blumberg PM: Vanilloid (capsaicin) receptors and mechanisms. Pharmacol Rev 1999;51: 159-211.

12. De Mey JGR, van Eijndhoven HWF, Sanders MW: A strong relationship between peri-arterial sensory motor nerves and arterial relaxing responses to calcitonin gene-related peptide (CGRP). J Vasc Res 2001;38:S1: 9

13. Rymaszewski Z: Estimation of cellular DNA content in cell lysates suitable for RNA isolation. Anal Biochem 1990;188:91-96.

14. Stassen FRM, Raat NJH, Brouwers-Ceiler DL, Fazzi GE, Smits JFM, De Mey JGR: Angiotensin II induces media hypertrophy and hyperreactivity in mesenteric but not in epigastric small arteries of the rat. J Vasc Res 1997;34:289-297.

15. Lanlua P, Bukoski RD, Wimalawansa SJ, Yallampalli C: Effects of pregnancy and female sex steroid hormones on calcitonin gene-related peptide content of mesenteric artery in rats. Biol Reprod 2002; 67(5):1430-1434.

16. Nelson SH, Steinsland OS, Suresh MS: Possible physiologic role of calcitonin gene-related peptide in the human uterine artery. Am J Obstet Gynecol 1993;168:605-611.

17. Yallampalli C, Dong Y, Wimalawansa SJ: Calcitonin gene-related peptide reverses the hypertension and significantly decreases the fetal mortality in pre-eclampsia rats induced by $\mathrm{N}^{\mathrm{G}}$-nitro-L-arginine methyl ester. Hum Reprod 1996;11:895-899.

18. Gangula PRR, Supowit SC, Wimalawansa SJ, Zhao H, Hallman DM, DiPette DJ, Yallampalli C: Calcitonin gene-related peptide is a depressor in NG-nitro-L-arginine methyl ester-induced hypertension during pregnancy. Hypertension 1997;29:248-253.

19. Slangen BFM, van Ingen Schenau DS, van Gorp AW, De Mey JGR, Peeters LLH: Aortic distensibility and compliance in conscious pregnant rats. Am J Physiol Heart Circ Physiol 1997;272:H1260-H1265. 


\section{CHAPTER 3}

20. Bell D, McDermott BJ: Calcitonin gene-related peptide in the cardiovascular system: characterization of receptor populations and their (patho)physiological significance. Pharmacol Rev 1996;48:253-288.

21. Ahluwalia A, Vallance P: Interaction between sympathetic and sensory nerves in rat small arteries: Involvement of nitric oxide. Am J Physiol Heart Circ Physiol 1996;271:H969-H976.

22. Dong Y, Fang L, Kondapaka S, Gangula PR, Wimalawansa SJ, Yallampalli C: Involvement of calcitonin gene-related peptide in the modulation of human myometrial contractility during pregnancy. $\mathrm{J}$ Clin Invest 1999;104:559-565.

23. Yallampalli C, Gangula PRR, Kondapaka S, Fang L, Wimalawansa S: Regulation of calcitonin generelated peptide receptors in the rat uterus during pregnancy and labor and by progesterone. Biol Reprod 1999;61(4):1023-1030. 



\title{
CHAPTER 4
}

\author{
MECHANISMS LEADING TO INCREASED VASODILATOR \\ RESPONSES TO CALCITONIN GENE-RELATED PEPTIDE \\ IN MESENTERIC RESISTANCE ARTERIES OF \\ EARLY PREGNANT RATS
}

Hugo W.F. van Eijndhoven, Ger M.J. Janssen, Robert Aardenburg, Marc E.A. Spaanderman, Louis L.H. Peeters, Jo G.R. De Mey

Journal of Vascular Research 2008;45(4):350-356 



\title{
CHAPTER 4
}

\begin{abstract}
The objective of this study was to explore the mechanism responsible for the higher relaxing responses of mesenteric arteries to calcitonin gene-related peptide (CGRP) in pregnancy. We performed myograph and ligand binding studies to determine the role of matrix metalloproteinase-2 (MMP-2) and the CGRP-receptor density. MMP activity was manipulated in isolated arteries by exposing them to the blocking effects of doxycycline. Vascular activity of MMP-2 was studied by gelatin zymography and CGRP receptor density was determined by ligand binding analysis. As compared to nonpregnancy, CGRP elicited stronger arterial relaxation in pregnancy. The latter effect was neither accompanied by a change in relaxing responses to direct activation of adenylyl cyclase by forskolin, nor by a change in the response to stimulation of G-protein coupled adrenergic receptors by isoproterenol. Doxycycline did not affect the stronger arterial relaxation in pregnancy in spite of the observed more than 3-fold higher arterial MMP-2 activity. Density of binding sites for $\left[{ }^{125} \mathrm{I}\right]$ CGRP in arteries from pregnant rats $(64 \pm 14 \mathrm{fmol} / \mathrm{mg}$ protein) and from virgin rats $(54 \pm 5$ fmol/mg protein) were comparable. The results of this study provide evidence for increased coupling of CGRP-receptors to adenylyl cyclase in early pregnancy.
\end{abstract}

\section{INTRODUCTION}

In most mammals, including rat [1,2] and man [3-5], pregnancy induces systemic vasorelaxation. Various observations support an important role for CGRP in triggering this phenomenon [6,7]. CGRP is a 37-amino-acid vasoactive neuropeptide. After its release from sensory-motor nerves, it acts as a potent vasodilator throughout the cardiovascular system [8]. Recently, we demonstrated higher vasodilator responses to exogenous CGRP in mesenteric resistance arteries of early-pregnant rats relative to nonpregnant control rats [9]. The mechanism leading to this effect was unclear.

In human [10] and rat pregnancy [11], the circulating levels of CGRP are elevated. Whether this rise and the development of a stronger CGRP vasodilator activity result from a shared pregnancy-related mechanism, is unknown. In early-pregnant rat, we did not find a higher density of perivascular sensory-motor nerves nor an enhanced content of CGRP in the wall of the mesenteric arteries [9], suggesting no accelerated synthesis or release of CGRP by the sensory-motor nerve endings. However, a lower metabolic clearance of CGRP in pregnancy could also result in higher CGRP levels in the direct vicinity of sensory-motor nerves. In this context, MMP-2 could be important, because this enzyme inactivates endogenous 
CGRP [12]. It follows that a condition-specific inhibition of MMP-2 activity in early pregnancy could explain the higher circulating levels of CGRP as well as a higher CGRP activity in the vascular bed. To our knowledge, the role of MMP-2 as a modulator of the neurohormonal activity of CGRP in early pregnancy has not been addressed.

Besides the latter mechanism for a more pronounced effect of CGRP in pregnancy, it is also conceivable that CGRP activity in the vascular bed is higher in pregnancy in conjunction with upregulation of the CGRP receptors.

This study was designed to test the hypothesis that in early pregnancy arterial vasodilatation in selected areas results from a stronger CGRP effect due to a condition-specific fall in vascular MMP-2 activity, possibly potentiated by a concomitant rise in the density and affinity of CGRP receptors. To test this hypothesis, we studied the effect of exogenous CGRP on $\mathrm{K}^{+}$-induced contractions in mesenteric arteries from both nonpregnant and pregnant rats and assessed, whether the MMP inhibitor doxycycline amplified these effects in pregnancy to a higher degree than in the nonpregnant state. In addition, we determined the MMP-2 activity in the arterial wall by gelatin zymography. The possible contribution of CGRP receptor upregulation was addressed by ligand-binding studies in isolated intact mesenteric resistance arteries.

\section{MATERIAL AND METHODS}

\section{Preparation}

The present study was carried out in 3-4-month-old female Wistar rats (Iffa Credo, Someren, The Netherlands). The animals $(\mathrm{n}=20)$ were divided into two subgroups of pregnant $(n=10)$ and nonpregnant rats $(n=10)$. To establish pregnancy, we allowed the animals in the pregnant group to mate with a male rat. The retrieval of a sperm plug from the cage confirmed the first day of pregnancy. On day 10 of pregnancy we sacrificed the rats by cervical dislocation and isolated a first order branch of the superior mesenteric artery. Segments of these arteries (1.5-2 mm long) were mounted on two stainless wires (diameter: $40 \mu \mathrm{m}$ ) in an isometric myograph (JP Trading, Aarhus, Denmark) between an isometric force transducer (Kistler Morse, DSC6, Seattle, WA, USA) and a displacement device. The organ chamber (10 $\mathrm{ml}$ ) of the myograph was filled with Krebs-Ringer bicarbonate solution (KRB, composition in $\mathrm{mM}: \mathrm{NaCl} 118.3, \mathrm{KCl} 4.7, \mathrm{CaCl}_{2} 2.5, \mathrm{MgSO}_{4} \cdot \mathrm{H}_{2} \mathrm{O} 1.2, \mathrm{KH}_{2} \mathrm{PO}_{4} 1.2, \mathrm{NaHCO}_{3} 25.0$ and glucose 5.5) which was maintained at $37^{\circ} \mathrm{C}$ and aerated with $95 \% \mathrm{O}_{2} / 5 \% \mathrm{CO}_{2}$. Then, we distended the arteries by increments of $50 \mu \mathrm{m}$ to their optimal lumen diameter. Intermittently, we induced contractile responses to maximal depolarisation by exposing the preparations to 


\section{CHAPTER 4}

high potassium solution (K-KRB, $\mathrm{KRB}$ with $\mathrm{NaCl}$ replaced by an equimolar amount of $\mathrm{KCl}$ ). We defined the optimal diameter as the one that enabled the largest contractile response. All experiments were performed at this diameter. We also applied this procedure to the corresponding arteries of nonpregnant female rats, which served as controls. In both groups we prepared a second segment of the arteries in a myograph as described above, to create an identical set-up enabling the execution of parallel experiments.

\section{Experimental protocol}

Exposure of an artery with a high density of sensory-motor nerves to $\mathrm{K}^{+}$not only induces a contractile response, but also causes the release of endogenous CGRP [9]. Therefore, the arteries in both settings were first incubated with $1 \mu \mathrm{mol} / 1$ capsaicin (Sigma Chemical Co., St. Louis, MO, USA) for at least $20 \mathrm{~min}$. Initially, capsaicin stimulates the sensory-motor nerves, but prolonged exposure leads to persistent desensitization and destruction of these nerves [14]. The effect of capsaicin on $\mathrm{K}^{+}$-induced contraction was discussed in detail in our previous report [9]. In our hands this treatment results in a very stable, long lasting contraction without the possibility of interference by endogenous CGRP. After this treatment we tested the response to exogenously applied human $\alpha$ CGRP $(0.1$ to $100 \mathrm{nmol}$; Natick, MA, USA) during a steady-state contraction induced by $40 \mathrm{mmol} / 1 \mathrm{~K}^{+}$. Than, we incubated for a period of $20 \mathrm{~min}$, the arteries in one of the 2 set-ups in media containing $20 \mathrm{nM}$ doxycycline, thus blocking all MMP-2 activity, and repeated the experimental protocol with CGRP. Between the consecutive sections of the protocol, we allowed the arteries to return to their basal tone by rinsing the applied compounds. Subsequently, we conducted a dose-response curve for forskolin (0.01 to $100 \mathrm{nmol} / \mathrm{l}$, Sigma Chemical Co., St. Louis, MO, USA), a direct activator of adenylyl cyclase. This experiment served as control for a possible difference between the pregnant and nonpregnant groups in the downstream cascade of signal transduction. That is to say, at the level of the contractile machinery in the vascular smooth muscle cell itself. Finally, we constructed dose-response curves for isoproterenol $(0.01$ to $100 \mathrm{nmol} / 1$ Sigma Chemical Co., St. Louis, MO, USA), an activator of adrenerge receptors. The latter consists - similar as the CGRP receptor - of a seven-transmembrane G-protein-coupled receptor. Therefore, a difference between pregnancy and controls in the relaxing response to both vasodilator agents would indirectly indicate a difference at the level of G-proteins.

\section{Ligand-binding}

Because of the use of intact arteries in the myograph, we decided to perform the analysis of $\left[{ }^{125} \mathrm{I}\right] \mathrm{CGRP}$ binding in comparable arterial segments [15]. The arteries were obtained from pregnant $(n=4)$ and nonpregnant $(n=3)$ rats. After collection these segments were pooled and first incubated for $60 \mathrm{~min}$ at $37^{\circ} \mathrm{C}$ in $250 \mu \mathrm{l} 50 \mathrm{mM}$ Tris- $\mathrm{HCl}, 5 \mathrm{mM} \mathrm{MgCl}, 100 \mathrm{mM} \mathrm{NaCl}$, 
$0.2 \%$ bovine serum albumin ( $\mathrm{pH} 7.4$ ) containing 100 to $2000 \mathrm{pM}\left[{ }^{125} \mathrm{I}\right] \mathrm{CGRP}$ (Amersham Biosciences). In parallel incubations nonspecific binding was determined in the continuous presence of $2 \mu \mathrm{M}$ CGRP. After incubation the arterial segments were placed over Whatman filters and washed 5 times with incubation buffer. Then the segments were recovered from the filters and dissolved in $100 \mu \mathrm{l} 1 \mathrm{~N} \mathrm{KOH}$. Radioactivity was determined in a $\gamma$-counter (Wallace). Specific binding was calculated by subtracting nonspecific binding from total binding. The data were analysed with the scatchard method using 17 points for the control and 20 points for the pregnant group. Finally, the protein content was analysed using bovine serum albumin as standard. Specific binding was expressed as CGRP bound to the protein content (fmol/mg BSA).

\section{Gelatin zymography}

We placed mesenteric arteries in ice-cold extraction buffer, which contained $10 \mathrm{mmol} /$ cacodylic acid, $150 \mathrm{mmol} / 1 \mathrm{NaCl}, 20 \mathrm{mmol} / \mathrm{l} \mathrm{CaCl} 2,1 \mathrm{mmol} / 1 \mathrm{ZnCl}_{2}, 1.4 \mathrm{mmol} / 1 \mathrm{NaN}_{3}, 0.01 \%$ Triton for $48 \mathrm{~h}$. The detergent-soluble fractions of the incubated tissues were retained and protein concentrations in the samples were equalized by using a Bicinchonine acid protein assay Then samples were rinsed with SDS-PAGE sample buffer, and applied to $10 \%$ SDSpolyacrylamide gel, which contained $1 \mathrm{mg} / \mathrm{ml}$ gelatin, followed by separation using electrophoresis. By washing the gels twice with $2.5 \%$ Triton X-100, the SDS was removed. Subsequently, the gels were incubated overnight at $37^{\circ} \mathrm{C}$ in zymography buffer $(50 \mathrm{mmol} / 1$ Tris, $5 \mathrm{mmol} / 1 \mathrm{CaCl}_{2}, 0.02 \% \mathrm{NaN}_{3}$ ) and stained with Coomassie brilliant blue $\mathrm{G} 250$ in $40 \%$ methanol and $10 \%$ acetic acid. Gelatinolytic activity was visualized as clear areas of lysis in the gel. Densitometric analysis was performed by using the Leica Image Processing and Analysis system. Gelatin zymographic analysis revealed multiple lytic bands with the presence of the pro-form of MMP-2 at $72 \mathrm{kDa}$ and the active form at $64 \mathrm{kDa}$.

\section{Statistics}

We expressed vascular reactivity as percentage change of maximum steady-state $\mathrm{K}^{+}$-induced contraction. Sensitivity (represented by the negative logarithm of $\mathrm{EC}_{50}=\mathrm{pD}_{2}$ ) and maximum response $\left(\mathrm{E}_{\max }\right)$ to $\mathrm{CGRP}$ were calculated by a square sigmoidal curve fit of the concentration response curves. We calculated specific binding of $\left[{ }^{125} \mathrm{I}\right] \mathrm{CGRP}$ in terms of maximal density $\left(\mathrm{B}_{\max }\right)$ and affinity $\left(\mathrm{K}_{\mathrm{D}}\right)$. MMP-2 activity in the arteries of pregnant animals was expressed as a percentage of the activity in the control group. Data are presented as means \pm SEM. We evaluated differences between the pregnant and nonpregnant groups by two-way analysis of variance (ANOVA) followed by $t$-test using Bonferroni method to correct for multiple testing. We considered a p-value of less than 0.05 to indicate statistical significance. 


\section{CHAPTER 4}

\section{RESULTS}

\section{Reactivity}

Mesenteric resistance arteries of pregnant and nonpregnant rats responded similarly to stimulation with $40 \mathrm{mmol} \mathrm{K}^{+}$. A first transient contraction was followed by a smaller steadystate contraction. The amplitudes of both phases were comparable between the arteries of pregnant and nonpregnant rats (data not shown). As we have reported previously [9] the application of capsaicin $(1 \mu \mathrm{mol} / \mathrm{l})$ induces a rapid and transient decline in the $\mathrm{K}^{+}$-induced contraction in conjunction with the release of CGRP from the sensory-motor nerves. After approx. $5 \mathrm{~min}$ this decline fades over an interval of 10 to $20 \mathrm{~min}$ to give way to a new and higher steady-state contraction as compared to the one during the pretreatment period, reflecting the condition of complete desensitization of the sensory-motor nerves.

Administration of exogenous CGRP during the $\mathrm{K}^{+}$-induced steady-state post-capsaicin contraction caused a concentration-dependent relaxation in mesenteric arteries of both the pregnant and nonpregnant rats. Both the sensitivity $\left(\mathrm{pD}_{2}\right)$ and the maximum response $\left(\mathrm{E}_{\max }\right)$ were significantly larger in the pregnant - as compared to the nonpregnant rats (figure 1, table 1). Incubation of the arteries with doxycycline neither changed the relaxant responses to CGRP, nor abolished the difference between the pregnant and nonpregnant group (figure 2,

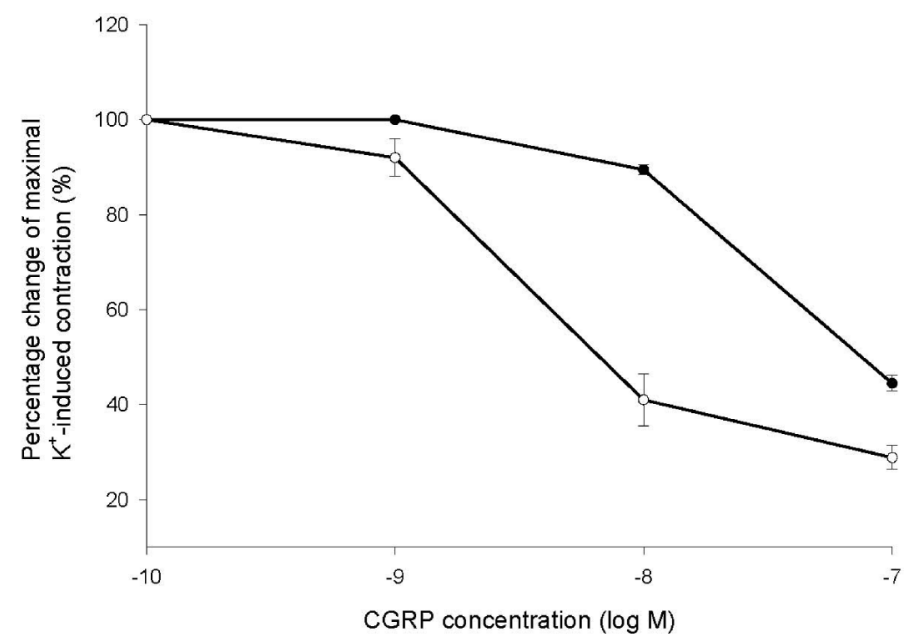

Fig. 1. Relaxing responses to CGRP (0.1-100 nmol/1) during $\mathrm{K}^{+}$-induced contraction in mesenteric arteries of pregnant (open circle) and non-pregnant (closed circle) rats. $\mathrm{p}<0.05$ for $\mathrm{pD}_{2} ; \mathrm{p}<0.05$ for $\mathrm{E}_{\max }$. 


\section{MECHANISMS OF VASODILATOR RESPONSES TO CGRP IN PREGNANCY}

Table 1. $\mathrm{pD}_{2}$ values (-log molar $\left.\left[\mathrm{EC}_{50}\right]\right)$ and $\mathrm{E}_{\max }$ to exogenous CGRP before and after pretreatment with doxycycline in mesenteric arteries

\begin{tabular}{lll}
\hline & $\mathrm{PD}_{2}$ & $\mathrm{E}_{\max }$ \\
\hline \hline Non-pregnant & $7.03 \pm 0.09$ & $56 \pm 2$ \\
Pregnant & $8.40 \pm 0.33^{*}$ & $71 \pm 3^{*}$ \\
& after doxycycline & \\
Non-pregnant & $8.11 \pm 0.20$ & $39 \pm 1$ \\
Pregnant & $8.54 \pm 0.09^{*}$ & $68 \pm 13^{*}$ \\
\hline
\end{tabular}

Data are shown as mean \pm SEM.

$\mathrm{p}<0.05$.

table 1). In contrast to CGRP, the relaxing effects of the diterpene 'forskolin' did not differ between the arteries of pregnant and nonpregnant rats (figure 3 ). The sensitivity and maximal relaxing responses of the mesentery artery to this compound that directly activates adenylyl cyclase were similar in pregnant and nonpregnant animals. The relaxing response to isoproterenol was even larger in the nonpregnant rats (figure 4), however, without significant difference in the derived parameters of the concentration-response curves.

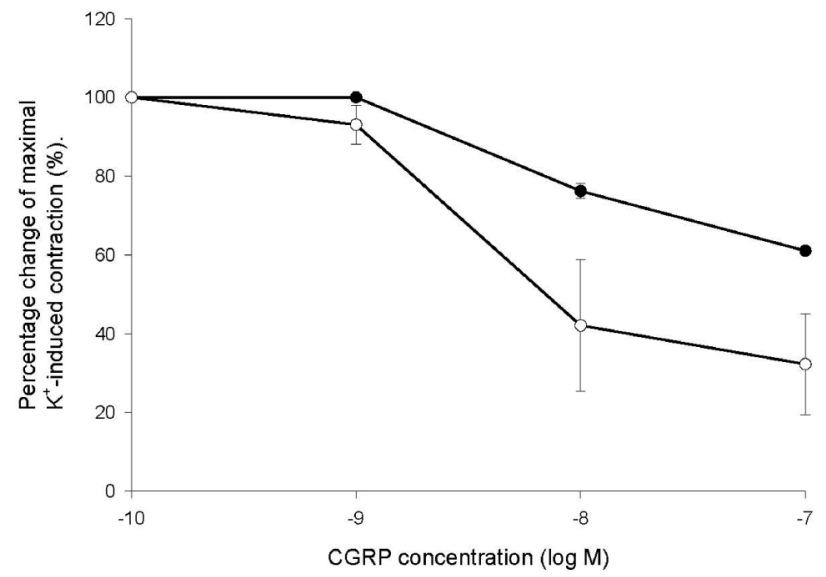

Fig 2. Relaxing responses to CGRP $(0.1-100 \mathrm{nmol} / \mathrm{l})$ during $\mathrm{K}^{+}$-induced contraction after incubation with doxycycline in mesenteric arteries of pregnant (open circle) and non-pregnant (closed circle) rats. $p<0.05$ for $\mathrm{pD}_{2} ; \mathrm{p}<0.05$ for $\mathrm{E}_{\max }$. 


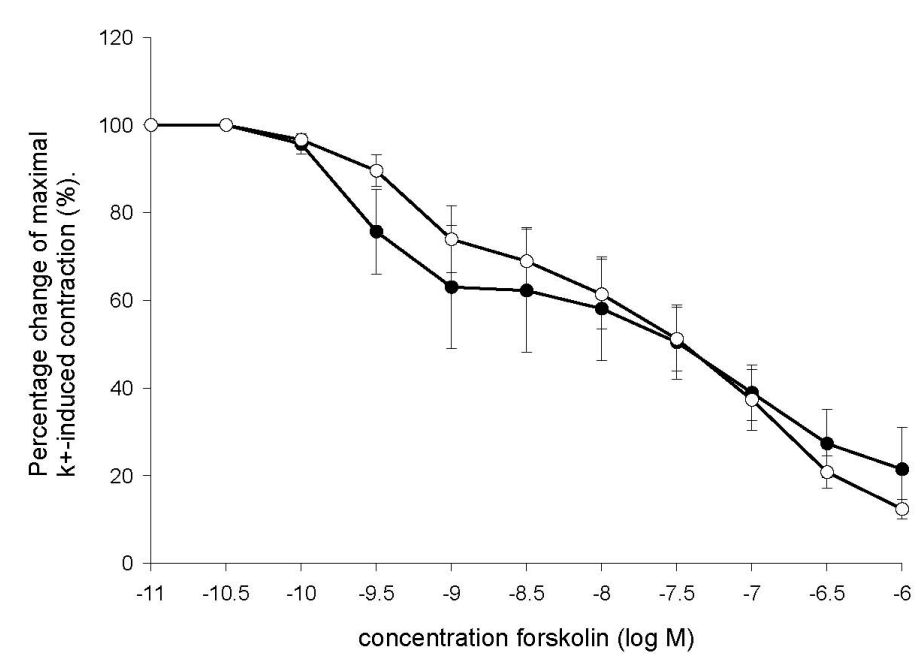

Fig. 3. Relaxing responses for forskolin during $\mathrm{K}^{+}$-induced contraction in mesenteric arteries of pregnant (open circle) and non-pregnant (closed circle) rats.

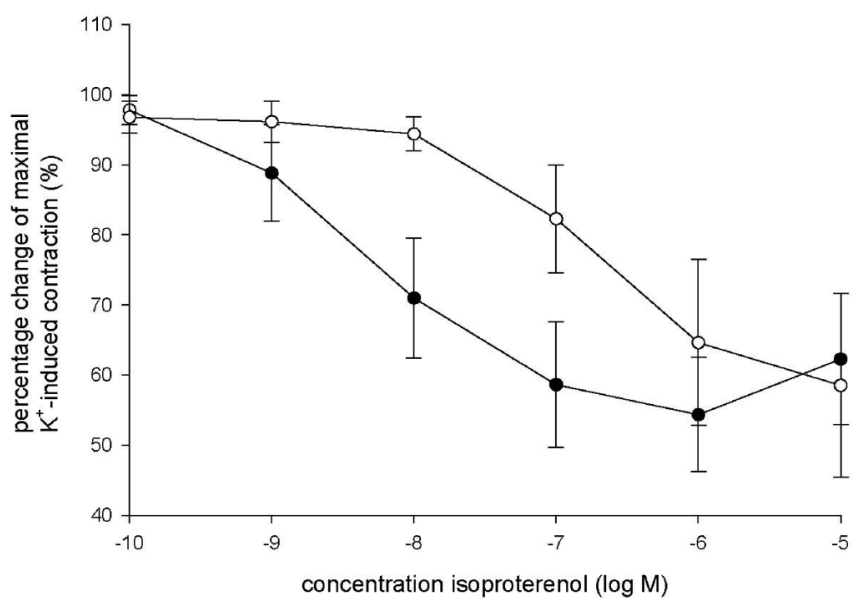

Fig. 4. Relaxing responses to isoproterenol during $\mathrm{K}^{+}$-induced contraction in mesenteric arteries of pregnant (open circle) and non-pregnant (closed circle) rats. 


\section{Ligand-binding}

Analysis of the specific binding of $\left[{ }^{125} \mathrm{I}\right] \mathrm{CGRP}$ revealed a similar dissociation constant and density of specific binding sites in the pregnant $\left(\mathrm{K}_{\mathrm{d}}=144 \mathrm{pM} ; \mathrm{B}_{\max }=64 \pm 14 \mathrm{fmol} / \mathrm{mg}\right.$ protein) and nonpregnant group $\left(\mathrm{K}_{\mathrm{d}}=171 \mathrm{pM} ; \mathrm{B}_{\max }=54 \pm 5 \mathrm{fmol} / \mathrm{mg}\right.$ protein $)$.

\section{Gelatin zymography}

Zymographic analysis of MMP-2 in mesenteric arteries indicated a more than threefold higher activity of the $64 \mathrm{kDa}$ isoform of MMP-2 in pregnant - (352\%) than in nonpregnant rats ( $100 \%$ by definition) (figure 5$)$.

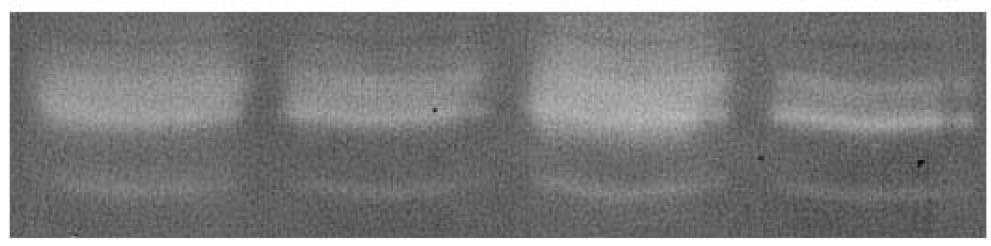

pro MMP-2 (72 kDa)

active MMP-2 (64 kDa)

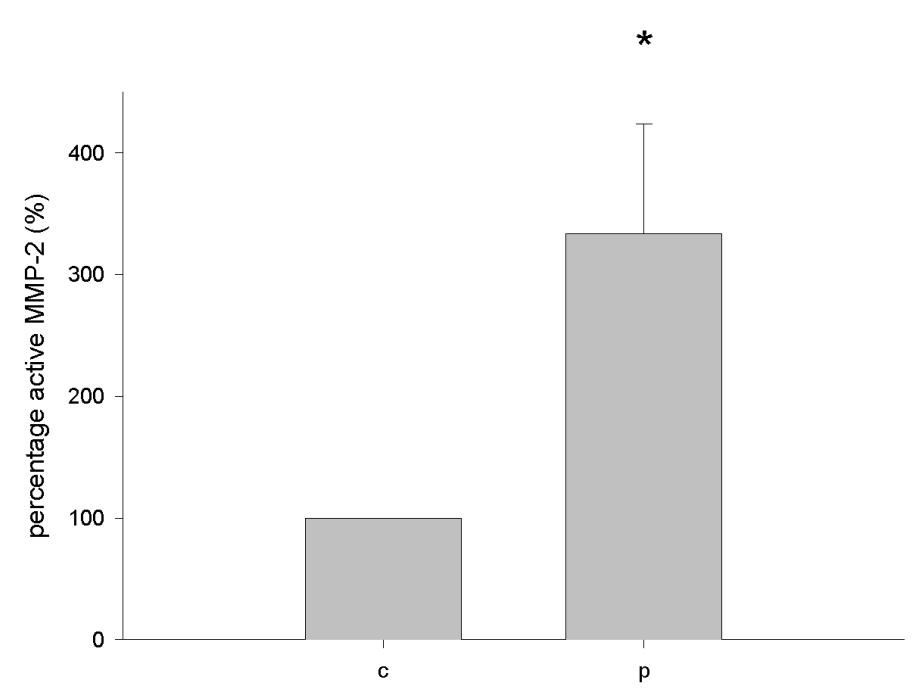

Fig. 5. Expression of pro MMP-2 (72 kDa) and active MMP-2 (64 kDa) and its level in intact mesenteric arteries of pregnant and controls considering activity in the control group as $100 \%(\mathrm{C}) ;{ }^{*} \mathrm{p}<0.05$. 


\section{CHAPTER 4}

\section{DISCUSSION}

The results of this study are consistent with a higher responsiveness to exogenous CGRP of mesenteric arteries in 10-day pregnant rats relative to nonpregnant rats. A possible explanation for this effect is a higher availability of circulating CGRP to the vascular smooth muscle cells. In rat pregnancy peripheral levels of CGRP are higher than in the nonpregnant state [11]. However, it is not clear whether the latter results from accelerated synthesis/excretion or reduced metabolization of CGRP. Recently, we have demonstrated that mesenteric arteries of both pregnant and nonpregnant rats have a dense network of CGRPcontaining sensory-motor nerves with comparable CGRP content [9]. There is some indirect evidence for an elevated release of CGRP from perivascular sensory-motor nerves in nearterm rat pregnancy [16]. In this study and our recent report [9] we demonstrated a higher arterial responsiveness to CGRP after incubation with capsaicin in pregnancy as compared to the nonpregnant state. Although this observation opposes the possibility of higher mesenteric artery responsiveness to CGRP in pregnancy due to a higher release of endogenous CGRP, it does not exclude the possibility of increased CGRP availability for its receptors in conjunction with a slower metabolic clearance.

MMP-2 is one of the key enzymes in trophoblast invasion and placentation, with increased expression in trophoblast cells in the first trimester [17,18]. In rat uterine arteries MMP-2 activity is enhanced particularly in late pregnancy [19], on the other hand progesterone is known to down-regulate MMP-2 [20]. MMP-2 is also a modulator of vascular function by its capacity to cleave CGRP, which will promote vasoconstriction [12]. In this study, inhibition of MMP-2 by doxycycline did not change the response to exogenously applied CGRP in mesenteric arteries of pregnant and nonpregnant animals. Not only was the effect of doxycycline on the vascular reactivity to CGRP in pregnancy, negligible, we also demonstrated a markedly elevated MMP-2 activity in the mesenteric artery already in early pregnancy as compared to the nonpregnant state. Although MMP-2 is able to promote vasoconstriction in mesenteric arteries of rats, the specific cleavage responsible for this effect only takes place after hours and this effect is mainly demonstrated after incubation with exogenous MMP-2 [12]. Even the high endogenous MMP-2 level in pregnancy, apparently does not change the short-term effect or metabolic clearance of circulating CGRP. Instead, pregnancy is associated with higher circulating levels of CGRP [11]. One can only speculate on the effect of MMP-2 on the CGRP level in pregnancy. However, only strong inhibition of MMP-2 activity in pregnancy could be responsible for a higher release of CGRP. The existence of such mechanism in pregnancy is unknown and from a physiological point of 
view unlikely. Our data taken together do not support a role for MMP-2 in the pregnancydependent rise in arterial responsiveness to CGRP

The vasodilator effect of CGRP is achieved by mechanisms that are both endotheliumdependent and independent $[8,21]$. However, the involvement of nitric oxide in the changes in CGRP reactivity in pregnancy seems negligible $[22,23]$. The other mechanisms by which CGRP modulates vascular tone involve the activation of $\mathrm{K}^{+}$channels and the stimulation of adenylate cyclase, resulting in an increase of cyclic AMP in arterial smooth muscle cells [21]. Both these mechanisms play a role in the vasodilating response to CGRP in late pregnancy [24]. A third mechanism, the accumulation of cGMP was also demonstrated in pregnancy [24]. However, there is convincing evidence that the latter is an endothelium-dependent effect mediated by increased synthesis of NO [25] and therefore seems not to be responsible for the changes in pregnancy.

We studied the relaxing responses to CGRP in the presence of a high concentration $\mathrm{K}^{+}$. Because of the almost identical response to $\mathrm{K}^{+}$in both the pregnant - and nonpregnant states, it is highly unlikely that the difference in vasodilator response to CGRP between the pregnant and nonpregnant states can be explained by a difference in activated outward potassium channel current.

The other signal transduction mechanisms trigger the accumulation of cyclic AMP by stimulation of adenylate cyclase by G-protein coupled CGRP receptors. Our results clearly indicate that the direct activation of adenylyl cyclase by forskolin or stimulation of other Gprotein coupled receptors, as the adrenergic receptors does not alter the vasodilator response in pregnancy relative to the nonpregnant state. Therefore, we conclude that the difference in vasodilator response between pregnancy and nonpregnancy is the result of a difference at the level of the CGRP receptors rather than a difference downstream the signal transduction pathway.

CGRP receptors are characterized by a complex structure with still obscure regulation during pregnancy. Based on recent observations CGRP receptors can be subdivided into CGRP-A and CGRP-B receptors [26]. CGRP-A receptors consist of a seven transmembrane G-coupled protein, a so called calcitonin receptor-like receptor (CRLR). When CRLR binds to the accessory protein, receptor activity modifying protein $\left(\mathrm{RAMP}_{1}\right)$ its biological behaviour resembles that of a CGRP-A receptor [27,28]. In mesenteric arteries of pregnant rats mRNA levels of CRLR only increase after day 18 [13], whereas those of RAMP ${ }_{1}$ have been reported to increase more gradually from early pregnancy onward [13]. The latter would be consistent with our data, which suggest that CGRP binding sites have not increased appreciably by day 10 of pregnancy. Whether the RAMPs are involved in the increased arterial responsiveness to CGRP in pregnancy, is still obscure. Another factor that is still unsettled is the role of CGRPreceptor component (RCP). Unlike RAMP, which acts more as a chaperone in the CGRP- 


\section{CHAPTER 4}

receptor complex, RCP allows direct coupling to the intracellular signaling pathway $[29,30]$. It is unknown whether the level or function of RCP in pregnancy is changed. However, with unchanged CGRP receptor density or a postreceptor signaling pathway, it is possible that changes in receptor coupling modulated by changes in RCP or RAMP are responsible for the increased relaxing responses to CGRP in pregnancy.

In summary, pregnancy induces a rise in the mesenteric artery responsiveness to CGRP, which appears unrelated to a higher MMP-2 activity, CGRP-receptor density or changes in the intracellular signaling pathway. Whether the pregnancy-specific rise in vasodilator activity is a consequence of increased coupling secondary to changes in RCP or RAMP requires further study. 


\section{MECHANISMS OF VASODILATOR RESPONSES TO CGRP IN PREGNANCY}

\section{REFERENCES}

1. Slangen BFM, Out ICM, Verkeste CM, Peeters LLH: Hemodynamic changes in early pregnancy in chronically instrumented conscious rats. Am J Physiol 1996;270:H1779-H1784.

2. Van Eijndhoven HWF, Slangen BFM, van der Heijden OWH, Aardenburg R, Spaanderman MEA, Peeters LLH: Hemodynamic changes in in pseudopregnancy in chronically instrumented, conscious rats are preserved after hysterectomy. Pflugers Arch 2002;443:427-431.

3. Duvekot JJ, Cheriex EC, Pieters FAA, Menheere PPCA, Peeters LLH: Early pregnancy changes in hemodynamics and volume homeostasis are consecutive adjustments triggered by a primary fall in systemic vascular tone. Am J Obstet Gynecol 1993;169:1382-1392.

4. Chapman AB, Abraham WT, Zamudio S, Coffin C, Merouani A, Young D, Johnson A, Osorio F, Goldberg C, Moore LG, Dahms T, Schrier RW: Temporal relationships between hormonal and hemodynamic changes in early human pregnancy. Kidney Int 1998;54:2056-2063.

5. Spaanderman MEA, willekes C, Hoeks APG, Ekhart THA, Peeters LLH: The effect of pregnancy on the compliance of large arteries and veins in normal parous controls and formerly preeclamptics. Am J Obstet Gynecol 2000;183:1278-1286.

6. Gangula PRR, Zhao H, Supowit SC, Wimalawansa S, Dipette D, Yallampalli C: Pregnancy and steroid hormones enhance the vasodilatation responses to CGRP in rats. Am J Physiol 1999;276:H284-H288.

7. Grewal M, Cuevas J, Chaudhuri G, Nathan L: Effects of calcitonin gene-related peptide on vascular resistance in rats: Role of sex steroids. Am J Physiol 1999;276:H2063-2068.

8. Brain SD, Grant AD: Vascular actions of calcitonin gene-related peptide and adrenomedullin. Physiol Rev 2004;84:903-934.

9. Van Eijndhoven HWF, van der Heijden OWH, Fazzi GE, Aardenburg R, Spaanderman MEA, Peeters LLH, De Mey JGR: Vasodilator reactivity to calcitonin gene-related peptide is increased in mesenteric arteries of rats during early pregnancy. J Vasc Res 2003;40:344-350.

10. Stevenson JC, MacDonald DWR, Warren RC: Increased concentration of calcitonin gene-related peptide during normal human pregnancy. Br Med J 1986;293:1329-1330.

11. Gangula PRR, Wimalawansa SJ, Yallampalli C: Pregnancy and sex steroids enhance circulating Calcitonin Gene-Related Peptide concentrations in rats. Hum Reprod 2000;15:949-953.

12. Fernandez-Patron C, Stewart KG, Zhang Y, Koivunen E, Radomski MW, Davidge ST: Vascular Matrix Metalloproteinase-2-dependent cleavage of calcitonin gene-related peptide promotes vasoconstriction. Circ Res 2000;87:670-676.

13. Yallampalli C, Kondapaka SB, Lanlua P, Wimalawansa SJ, Gangula PRR: Female sex steroid hormones and pregnancy regulate receptors for calcitonin gene-related peptide in rat mesenteric arteries, but not in aorta. Biol Reprod 2004;70:1055-1062.

14. Szallassi A, Blumberg PM: Vanilloid (capsaicin) receptors and mechanisms. Pharmacol Rev 1999;51:159-211.

15. Stassen FR, Willemsen MJ, Janssen GM, DeMey JGR: Alpha 1-adrenoreceptor subtypes in rat aorta and mesenteric small arteries are preserved during left ventricular dysfunction post-myocardial infarction. Cardiovasc Res 1997;33:706-713.

16. Lanlua P, Bukoski RD, Wimalawansa SJ, Yallampalli C: effects of pregnancy and female steroid hormones on Calcitonin Gene-Related Peptide content of mesenteric artery in rats. Biol Reprod 2002;67:1430-1434.

17. Xu P, Wang YL, Zhu SJ, Luo SY, Piao YS, Zhuang LZ: Expression of matrix metalloproteinase-2, -9 and -14 , tissue inhibitors of metalloproteinase-1, and matrix proteins in human placenta during the first trimester. Biol Reprod 2000;62:988-994.

18. Staun-Ram E, Goldman S, Gabarin D, Shalev E: Expression and importance of matrix metalloproteinase 2 and 9 (MMP-2 and -9) in human trophoblast invasion. Reprod Biol Endocrinol 2004;2:59. 


\section{CHAPTER 4}

19. Kelly BA, Bond BC, Poston L: Gestational profile of matrix metalloproteinases in rat uterine artery. Mol Hum Reprod 2003;187:1377-1383.

20. Huang HF, Hang LH, Tan Y, Sheng JZ: Matrix metalloproteinase 2 is associated with changes in steroid hormones in the sera and peritoneal fluid of patients with endometriosis. Fertil Steril 2004;81:12351239.

21. Bell D, McDermott BJ: Calcitonin Gene-Related Peptide in the cardiovascular system: Characterization of receptor populations and their (patho)physiological significance. Pharmacol Rev 1996;48:252-288.

22. Ahluwia A, Vallance P: Interaction between sympathetic and sensory nerves in rat small arteries: Involvement of nitric oxide. Am J Physiol 1996;271:H969-H976.

23. Gangula PRR, Supowit SC, Wimalawansa SJ, Zhao H, Hallman DM, DiPette DJ, Yallampalli C: Calcitonin Gene-Related Peptide is a depressor in $\mathrm{N}^{\mathrm{G}}$-nitro-L-arginine methyl ester-induced hypertension during pregnancy. Hypertension 1997;29:248-253.

24. Gangula PR, Lanlua P, Bukoski RD, Wimalawansa SJ, Yallampalli C: Mesenteric arterial relaxation to calcitonin gene-related peptide is increased during pregnancy and by sex steroid hormones. Biol Reprod 2004;71:1739-1745.

25. Gray DW, Marshall: A pharmacological profile of the endothelium-derived relaxant factor released by calcitonin gene-related peptide in rat aorta. Ann NY Acad Sci 1992;657:517-518.

26. Chaunan M, Thota CS, Kondapaka S, Wimalawansa SJ, Yallampalli C: Evidence for the existence of a new receptor for CGRP, which is not CRLR. Peptides 2003;24:65-71.

27. McLatchie LM, Fraser NJ, Main MJ, Wise A, Brown J, Thomson N, Solari R, Lee MG, Foord SM RAMP's regulate the transport and ligand specificity of the calcitonin-receptor-like receptor. Nature 1998;393:333-339.

28. Thota C, Gangula PRR, Dong YL, Yallampalli C: Changes in the expression of Calcitonin ReceptorLike Receptor, Receptor Activity-Modifying Protein (RAMP) 1, RAMP2, and RAMP3 in rat uterus during pregnancy, labor and by steroid hormone treatments. Biol Reprod 2003;69:1432-1437.

29. Evans BN, Rosenblatt MI, Mnayer LO, Oliver KR, Dickerson IM: CGRP-RCP, a novel protein required for signal transduction at calcitonin gene-related peptide and adrenomedullin receptors. J Biol Chem 2000;275:31438-31443.

30. Prado MA, Evans-Bain B, Dickerson IM: Receptor component protein (RCP): a member of a multiprotein complex required for G-protein-coupled signal transduction. Biochem Soc Trans 2002;30:460464. 



\section{CHAPTER 5}

\section{PREGNANCY ENHANCES THE PREJUNCTIONAL VASODILATOR RESPONSE TO ADRENOMEDULLIN IN SELECTIVE REGIONS OF THE ARTERIAL BED OF WISTAR RATS}

Hugo W.F. van Eijndhoven, Robert Aardenburg, Marc E.A. Spaanderman, Jo G.R. De Mey, Louis L.H. Peeters 



\section{CHAPTER 5}

\section{ABSTRACT}

The objective of this study was to determine whether the vascular response to adrenomedullin is modulated by pregnancy. To this end, we studied the effect of adrenomedullin on different contractile responses of mesenteric, uterine, renal and saphenous arteries of 10day pregnant and nonpregnant rats in myographs. Adrenomedullin inhibited contractile responses induced by electrical field stimulation (EFS) only in the mesenteric and uterine arteries. This effect was more pronounced during pregnancy than in the nonpregnant state. Adrenomedullin did not modify concentration response curves to noradrenaline. The reduction of contractile responses to $40-\mathrm{mmol} / 1 \mathrm{~K}^{+}$by adrenomedullin was similar in arteries of pregnant and nonpregnant rats. However, after incubation with capsaicin this effect was significantly increased in mesenteric arteries of the pregnant group.

We conclude that pregnancy is associated with a rise in the prejunctional inhibitory effect of adrenomedullin in some regions of the arterial system.

\section{INTRODUCTION}

Adrenomedullin is a vasorelaxing hypotensive peptide, initially isolated from human pheochromocytoma [1], and has also been retrieved from other human tissues such as the adrenal glands, heart and kidneys. Detectable peripheral levels of adrenomedullin, mainly produced by vascular smooth muscle cells, support a role as a vasodilator hormone [2]. Circulating plasma adrenomedullin levels are elevated in a wide range of disease states, including cardiovascular, renal and endocrine disorders [3].

The normal hemodynamic adaptation to pregnancy includes a rise in cardiac output and a fall in total peripheral resistance [4,5]. In the rat these changes can already be detected at day 10 of pregnancy [6]. This state of a high flow-low resistance circulation is accompanied by a decreased arterial responsiveness to vasoconstrictors and sympathetic nerves [7]. Whether adrenomedullin is involved in these changes is obscure. During pregnancy circulating levels of adrenomedullin are higher than in the nonpregnant state [8-11], partly due to placental production of the peptide [12]. Higher plasma levels of adrenomedullin in pregnancy relative to the nonpregnant state have also been found in the rat [13]. This suggests that the rat may be a suitable model to study the possible role of adrenomedullin in the vasodilator response to pregnancy.

The present study was designed to determine in the rat, the effect of pregnancy on arterial responses to exogenous adrenomedullin. To this end, we assessed the responsiveness to 
adrenomedullin in isolated mesenteric, renal, uterine and saphenous arteries obtained from nonpregnant and from 10-day pregnant Wistar rats. Because of the close relationship of adrenomedullin to calcitonin gene-related peptide [3] and the use of a common receptor, we also studied its effect on sensory-motor nerves.

\section{MATERIAL AND METHODS}

\section{Animals and arteries}

We performed our experiments in isolated arteries of 3-4-month-old virgin and pregnant rats (approx. $250 \mathrm{~g}$, Iffa Credo, Someren, The Netherlands). After arrival from the supplier, the animals were housed in individual cages and the ones allocated to the pregnant group $(n=8)$ were allowed to mate. We defined the first day of pregnancy as the day of sperm plug retrieval. On the tenth day of pregnancy, the animals were sacrificed by cervical dislocation and exsanguination. The virgin rats (controls, $n=5$ ) were sacrificed at a corresponding day after arrival in our laboratory facility. We removed by careful dissection under the dissection microscope, a renal, uterine and saphenous artery and a first order branch of the superior mesenteric artery. These choices were inspired by the different contributions of different vascular beds to the pregnancy-related hemodynamic changes [14] and regional differences in autonomic control of the vessel wall [15]. That is to say, the mesenteric artery represents the systemic circulation the uterus is the target organ of the changed circulation, while the kidney plays an important role in hemodynamic regulation. The saphenous artery serves as a control vessel. Segments of these arteries (1.5-2 mm long) were mounted on two stainless wires (40 $\mu \mathrm{m}$ ) in an isometric myograph (JP Trading, Aarhus, Denmark) connected between a force transducer (Kistler Morse DSC6, Seattle, WA, USA) and a displacement device for the recording of isometric tension development. The organ chamber $(10 \mathrm{ml})$ of the myograph was filled with Krebs-Ringer bicarbonate solution (KRB, composition in $\mathrm{mM}$ : $\mathrm{NaCl} 118.3, \mathrm{KCl}$ 4.7, $\mathrm{CaCl}_{2} 2.5, \mathrm{MgSO}_{4} \cdot \mathrm{H}_{2} \mathrm{O} 1.2, \mathrm{KH}_{2} \mathrm{PO}_{4} 1.2, \mathrm{NaHCO}_{3} 25.0$ and glucose 5.5), maintained at $37^{\circ} \mathrm{C}$ and aerated with $95 \% \mathrm{O}_{2} / 5 \% \mathrm{CO}_{2}$. Each arterial segment was stretched to its own optimal lumen diameter, which was determined by a stepwise increase of the lumen diameter in $50 \mu \mathrm{m}$ (mesenteric, uterine and saphenous artery) or $100 \mu \mathrm{m}$ (renal artery) increments and induction of contractile responses to depolarization with $40 \mathrm{mmol} / \mathrm{l}$ potassium solution $(\mathrm{K}$ $\mathrm{KRB}, \mathrm{KRB}$ in which part of the $\mathrm{NaCl}$ was replaced by an equimolar amount of $\mathrm{KCl}$ ). We performed all our experiments at the optimal lumen diameter of each artery. The Ethics Committee for the Use of Experimental Animals of the University of Maastricht approved the experimental procedures. 


\section{CHAPTER 5}

\section{Experimental protocol}

We induced contractile responses of the mounted arteries by stimulating perivascular sympathetic nerves using EFS $(90 \mathrm{~V}, 4-32 \mathrm{~Hz})$ at basal tone. For this purpose we used two platinum electrodes along the axial direction of the arterial segment. This stimulation leads to contraction of vessels only with and not without sympathetic nerves [16]. In rat mesenteric arteries these contractile responses are abolished by $1 \mu \mathrm{mol} / 1$ tetrodotoxin, $1 \mu \mathrm{mol} / \mathrm{l}$ guanethidine and $300 \mu \mathrm{mol} / 1$ 6-hydroxydopamine and are reduced for more than $95 \%$ by 1 $\mu \mathrm{mol} / \mathrm{l}$ prazosin, indicating sympathetic stimulation [16]. The arteries were exposed to adrenomedullin (Peninsula laboratories, Belmont, CA, USA) by administering the compound to the organ chamber of the myograph for a period of $10 \mathrm{~min}$. Afterwards, we repeated the vasoconstrictor response to EFS followed by a recovery period, to allow the artery to return to baseline and to rinse the adrenomedullin. By a stepwise increase in the concentration of adrenomedullin $(0.1$ to $100 \mathrm{nmol} / \mathrm{l})$ in between a series of EFS as specified above, we were able to quantify the adrenomedullin-dependent inhibition of the sympathetic vasoconstriction.

Subsequently, the same experiment was run again, but instead of EFS, concentration response curves for exogenous noradrenaline $(10 \mathrm{nmol} / \mathrm{l}-10 \mu \mathrm{mol} / \mathrm{l})$ were conducted and thus used to define the postjunctional vasodilator effect of adrenomedullin. Concentrations of adrenomedullin and the design of the experiment were identical to the protocol as described above.

Finally, a third type of contractile response was induced by adding $40 \mathrm{mmol} / 1 \mathrm{~K}^{+}$to the organ chamber. During a steady-state contraction the vasodilator response to adrenomedullin ( 0.1 to $100 \mathrm{nmol} / \mathrm{l})$ was tested. As we have demonstrated recently, $\mathrm{K}^{+}$-induced contractile responses are modulated by endogenous calcitonin gene-related peptide [17], a strong vasodilator peptide, released by perivascular sensory-motor nerves. In order to investigate the role of these sensory-motor nerves we repeated this last experiment after incubation of the arteries during 20 min with $1 \mu \mathrm{M}$ capsaicin, a vanilloid pungent that irreversibly desensitizes the sensory-motor nerves [18], resulting in an augmentation of the $\mathrm{K}^{+}$-induced contraction.

\section{Data analysis}

We expressed the magnitude of the arterial response as wall tension (isometric force divided by twice the segment length). We calculated the vasodilator response to adrenomedullin as a percentage of the initial response to EFS, as percentage of the initial response to noradrenaline or as percentage of the steady-state contraction induced by 40 $\mathrm{mmol} / \mathrm{l} \mathrm{K}{ }^{+}$. The latter response curves were further analyzed by a square curve fit to calculate $\mathrm{pD}_{2}$ and $\mathrm{E}_{\max }$. Data are shown as means \pm SEM. Differences in vascular response between pregnant and nonpregnant animals were evaluated by ANOVA with repeated measurements. A p-value below 0.05 was considered statistically significant. 


\section{RESULTS}

Mechanical properties and effects of early pregnancy vasoconstrictor responses to EFS, noradrenaline and $\boldsymbol{K}^{+}$

Optimal lumen diameter did not differ between pregnant and nonpregnant rats for mesenteric $(287 \pm 17$ and $294 \pm 19 \mu \mathrm{m})$, uterine $(276 \pm 6$ and $280 \pm 15 \mu \mathrm{m})$ renal $(741 \pm 21$ and $767 \pm 35 \mu \mathrm{m})$ and saphenous arteries $(355 \pm 15$ and $367 \pm 9 \mu \mathrm{m})$. EFS and noradrenaline induced a frequency- and concentration-dependent vasoconstrictor response in all four types of arteries. Pregnancy attenuated the contractile response to EFS of mesenteric arteries (figure 1A) and, only for the lower EFS frequencies, of uterine arteries (figure 1B). These differences were not observed in the renal and saphenous arteries. Responses to noradrenaline and $\mathrm{K}^{+}$ were comparable between both groups for all types of arteries.
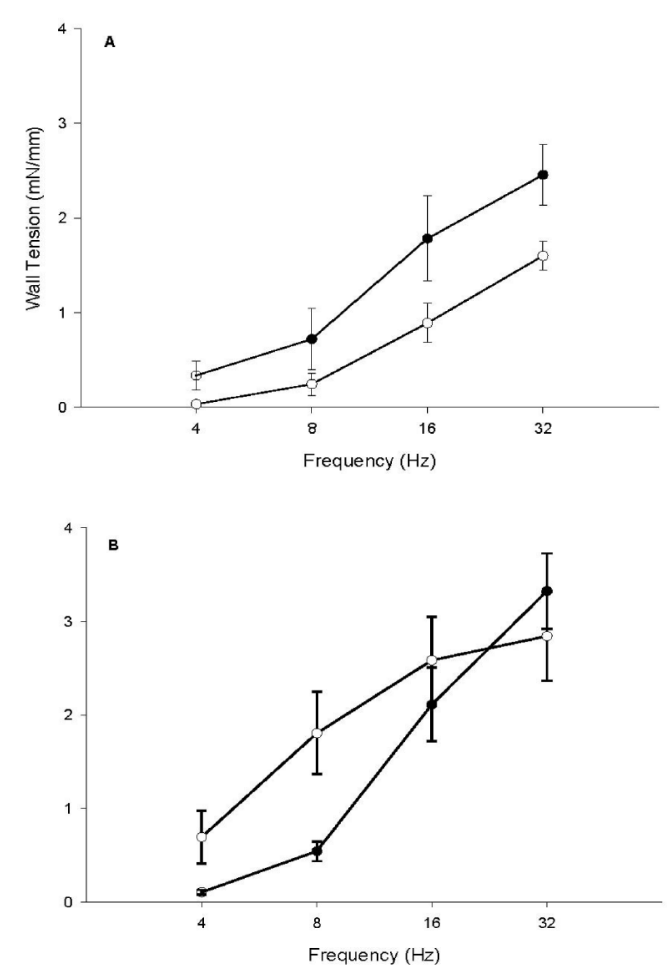

Fig. 1. Vasoconstrictor responses expressed as wall tension of (A) mesenteric and (B) uterine arteries of control (closed circles; $n=5)$ and pregnant (open circles; $n=8)$ rats to electrical field stimulation $(4-32 \mathrm{~Hz}$, $90 \mathrm{~V})$ at basal tone. 


\section{CHAPTER 5}

\section{Effect of adrenomedullin on vasoconstrictor responses}

Exogenous adrenomedullin reduced the sympathetic contractile responses of EFS in mesenteric and uterine arteries of pregnant and nonpregnant rats (figure $2 a$ and $b$ ). This effect was dose-dependent, but for all concentrations stronger in pregnancy than in the nonpregnant state (tables 1 and 2). After rinsing all of the compound, EFS elicited a comparable contraction as the initial one excluding a time-dependent effect. Neither in the renal, nor in the saphenous arteries did adrenomedullin elicit a significant reduction of the sympathetic constrictor responses in either the pregnant or nonpregnant group (figure $2 \mathrm{c}$ and $\mathrm{d}$ ).

$2 \mathrm{a}$

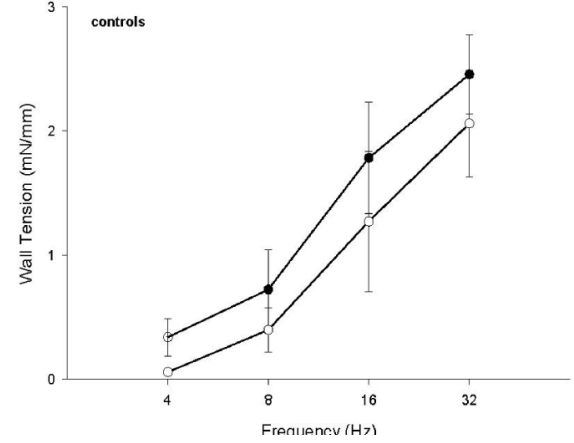

$2 b$

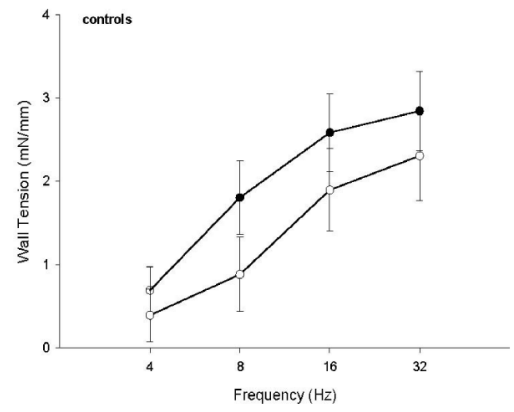

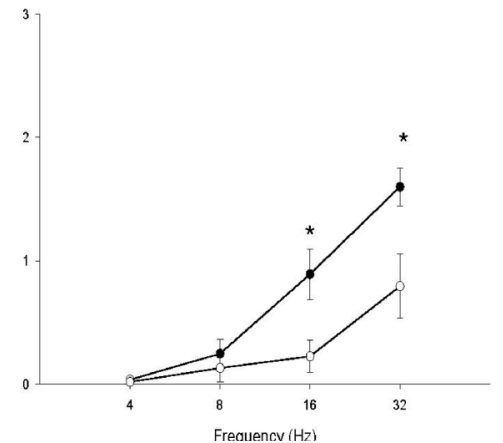

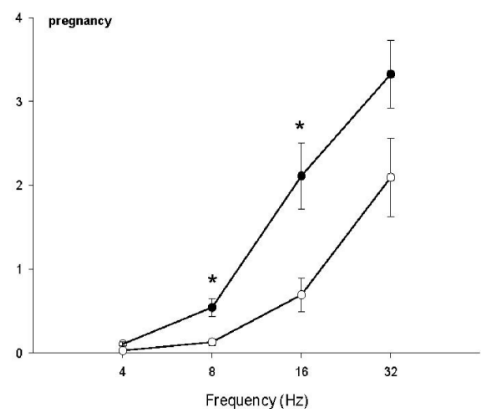

Fig. 2 ( $\mathrm{a}$ and b). Response curves to EFS $(4-32 \mathrm{~Hz}, 90 \mathrm{~V}$ ) in the absence (closed circles) and presence (open circles) of $100 \mathrm{nmol} / \mathrm{l}$ adrenomedullin in control and pregnant rats in (a) mesenteric and (b) uterine arteries. ${ }^{*} p<0.05$ indicates a significant reduction of responses in the presence of adrenomedullin. 
$2 \mathrm{c}$

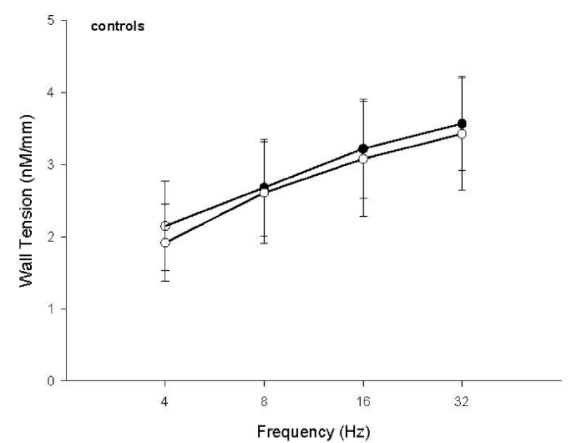

$2 d$

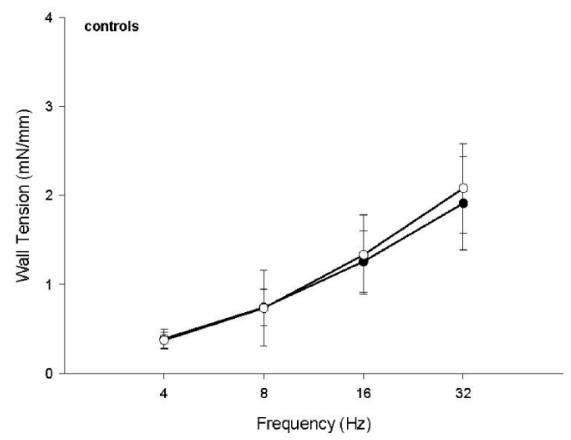

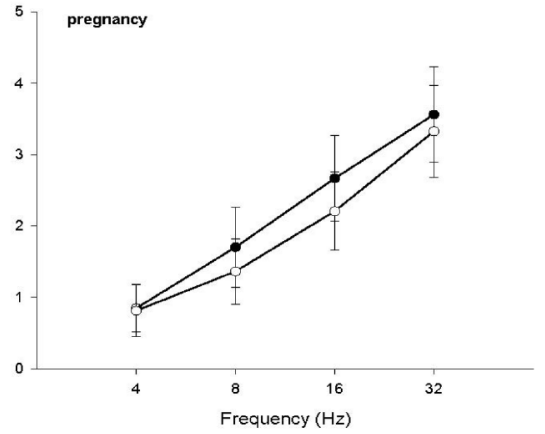

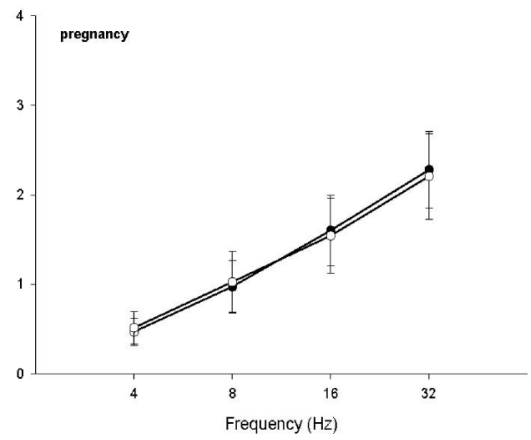

Fig 2 (c and d). Response curves to EFS (4-32 Hz, $90 \mathrm{~V}$ ) in the absence (closed circles) and presence (open circles) of $100 \mathrm{nmol} / \mathrm{l}$ adrenomedullin in control and pregnant rats in (c) renal and (d) saphenous arteries. ${ }^{*} \mathrm{p}<0.05$ indicates a significant reduction of responses in the presence of adrenomedullin.

Table 1. Percentage of baseline contractile response of mesenteric arteries to EFS (4-32 Hz, $90 \mathrm{~V})$ in the presence of 1 to $100 \mathrm{nmol} / \mathrm{l}$ adrenomedullin. Data are expressed as mean $\pm \mathrm{SEM}$.

\begin{tabular}{|c|c|c|c|c|c|c|}
\hline \multirow[t]{2}{*}{ Frequency } & \multicolumn{2}{|c|}{$\begin{array}{c}1 \mathrm{nmol} / \mathrm{l} \\
\text { adrenomedullin }\end{array}$} & \multicolumn{2}{|c|}{$\begin{array}{c}10 \mathrm{nmol} / 1 \\
\text { adrenomedullin }\end{array}$} & \multicolumn{2}{|c|}{$\begin{array}{c}100 \mathrm{nmol} / \mathrm{l} \\
\text { adrenomedullin }\end{array}$} \\
\hline & control & pregnancy & control & pregnancy & control & pregnancy \\
\hline 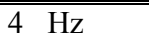 & $92 \pm 19$ & $93 \pm 35$ & 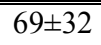 & $29 \pm 24$ & $60 \pm 23$ & $23 \pm 22$ \\
\hline $8 \mathrm{~Hz}$ & $98 \pm 10$ & $89 \pm 19$ & $76 \pm 12$ & $45 \pm 19$ & $53 \pm 12$ & $32 \pm 13$ \\
\hline $16 \mathrm{~Hz}$ & $108 \pm 7$ & $79 \pm 8^{*}$ & $83 \pm 10$ & $38 \pm 12^{*}$ & $96 \pm 24$ & $29 \pm 10^{*}$ \\
\hline $32 \mathrm{~Hz}$ & $109 \pm 7$ & $92 \pm 8$ & $96 \pm 13$ & $62 \pm 16$ & $92 \pm 20$ & $52 \pm 14$ \\
\hline
\end{tabular}

${ }^{*} \mathrm{p}<0.05$ indicates a significant difference between the control and pregnant group. 


\section{CHAPTER 5}

Table 2. Percentage of baseline contractile response of uterine arteries to EFS (4-32 Hz, $90 \mathrm{~V})$ in the presence of 1 to $100 \mathrm{nmol} / 1$ adrenomedullin. Data are expressed as mean $\pm \mathrm{SEM}$.

\begin{tabular}{|c|c|c|c|c|c|c|}
\hline \multirow[t]{2}{*}{ Frequency } & \multicolumn{2}{|c|}{$\begin{array}{c}1 \mathrm{nmol} / \mathrm{l} \\
\text { adrenomedullin }\end{array}$} & \multicolumn{2}{|c|}{$\begin{array}{c}10 \mathrm{nmol} / \mathrm{l} \\
\text { adrenomedullin }\end{array}$} & \multicolumn{2}{|c|}{$\begin{array}{c}100 \mathrm{nmol} / \mathrm{l} \\
\text { adrenomedullin }\end{array}$} \\
\hline & control & pregnancy & control & pregnancy & control & pregnancy \\
\hline $4 \quad \mathrm{~Hz}$ & $109 \pm 28$ & $68 \pm 21$ & $97 \pm 25$ & $23 \pm 7 *$ & $70 \pm 26$ & $19 \pm 10$ \\
\hline $8 \mathrm{~Hz}$ & $108 \pm 19$ & $79 \pm 14$ & $99 \pm 17$ & $37 \pm 8^{*}$ & $55 \pm 22$ & $23 \pm 6$ \\
\hline $16 \mathrm{~Hz}$ & $109 \pm 7$ & $80 \pm 9 *$ & $103 \pm 7$ & $55 \pm 14^{*}$ & $78 \pm 16$ & $37 \pm 12$ \\
\hline $32 \mathrm{~Hz}$ & $106 \pm 5$ & $103 \pm 7$ & $106 \pm 6$ & $85 \pm 9$ & $88 \pm 14$ & $71 \pm 14$ \\
\hline
\end{tabular}

Neither in the pregnant nor in the nonpregnant group did we observe a consistent effect of exogenous adrenomedullin on the concentration response curves to noradrenaline in any of the four types of arteries (figure 3).

$3 \mathrm{a}$

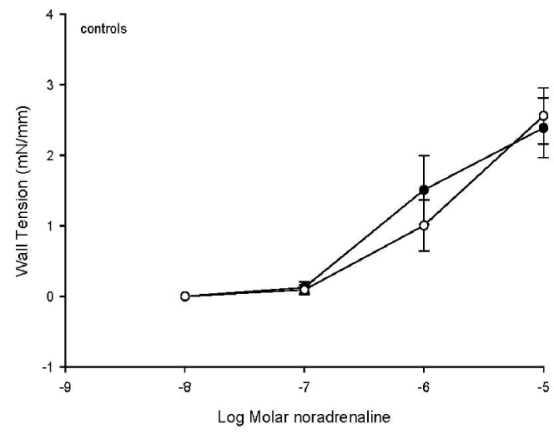

$3 b$

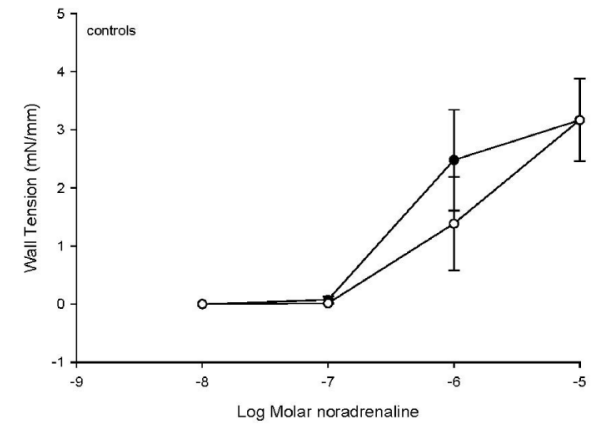

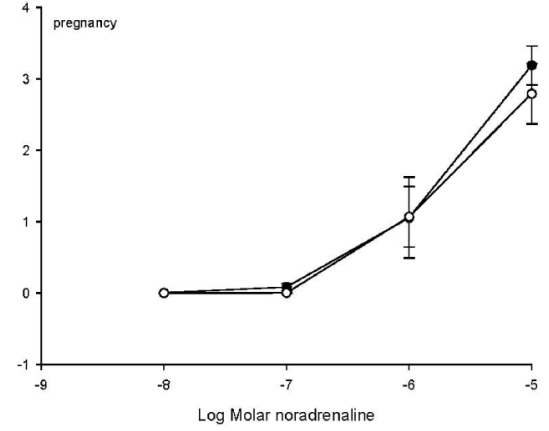

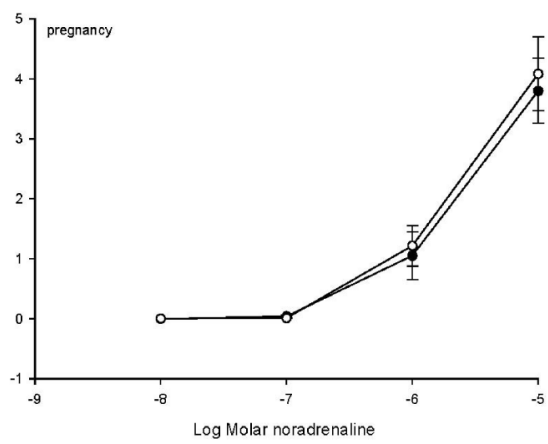

Fig. 3 (a and b). Response curves to noradrenaline $(10 \mathrm{nmol} / \mathrm{l}-10 \mu \mathrm{mol} / \mathrm{l})$ in the absence (closed circles) and presence (open circles) of $100 \mathrm{nmol} / \mathrm{l}$ adrenomedullin in control and pregnant rats in (a) mesenteric and (b) uterine arteries. 
$3 c$

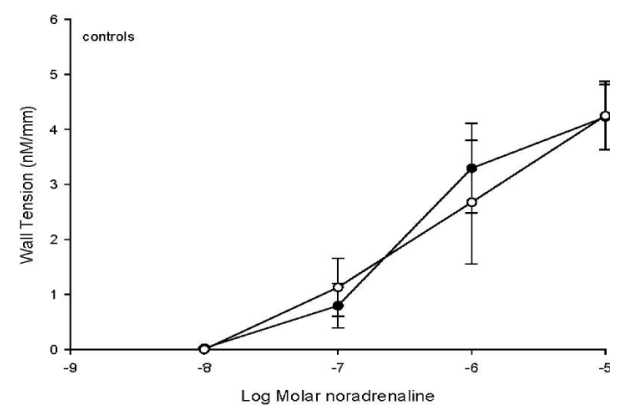

$3 d$

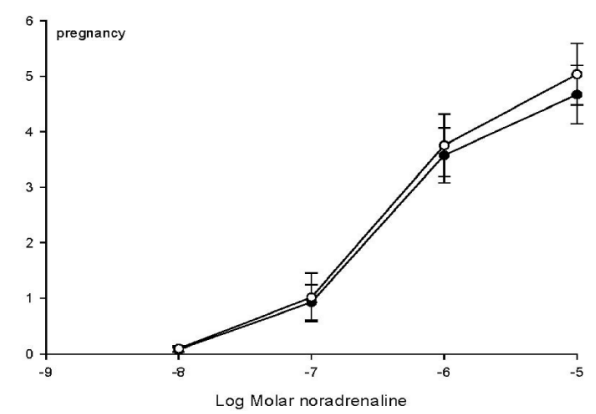

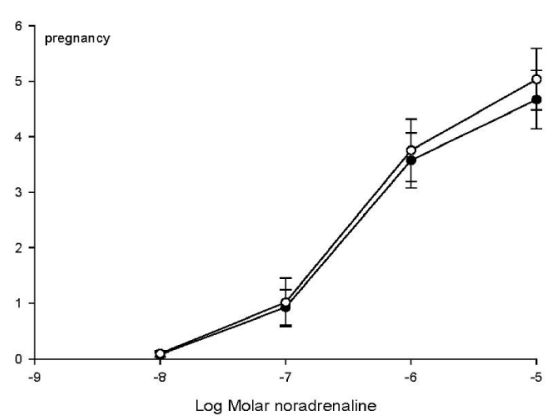

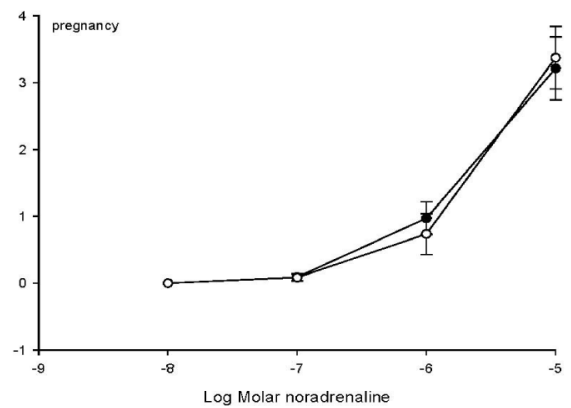

Fig. 3 (c and d). Response curves to noradrenaline $(10 \mathrm{nmol} / \mathrm{l}-10 \mu \mathrm{mol} / \mathrm{l})$ in the absence (closed circles) and presence (open circles) of $100 \mathrm{nmol} / \mathrm{l}$ adrenomedullin in control and pregnant rats in (c) renal and (d) saphenous arteries.

At a steady-state $\mathrm{K}^{+}$-induced contraction adrenomedullin elicited vasodilator responses in mesenteric and uterine arteries (figure 4A and C). Again we did not observe any response to adrenomedullin in the renal or saphenous arteries in either pregnant or nonpregnant rats (data not shown). The vasodilator responses observed in the mesenteric and uterine arteries did not differ significantly between the pregnant and nonpregnant state (figure 4A and C). However, after incubation with capsaicin the reduction of maximal constriction by adrenomedullin was significantly stronger in mesenteric arteries of pregnant rats $\left(\mathrm{pD}_{2} 10.12 \pm 0.12\right.$ versus $9.77 \pm 0.25, \mathrm{p}<0.05 ; \mathrm{E}_{\max } 29 \pm 5$ versus $66 \pm 5, \mathrm{p}<0.05$; figure $\left.4 \mathrm{~B}\right)$. 

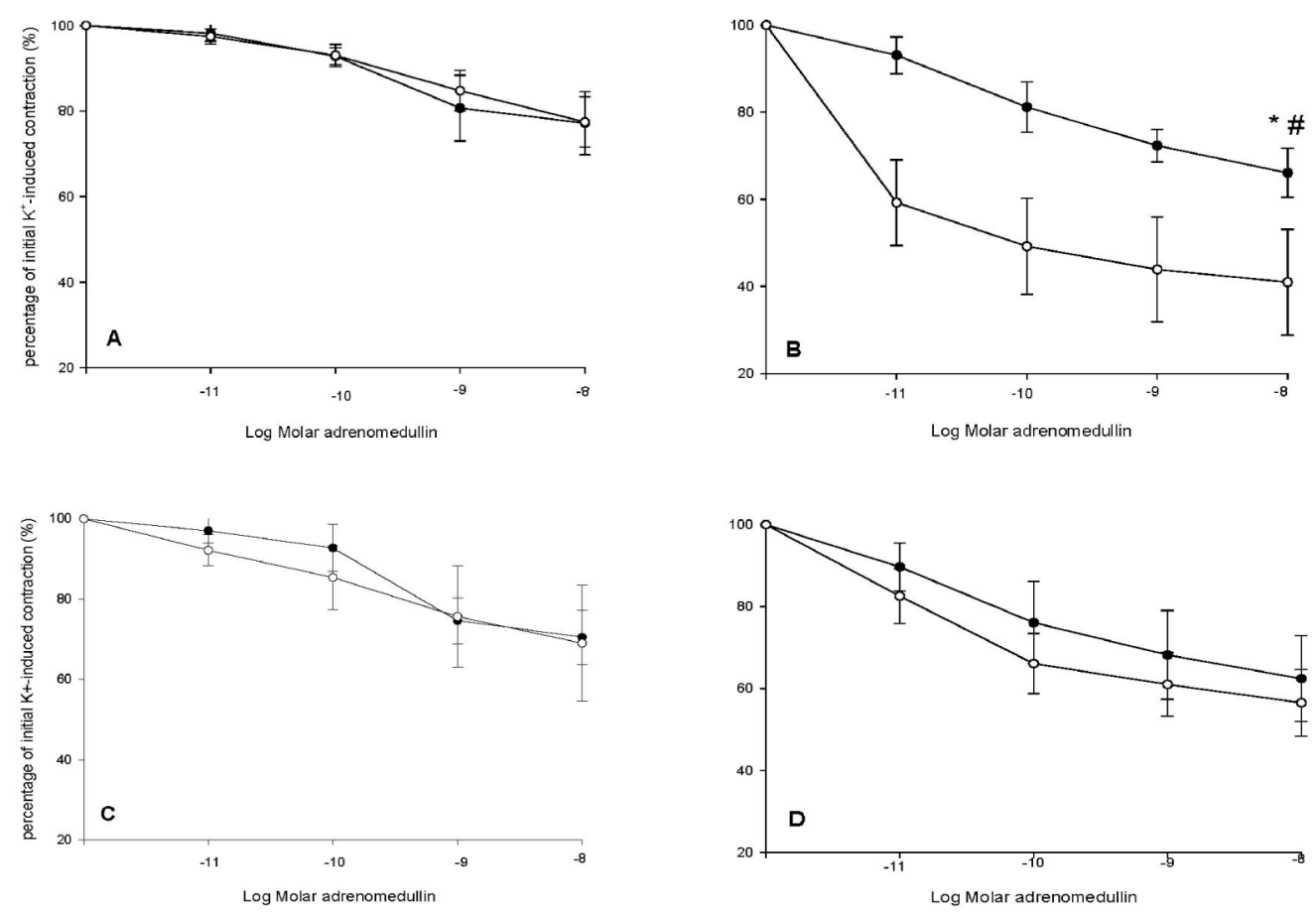

Fig. 4. Effect of various concentrations adrenomedullin $(0.1$ to $100 \mathrm{nmol} / \mathrm{l})$ on a $\mathrm{K}^{+}$-induced contraction of mesenteric arteries, of control (closed circles) and pregnant (open circles) before (A) and after (B) incubation with capsaicin and of uterine arteries before (C) and after (D) incubation with capsaicin. ${ }^{*} \mathrm{p}<0.05$ for $\mathrm{pD}_{2}$ and $\# \mathrm{p}<0.05$ for $\mathrm{E}_{\max }$.

\section{DISCUSSION}

The fall in vascular tone that develops in early pregnancy may be triggered either by reduced vascular responsiveness to vasoconstrictors, or by increased vascular responsiveness to vasodilators, or by a change in plasma levels of these agents. A combination of these effects is also possible. A well-known feature of normal pregnancy is the lower pressor responsiveness to vasoconstrictors such as angiotensin II, noradrenaline and vasopressin [7,19] and to selective sympathetic nerve stimulation [7]. We suppose the latter to be a prejunctional effect because in our hands there was no difference in response to noradrenaline between the groups. This effect may thus involve changes in the prejunctional control of transmitter release. Such mechanisms are less effective at a high level of sympathetic 
stimulation [20]. This could explain the fact that the significant lower uterine arterial responsiveness in pregnancy was only demonstrated for the lower frequencies of EFS. These data are in line with other findings [7] revealing also no significant difference at high frequencies between the pregnant and nonpregnant group.

The reported data on the responsiveness to vasodilators of non-uterine vessels in pregnancy is limited [7]. Therefore, it is still unclear, whether vasodilators contribute to the pregnancy-induced systemic vasorelaxation. In pregnancy, the circulating plasma level of adrenomedullin is higher than in the nonpregnant state $[8,11,21]$. In addition, the cytotrophoblast releases adrenomedullin already in the post-implantation period [22]. These observations suggest that this vasodilator could be involved in the early-pregnancy vasodilatation. For this reason, we used adrenomedullin to test the hypothesis that increased vascular responsiveness to vasodilators contributes to the systemic vasorelaxation in early pregnancy.

Our findings are in line with the previously reported rise in vascular sensitivity to adrenomedullin during pregnancy $[23,24]$. They document for the first time that this is already the case at mid-pregnancy and because of the selective effect of EFS it must involve increased sensitivity of sympathetic nerves to the inhibitory action of the peptide in some but not all vascular beds. In the mid-pregnant rat, adrenomedullin elicits a higher vascular response of the mesenteric and uterine arteries than seen in the nonpregnant rat during sympathetic stimulation. Especially in the uterine artery we were not able to demonstrate a different response to the highest frequency with or without adrenomedullin between the groups. As stated before this may be the result of prejunctional control of neurotransmitter release [20]. In contrast with the vasodilator responses in the mesenteric and uterine artery, and irrespective whether the rats were pregnant or not, we did not find a response to adrenomedullin in the renal and saphenous arteries. Possibly these differences are related to the fact that the latter are conduit arteries, and therefore differ in diameter and function. However, one should also keep in mind, that the conduit characteristics of the renal and hind limb arteries may change towards resistance vessels downstream the microcirculation. In that case, the experimental data obtained in the larger upstream portions of the arteries are not representative for the entire arterial bed of the tissues supplied. Furthermore, the study of isolated vessels in pregnancy excludes the normal influence of a unique and complex endocrine environment, which is likely to play an important role [25].

It is of interest that adrenomedullin lacked effects on noradrenaline-evoked contractions, while blunting electrical field stimulation-induced responses. In view of the sympathetic nature of the field stimulation-induced contractions [16] this discrepancy indicates a prejunctional inhibitory effect of adrenomedullin on the sympathetic neurotransmission. As we have demonstrated, this effect is stronger in pregnancy compared to the nonpregnant state.

In order to investigate whether adrenomedullin has a comparable effect on sensory- 


\section{CHAPTER 5}

motor nerves, its reactivity on $\mathrm{K}^{+}$-induced contractions was studied before and after incubation with capsaicin. As we have recently demonstrated [17] $\mathrm{K}^{+}$-induced contractions are modulated by calcitonin gene-related peptide released by perivascular sensory-motor nerves. Capsaicin selectively destroys these sensory-motor nerves [18] resulting in an augmentation of $\mathrm{K}^{+}$-induced contractions. Therefore, a modulating effect of adrenomedullin on sensory-motor nerve activity would have resulted in a rise of $\mathrm{K}^{+}$-induced contractions after incubation with capsaicin. However, we were unable to demonstrate such an effect. Instead, we found an increased response to adrenomedullin after incubation with capsaicin in mesenteric arteries of pregnant rats. Therefore, the effect of adrenomedullin during the $\mathrm{K}^{+}$induced contraction and its modulation by pregnancy suggests a postjunctional rather than a prejunctional effect. Together with adrenomedullin, calcitonin gene-related peptide is a member of the calcitonin gene-related peptide superfamily. Like adrenomedullin, calcitonin gene-related peptide is a potent vasodilator peptide, with an enhanced hypotensive effect in pregnancy $[26,27]$. Both peptides use the calcitonin-receptor-like receptor (CRLR), which can function as either a calcitonin gene-related peptide receptor or an adrenomedullin receptor, depending on the coupling to so called receptor-activity-modifying proteins (RAMPs). CRLR may either bind to RAMP ${ }_{1}$ to form the CGRP-A receptor, or to $\mathrm{RAMP}_{2}$ or $\mathrm{RAMP}_{3}$ to form the adrenomedullin receptor [28]. In mesenteric arteries of pregnant rats the mRNA level for CRLR is stable throughout pregnancy with a sudden and significant increase at day 18 of pregnancy, whereas the mRNA level of RAMP ${ }_{1}$ is already elevated at day 5 of pregnancy [29]. Therefore, one can speculate on the regulation of receptor systems and the role of RAMPs in pregnancy and the possibility that sex steroids modulate this regulation. In this perspective, the augmentation of the vascular response of mesenteric arteries to adrenomedullin by pregnancy together with capsaicin is interesting. That is to say, in this setting only the absence of endogenously released calcitonin gene-related peptide leads to an increased vasodilator response to adrenomedullin in pregnancy. This is in favor of an increasing availability of receptors to adrenomedullin. As early pregnancy is associated with a stable level of CRLR and increasing concentrations of RAMPs, it is likely that a change in coupling between the receptor and the different accessory proteins is responsible for this pregnancy-related change in vasodilator response. However, the exact contribution of receptor modulation by RAMPs to the vascular tone in early pregnancy requires further study.

In summary, our results demonstrate that pregnancy is associated with an increased vasodilator response to adrenomedullin. At least part of this effect is caused by prejunctional inhibition of sympathetic nerves. This change can already be detected in 10-day pregnant rats and could be confined to resistance arteries. The mechanism responsible for the increased vasodilator response and the role of adrenomedullin receptors, RAMPs and sex steroids merits to be elucidated. 


\section{REFERENCES}

1. Kitamura K, Kangawa K, Kawamoto M, Ichiki Y, Nakamura S, Matsuo H, Eto T: Adrenomedullin: a novel hypotensive peptide isolated from human pheochromocytoma. Biochem Biophys Res Commun 1993; 192:553-560.

2. Sugo S, Minamino N, Shoji H, Kangawa K, Matsuo H: Effects of vasoactive substances and cAMP related compounds on adrenomedullin production in cultured vascular smooth muscular cells. FEBS Lett 1995;369:311-314.

3. Hinson JP, Kapas S, Smith DM: Adrenomedullin, a multifunctional regulatory peptide. Endocr Rev 2000;21:138-167.

4. Chapman AB, Abraham WT, Zamudio S, Coffin C, Merouani A, Young D, Johnson A, Osorio F, Goldberg C, Moore LG, Dahms T, Schrier RW: Temporal relationships between hormonal and hemodynamic changes in early human pregnancy. Kidney Int 1998;54:2056-63.

5. Duvekot JJ, Cheriex EC, Pieters FAA, Menheere PPCA, Schouten HJA, Peeters LLH: Maternal volume homeostasis in early pregnancy in relation to fetal growth restriction. Obstet Gynecol 1995; 85:361-367.

6. Slangen BFM, Out ICM, Verkeste CM, Peeters LLH: Hemodynamic changes in early pregnancy in chronically instrumented conscious rats. Am J Physiol 1996;270:H1779-H1784.

7. Ralevic V, Burnstock G: Mesenteric arterial function in the rat in pregnancy: role of sympathetic and sensory-motor perivascular nerves, endothelium, smooth muscle, nitric oxide and prostaglandins. $\mathrm{Br} \mathrm{J}$ Pharmacol 1996;117:1463-1470.

8. Di Iorio R, Marinoni E, Letizia C, Villacio B, Alberini A, Cosmi E: Adrenomedullin production is increased in normal human pregnancy. Eur J Endocrinol 1999;140:201-206.

9. Hoshimoto $\mathrm{K}$, Hayashi $\mathrm{M}$, Ohkura $\mathrm{T}$ : Mature adrenomedullin concentrations in plasma during pregnancy. J Matern Fetal Neonatal Med 2002;11:126-129.

10. Jerat S, Morrish DW, Davidge ST, Kaufman S: Effect of adrenomedullin on placental arteries in normal and preeclamptic pregnancies. Hypertension 2001;7:227-231.

11. Kanenishi K, Kuwabara H, Ueno M, Sato C, Sakamoto H, Hata T: Change of adrenomedullin concentrations in plasma and amniotic fluid, and human placental adrenomedullin expression with advancing gestation. Placenta 2001;22:244-250.

12. Kobayashi K, Kubota T, Aso T, Hirata Y, Imai T, Marumo F: Immunoreactive adrenomedullin (AM) concentration in maternal plasma during human pregnancy and AM expression in placenta. Eur $\mathrm{J}$ Endocrinol 2000;142:683-687.

13. Jerat S, Kaufman S: Effects of pregnancy and steroid hormones on plasma adrenomedullin levels in the rat. Can J Physiol Pharmacol 1998;76:463-466.

14. Buelke-Sam J, Nelson CJ, Byrd RA, Holson JF: Blood flow during pregnancy in the rat: I. Flow patterns to maternal organs. Teratology 1982;26:269-277.

15. Heesen BJ, De Mey JGR: Effects of cyclic AMP-affecting agents on contractile reactivity in isolated mesenteric and renal resistance arteries of the rat. Br J Pharmacol 1990;101:859-864.

16. Stassen FRM, Raat NJH, Brouwers-Ceiler DL, Fazzi GE, Smits JFM, DeMey JGR: Angiotensin II induces media hypertrophy and hyperreactivity in mesenteric but not epigastric small arteries of the rat. J Vasc Res 1997;34:289-297.

17. Van Eijndhoven HWF, van der Heijden OWH, Fazzi GE, Aardenburg R, Spaanderman MEA, Peeters LLH, De Mey JGR: Vasodilator reactivity of calcitonin gene-related peptide is increased in mesenteric arteries of rats during early pregnancy. J Vasc Res 2003;40:344-350.

18. Szallasi A, Blumberg PM: Vanilloid (capsaicin) receptors and mechanisms. Pharmacol Rev 1999; 51:159-211.

19. Paller MS: Mechanism of decreased pressor responsiveness to ANG II, NE and vasopressin in pregnant rats. Am J Physiol 1984;269:H100-H108. 


\section{CHAPTER 5}

20. Vanhoutte P, Verbeuren T, Webb R: Local modulation of adrenergic neuroeffector interaction in the blood vessel wall. Physiol Rev 1981;61:151-247.

21. Minegishi T, Nakamura M, Abe K, Tano M, Andoh A, Yoshida M, Takagi T, Nishikimi T, Kojima M, Kangawa K: Adrenomedullin and atrial natriuretic peptide concentrations in normal pregnancy and preeclampsia. Mol Hum Reprod 1999;5:767-770.

22. Moriyama T, Otani T, Maruo T: Expression of adrenomedullin by human placental cytotrophoblast and choriocarcinoma JAr cells. J Clin Endocrinol Metab 2001;86:3958-3961

23. Makino I, Shibata K, Makino Y, Kangawa K, Kawarabayashi T: Adrenomedullin attenuates the hypertension in hypertensive pregnant rats induced by $\mathrm{N}^{\mathrm{G}}$-nitro-L-arginine methyl ester. Eur $\mathrm{J}$ Pharmacol 1999;371:159-167.

24. Ross GR, Yallampalli C: Vascular hyperresponsiveness to adrenomedullin during pregnancy is associated with increased generation of cyclic nucleotides in rat mesenteric artery. Biol Reprod 2007; 76:118-123.

25. Van Eijndhoven HWF, Slangen BFM, van der Heijden OWH, Aardenburg R, Spaanderman MEA, Peeters LLH: Hemodynamic changes in pseudopregnancy in chronically instrumented, conscious rats are preserved after hysterectomy. Pflügers Arch 2002; 443:427-431.

26. Gangula PRR, Zhao H, Supowit SC, Wimalawansa S, Dipette D, Yallampalli C: Pregnancy and steroid hormones enhance the vasodilatation responses to CGRP in rats. Am J Physiol 1999; 276:H284-288.

27. Grewal M, Cuevas J, Chaudhuri G, Nathan L: Effects of calcitonin gene-related peptide on vascular resistance in rats: role of sex steroids. Am J Physiol 1999;276:H2063-H2068.

28. McLatchie ML, Fraser NJ, Main MJ, Wise A, Brown J, Thompson N, Solari R, Lee MG, Foord SM: RAMPs regulate the transport and ligand specificity of the calcitonin-receptor-like receptor. Nature 1998;393:333-339.

29. Yallampalli C, Kondapaka SB, Lanlua P, Wimalawansa SJ, Gangula PRR: Female sex steroid hormones and pregnancy regulate receptors for calcitonin gene-related peptide in rat mesenteric arteries, but not in aorta. Biol Reprod 2004;70:1055-1062. 



\title{
CHAPTER 6
}

\author{
SYSTEMIC VASODILATATION IN EARLY PREGNANCY: \\ ROLE OF NITRIC OXIDE AND VASCULAR REMODELING \\ IN BLUNTED VASOCONSTRICTOR RESPONSES
}

H.W.F. van Eijndhoven, B.F.M. Slangen,

R. Aardenburg, M.E.A. Spaanderman,

L.L.H. Peeters and J.G.R. De Mey 



\title{
CHAPTER 6
}

\begin{abstract}
The objective of this study was to determine, whether blunted vasoconstrictor responses in pregnancy are nitric oxide (NO)-dependent or a consequence of vascular remodeling. To this end, we studied the effect of $\mathrm{NO}$ on contractile responses to sympathetic nerve stimulation, noradrenalin, angiotensin II and vasopressin of mesenteric arteries of pregnant and non-pregnant rats in myographs. To evaluate the role of arterial remodeling by pregnancy on these contractile responses, we established morphometric properties of the arteries. Pregnancy attenuated the vasoconstrictor responses to electrical field stimulation, noradrenalin and angiotensin II but not that to vasopressin. This effect was not abolished by incubation of the arteries with NO. Pregnancy did not alter the morphometry of mesenteric arteries. We conclude that pregnancy is associated with blunted arterial responses to selective stimulation of sympathetic nerves, noradrenalin and angiotensin II. Neither NO nor structural morphometric changes of the arterial wall modifies these pregnancy-related changes.
\end{abstract}

\section{INTRODUCTION}

Hemodynamic changes in early pregnancy are characterized by a rise in cardiac output and plasma volume, a fall in peripheral vascular resistance [1,2] and hemodilution. These changes seem to develop secondary to a fall in systemic vascular tone and have been observed in human [3], rat [4] and sheep [5] pregnancy. Although the functional meaning of this phenomenon is still obscure, the observation that its defective development in the human is associated with poor placentation and hypertensive complications of pregnancy [3] emphasizes its importance. Although these complications only occur in the second half of pregnancy, vasorelaxation can already be detected by 5 weeks human pregnancy [3] and 8 days rat pregnancy [4].

The mechanism responsible for the early-pregnancy vasorelaxation is still unclear. Several reports provide evidence that pregnancy in rat attenuates the constrictor response of isolated arteries to a wide range of agonists [6]. The agents tested sort their effect through different mechanisms of signal transduction, suggesting that the blunted vasoconstriction in pregnancy results from an effect on the common final pathway of the excitation-contraction coupling in the vascular smooth muscle cells [7]. Therefore, it is conceivable that the earlypregnancy systemic vasodilatation develops in response to pregnancy-specific hormones such as relaxin [8] acting in concert with higher circulating levels of endothelium-derived vasodilators such as nitric oxide $[9,10]$. 
In this study, we tested the hypothesis that the blunted response to constrictor agents in early pregnancy is at least in part due to elevated intra-arterial levels of nitric oxide. To test this hypothesis, we determined concentration-response curves for various vasoconstrictor agonists and sympathetic nerve stimulation in mesenteric resistance arteries from nonpregnant and 10days pregnant rats, in the absence and presence of $\mathrm{N}^{\mathrm{G}}$-nitro-L-arginine methyl ester (LNAME), an inhibitor of nitric oxide synthase. Finally, we compared the mesenteric artery structure in the pregnant with that in the nonpregnant rat to assess, whether arterial remodeling had contributed to the observed differences in response.

\section{MATERIAL AND METHODS}

\section{Animals and arteries}

The Ethics Committee for the Use of Experimental Animals of the University of Maastricht approved the experimental procedures. The study was carried out on arteries of 3-4-month-old pregnant and nonpregnant Wistar rats (Iffa Credo, Someren, The Netherlands). The rats were housed in individual cages and handled in a standardized fashion, which includes a $12 \mathrm{~h} / 12 \mathrm{~h}$ light/dark cycle and free access to standard rat chow (Hope Farms, Woerden, The Netherlands) and acidified water. Pregnancy was achieved by allowing the rats to mate with a male rat. The presence of a sperm plug was defined as the first day of pregnancy. At day 10 of pregnancy the animals were killed by cervical dislocation and exsanguination. At the same day after arrival in our laboratory facility, virgin 'control' rats were sacrificed similarly. A first order branch of the superior mesenteric artery was isolated under a dissection microscope. Arterial segments ( $2 \mathrm{~mm} \mathrm{long}$ ) were mounted on two stainless wires (diameter $40 \mu \mathrm{m}$ ) in an isometric myograph (JP Trading, Aarhus, Denmark) between a force transducer (Kistler Morse DSC6, Seattle, WA, USA) and a displacement device for the recording of isometric tension development. We kept the preparations in Krebs-Ringer bicarbonate (KRB) solution, at $37^{\circ} \mathrm{C}$ and aerated them with $95 \% \mathrm{O}_{2} / 5 \% \mathrm{CO}_{2}$. All arterial segments were stretched to their optimal lumen diameter by stepwise stretching them with increments of $50 \mu \mathrm{m}$. Maximal depolarization with high potassium solution (K-KRB) was used as activating stimulus. The diameter at which a maximal contractile response was obtained was considered to be the optimal diameter, at which all experiments were performed.

\section{Experimental protocol}

Concentration-response curves for noradrenaline, vasopressin, and angiotensin II were conducted at basal tone. After each experiment, the preparation was allowed to return to 


\section{CHAPTER 6}

baseline by rinsing the drug. We used electrical field stimulation (EFS; $90 \mathrm{~V}, 0.5-32 \mathrm{~Hz}$ ) to activate perivascular sympathetic nerves [11]. Than, we incubated the arteries for $30 \mathrm{~min}$ in a solution of $100 \mu \mathrm{M}$ L-NAME. Repeating the concentration-response curves for the different stimuli described above assessed the effect of L-NAME. Finally, we repeated the EFS after incubation of the vessels with cocaine $(3 \mu \mathrm{M})$ for at least $15 \mathrm{~min}$ to establish a neuronal uptake-blockade.

\section{Drugs and solutions}

The KRB-solution contained the following compounds (mmol/l): $\mathrm{NaCl} \mathrm{118.5,} \mathrm{KCl} 4.7$, $\mathrm{MgSO}_{4} \cdot 7 \mathrm{H}_{2} \mathrm{O}$ 1.2, $\mathrm{NaHCO}_{3} 25.0, \mathrm{CaCl}_{2} 2.5, \mathrm{KH}_{2} \mathrm{PO}_{4} 1.2$ and glucose 5.5. K-KRB contained an equimolar concentration of $\mathrm{KCl}$ instead of $\mathrm{NaCl}$. We diluted noradrenaline, vasopressin, angiotensin II and L-NAME (Sigma Chemical Co., St Louis, MO, USA) with distilled water to the final concentration.

\section{Morphometry}

After completion of the contractile experiments, the arteries were fixed at the optimal lumen diameter for $30 \mathrm{~min}$ in $4 \%$ phosphate-buffered $(\mathrm{pH}$ 7.4) paraformaldehyde and embedded in paraffin. Cross-sections $(4 \mu \mathrm{m})$ were stained with Lawson's solution (Boom B.V., Meppel, The Netherlands) to visualize the internal and external elastic laminae. By using a Zeis Axioscope (Zeiss, Germany) and a standard CCD camera (Stemmer, Germany), images of the cross-sections were generated. We calculated the media cross-sectional area (CSA) by subtracting the area enclosed by the internal elastic lamina from that enclosed by the media-adventitial border. Assuming a circular cross-sectional profile, we calculated the lumen radius from the internal circumference as well as the average media thickness $\left(\mathrm{M}_{\mathrm{t}}\right)$ and the wall-to-lumen ratio $(\mathrm{W} / \mathrm{L} ; \mathrm{x} 100)$.

\section{Statistics}

Contractile responses are expressed as increases in wall tension (force $/ 2 \mathrm{x}$ segment length). Concentration-response curves were analyzed by calculating sensitivity $\left(\mathrm{pD}_{2}=-\log \right.$ $\mathrm{EC}_{50}$ ) and maximal responses $\left(\mathrm{E}_{\max }\right)$ by curve fitting of the individual concentration-response curves. In the tables and figures we presented the data as means \pm SEM. We evaluated intergroup differences by analysis of variance (ANOVA). A $p<0.05$ was considered to indicate a significant difference. 


\section{RESULTS}

\section{Vasoconstrictor responses mediated by sympathetic nerves}

At basal tone EFS $(90 \mathrm{~V} ; 0.5-32 \mathrm{~Hz})$ induced a frequency-dependent vasoconstriction. These responses were diminished by over $95 \%$ in the presence of $1 \mu \mathrm{M}$ prazosin or $1 \mu \mathrm{M}$ tetrodotoxin indicating that they are mediated by peri-arterial sympathetic nerves. The maximal response of mesenteric arteries to EFS was $40 \%$ smaller in pregnant than in nonpregnant rats (figure 1a, table 1).
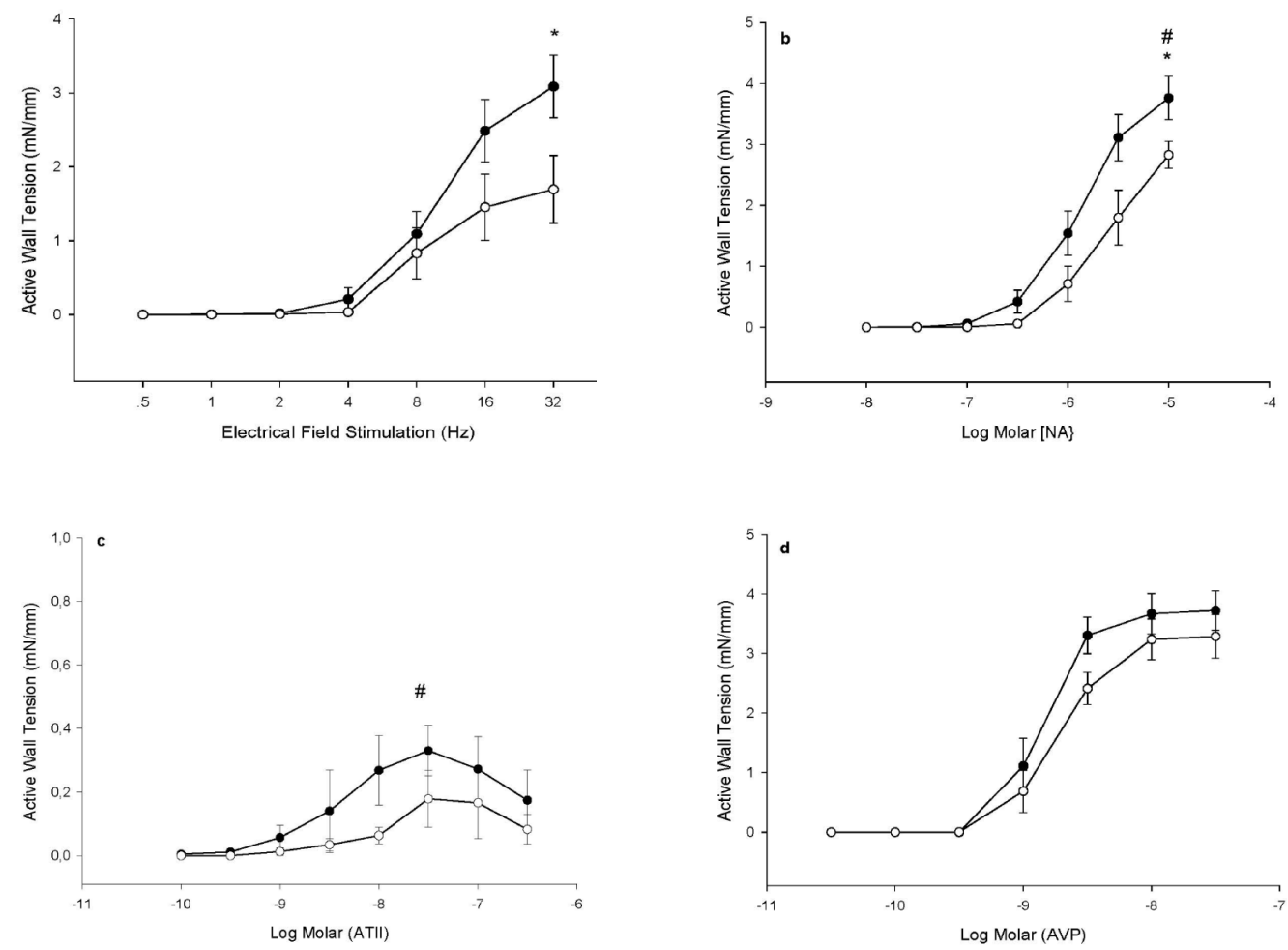

Fig. 1. Vasoconstrictor responses of mesenteric arteries in nonpregnant $(\bullet, n=12)$ and pregnant rats $(\mathrm{O}, \mathrm{n}=12)$ to (a) EFS, (b) noradrenaline (NA), (c) angiotensin II (ATII) and (d) vasopressin (AVP). $* \mathrm{p}<0.05$ for maximal responses $\left(\mathrm{E}_{\max }\right) ; \# \mathrm{p}<0.05$ for sensitivity $\left(\mathrm{pD}_{2}\right)$ 


\section{CHAPTER 6}

Table 1. Sensitivity $\left(\mathrm{pD}_{2}\right)$ and maximal contractile response $\left(\mathrm{E}_{\max }\right)$ presented as mean $\pm \mathrm{SEM}$.

\begin{tabular}{llllll}
\hline & & \multicolumn{1}{c}{ EFS } & \multicolumn{1}{c}{ NA } & \multicolumn{1}{c}{ ATII } & AVP \\
\hline \hline $\mathrm{PD}_{2}$ & $\mathrm{NP}$ & & $5.67 \pm 0.21$ & $8.95 \pm 0.06$ & $8.83 \pm 0.08$ \\
& $\mathrm{P}$ & & $4.49 \pm 0.52^{*}$ & $8.48 \pm 0.17^{*}$ & $8.70 \pm 0.12$ \\
& & & & \\
$\mathrm{E}_{\max }$ & $\mathrm{NP}$ & $3.08 \pm 0.42$ & $3.76 \pm 0.36$ & $0.33 \pm 0.17$ & $3.72 \pm 0.33$ \\
$(\mathrm{mN} / \mathrm{m})$ & $\mathrm{P}$ & $1.70 \pm 0.46^{*}$ & $2.82 \pm 0.22^{*}$ & $0.17 \pm 0.13$ & $3.28 \pm 0.37$ \\
\hline
\end{tabular}

$*$ indicates nonpregnant $(\mathrm{NP})$ being significant different $(\mathrm{p}<0.05)$ from pregnant rat $(\mathrm{P})$.

NA: noradrenaline; ATII: angiotensin II; AVP: vasopressin.

\section{Vasoconstrictor responses to noradrenaline, angiotensin II and vasopressin}

The vasoconstrictor response to noradrenaline and angiotensin II of mesenteric arteries was smaller in pregnant than in nonpregnant rats (figure $1 \mathrm{~b}$ and $\mathrm{c}$ ). Analysis of the concentration-response curves also indicated that pregnancy was associated with a lower sensitivity to noradrenaline and angiotensin II, a lower maximal response to noradrenaline, and a trend to a lower maximal response to angiotensin II, relative to the nonpregnant state (table 1; figure 1).

\section{Effect of L-NAME on vasoconstrictor response}

Only in nonpregnant rats, L-NAME seemed to increase the vasoconstrictor response to EFS, but this effect did not reach statistical significance (data not shown). The effect of LNAME on the mesenteric artery responses to EFS, noradrenaline, angiotensin II and vasopressin was small and inconsistent in both groups of rats. As a consequence, the observed difference in arterial response to EFS, noradrenaline and angiotensin II between both groups was not abolished by L-NAME. Specially, in the pregnant group responses to these stimuli were almost identical after incubation with L-NAME (figure 2).

Inhibition of the neuronal uptake by cocaine increased the magnitude of the responses to EFS similarly in both groups. However, the responses of mesenteric arteries were still smaller in pregnant rats than in nonpregnant rats (data not shown).

\section{Morphometry}

Morphometric parameters of mesenteric arteries from nonpregnant and 10-day pregnant rats were comparable (table 2). 

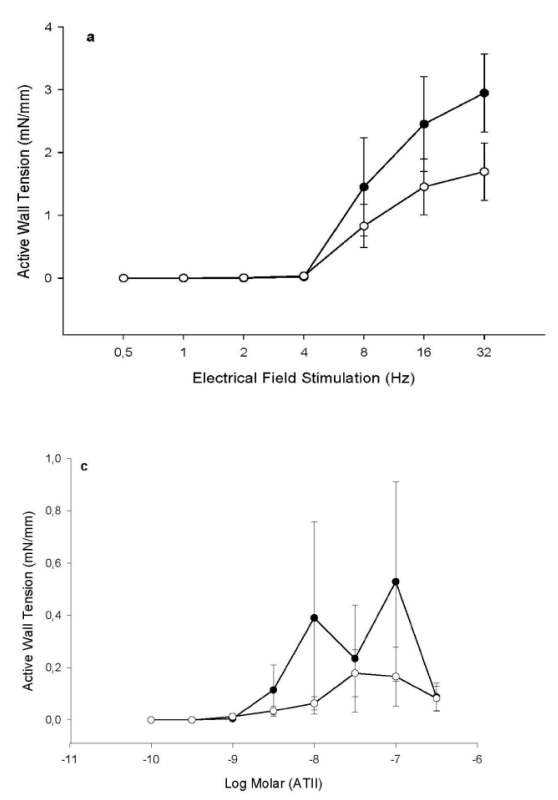

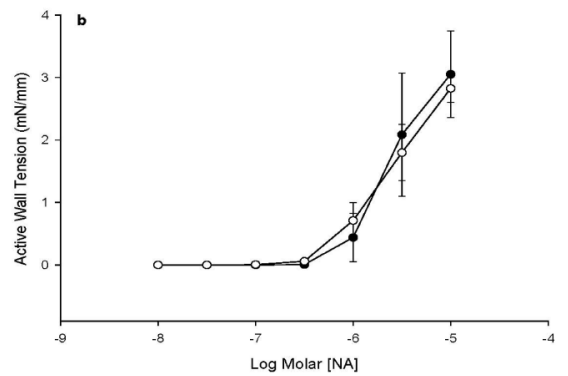

Fig.2. Vasoconstrictor responses of mesenteric arteries of pregnant rats to (a) EFS, (b) noradrenaline (NA), (c) angiotensin II (ATII) before - (O) and after incubation with L-NAME $(\bullet)$.

Table 2. Morphometric parameters in nonpregnant (NP) and pregnant rats (P)

\begin{tabular}{lcc}
\hline & $\mathrm{NP}$ & $\mathrm{P}$ \\
\hline \hline $\mathrm{CSA}\left(\mu \mathrm{m}^{2}\right)$ & $1217 \pm 198$ & $1286 \pm 304$ \\
radius $(\mu \mathrm{m})$ & $151 \pm 10$ & $147 \pm 8$ \\
$\mathrm{Mt}(\mu \mathrm{m})$ & $12.14 \pm 1.16$ & $12.93 \pm 2.14$ \\
$\mathrm{~W} / \mathrm{L}(\mathrm{x} 100)$ & $7.99 \pm 0.14$ & $8.65 \pm 1.23$ \\
\hline
\end{tabular}

Media cross-sectional area (CSA), radius, media thickness (Mt) and wall-to-lumen ratio (W/L), all expressed as mean \pm SEM for NP and P.

\section{DISCUSSION}

The results of this study in mesenteric arteries indicate that pregnancy reduces the vasoconstrictor response to perivascular sympathetic nerve stimulation, to angiotensin II and to noradrenaline, but not to vasopressin. We made these observations at day 10 of rat pregnancy, when pregnancy-related hemodynamic changes are instituted and measurable [4]. 


\section{CHAPTER 6}

Our observation on the effect of pregnancy on the vasoconstrictor response to sympathetic nerve stimulation confirms data reported by others [6,12-15]. However, the data on the effect of pregnancy on the vasoconstrictor response to noradrenaline are unsettled as some investigators reported a weaker response [12,16-18], whereas others reported inconsistent effects $[6,19]$. Almost all data reported on this topic, have been gathered in late pregnancy. Therefore, it is conceivable that inconsistent responses in late pregnancy are consequences of the increasing variability in many maternal functions with advancing pregnancy, caused by the progressively increasing metabolic and circulatory impact of the conceptus on the mother.

We observed a reduced sensitivity to noradrenaline in 10-days pregnant rats. It is still unclear, whether this reflects involvement of a prejunctional factor in the mechanism of early-pregnancy vasodilatation. To the best of our knowledge, there is no experimental evidence for degeneration of perivascular sympathetic nerves [12], a lower perivascular noradrenaline content [20] or enhanced re-uptake and/or degeneration of endogenously released noradrenaline in non-uterine arteries during rat pregnancy. Blockage of neuronal uptake of endogenously-released noradrenalin by cocaine did not abolish the lower arterial response in pregnancy, thus rejecting the option of an enhanced uptake of the transmitter. It is possible that neurotransmitters other than noradrenaline are involved in the weaker vasoconstrictor response to EFS in pregnancy. In a recent study, we found that mesenteric arteries release calcitonin gene-related peptide from their sensory-motor nerves during stimulation with $\mathrm{K}^{+}$ and that pregnancy had altered this response [21]. This could indicate that the attenuated neurogenic vasoconstrictor response of mesenteric arteries in pregnancy results from enhanced effects of calcitonin gene-related peptide released by sensory-motor nerves during EFS.

Pregnancy reduced the contractile response to angiotensin II and noradrenaline, but did not seem to affect that to vasopressin and $\mathrm{K}^{+}$[21]. This may indicate that pregnancy selectively inhibits the signal transduction pathways initiated by angiotensin 1 and $\alpha_{1}$ adrenergic receptor activation. In view of current knowledge about signal-transduction $[22,23]$, depolarisation-induced calcium-influx through voltage-operated calcium channels and modulation of calcium-sensitivity by the RhoA/Rho-kinase pathway would not be affected, while response due to signalling through phospholipase $\mathrm{C}$ and protein kinase $\mathrm{C}$ would be selectively impaired. Pregnancy may also indirectly reduce the vasoconstrictor response of the stimuli mentioned above, e.g. by the concomitant enhanced endometrial release of vasodilators. It is known that $\alpha_{2}$-adrenoreceptor stimulation triggers induciblenitric-oxide-dependent vasodilatation. Therefore, we also evaluated the effect of nitric oxide synthase inhibition by L-NAME on the pregnancy-related reduction in vasoconstrictor response. Neither we, nor others $[6,12,19,24]$ were able to demonstrate a consistent effect of L- 
NAME suggesting that the pregnancy-dependent decrease in vasoconstrictor response develops independently of nitric oxide modulation $[6,12,19,24]$.

In contrast to others $[6,12,25]$, we did not find a lower pressor response to vasopressin in pregnancy. Since we did find a trend to a decreased pressor response to vasopressin in midpregnancy, it is possible that the blunted pressor response described by others is limited to late pregnancy.

Vascular remodeling, which consists of an increase in distensibility and a decrease of the arterial wall thickness, could have contributed to blunted pressor responses in mid-pregnancy. Previously, we reported a rise in aortic compliance and distensibility [26] in mid-pregnant rat. Our data on vascular morphology in this study indicate absence of remodeling of the mesenteric artery by 10-days pregnancy. It follows that vascular remodeling does not contribute to the observed blunted vasoconstrictor response by 10-days pregnancy.

In summary, early pregnancy blunts some but not all vasoconstrictor responses in isolated mesenteric arteries of the rat. Neither modulation by endothelium-derived nitric oxide nor vascular wall remodeling can explain this effect. Therefore, it is likely that the reduced vasoconstrictor response in pregnancy is a selective effect of some yet unknown factor on the signal-transduction pathway in vascular smooth muscle cells. 


\section{CHAPTER 6}

\section{REFERENCES}

1. Chapman AB, Abraham WT, Zamudio S, Coffin C, Merouani A, Young D, Johnson A, Osorio F, Goldberg C, Moore LG, Dahms T, Schrier RW: Temporal relationship between hormonal and hemodynamic changes in early human pregnancy. Kidney Int 1998;54:2056-2063.

2. Duvekot JJ, Cheriex EC, Pieters FAA, Menheere PPC, Schouten HJA, Peeters LLH: Maternal volume homeostasis in early pregnancy in relation to fetal growth restriction. Obstet Gynecol 1995;85:361-367.

3. Duvekot JJ, Cheriex EC, Pieters FAA, Menheere PPC, Peeters LLH: Early pregnancy changes in hemodynamics and volume homeostasis are consecutive adjustments triggered by a primary fall in systemic vascular tone. Am J Obstet Gynecol 1993;169:1382-1392.

4. Slangen BFM, Out ICM, Verkeste CM, Peeters LLH: Hemodynamic changes in early pregnancy in chronically instrumented conscious rats. Am J Physiol 1996;270:H1779-1784.

5. Rosenfeld CR: Distribution of cardiac output in ovine pregnancy. Am J Physiol 1977;232:H231-235.

6. Ralevic V, Burnstock G: Mesenteric arterial function in the rat in pregnancy: role of sympathetic and sensory-motor perivascular nerves, endothelium, smooth muscle, nitric oxide and prostaglandins. $\mathrm{Br} \mathrm{J}$ Pharmacol 1996;117:1463-1470.

7. Meyer MC, Brayden JE, McLaughlin MK: Characteristics of vascular smooth muscle in the maternal resistance circulation during pregnancy in the rat. Am J Obstet Gynecol 1993;169:1510-1516.

8. Novak J, Danielson LA, Kerchner LJ, Sherwood OD, Ramirez RJ, Moalli PA, Conrad KP: Relaxin is essential for renal vasodilation during pregnancy in conscious rats. Clin Invest 2001;107:1469-1475.

9. Conrad K, Gandley RE, Ogawa T, Nakanishi S, Danielson LA: Endothelin mediates renal vasodilatation and hyperfiltration during pregnancy in chronically instrumented conscious rats. Am J Physiol 1999; 276: F767-776.

10. Brooks VL, Clow KA, Welch LS, Giraud GD: Does nitric oxide contribute to the basal vasodilatation of pregnancy in conscious rabbits? Am J Physiol 2001;281:R1624-1632.

11. Sanders M, Fazzi G, Janssen G, Blanco C, De Mey JG: Prenatal stress changes rat arterial adrenergic reactivity in a regionally selective manner. Eur J Pharmacol 2004;488:147-155.

12. Chu ZM, Beilin LJ: Mechanisms of vasodilatation in pregnancy: studies of the role of prostaglandins and nitric-oxide in changes of vascular reactivity in the in situ blood perfused mesentery of pregnant rats. Br J Pharmacol 1993;109:322-329.

13. Nelson SH, Steinsland OS, Johnson RL, Suresh MS, Gifford A, Ehardt JS: Pregnancy-induced alterations of neurogenic constriction and dilation of human uterine artery. Am J Physiol 1995;268: H1694-1701.

14. Coelho EB, Ballejo G, Salgado MC: Nitric oxide blunts sympathetic response of pregnant normotensive and hypertensive rat arteries. Hypertension 1997;30:585-588.

15. Chu ZM, Beilin LJ: Neuropeptide Y and mesenteric sympathetic vasoconstriction in pregnant and nonpregnant Wistar-Kyoto rats. Clin Exp Pharmacol Physiol 1998;25:630-632.

16. Paller MS: Mechanism of decreased pressor responsiveness to ANG II, NE and vasopressin in pregnant rats. Am J Physiol 1984;257:H100-108.

17. Parent A, Schiffrin EL, St-Louis J: Role of the endothelium in adrenergic responses of mesenteric artery rings of pregnant rats. Am J Obstet Gynecol 1990;163:229-234.

18. Weiner C, Liu KZ, Thompson L, Herrig J, Chestnut D: Effect of pregnancy on endothelium and smooth muscle: their role in reduced adrenergic sensitivity. Am J Physiol 1991;261:H1275-1283.

19. Chu ZM, Beilin: LJ: Demonstration of the existence of nitric oxide-independent as well as nitric oxidedependent vasodilator mechanisms in the in situ renal circulation in near term pregnant rats. $\mathrm{Br} \mathrm{J}$ Pharmacol 1997;122:307-315.

20. Hart JL, Freas W, Muldoon SM: Neurovascular function in the rat during pregnancy. Am J Physiol 1986;251:H1000-1008. 


\section{ROLE OF NO AND VASCULAR REMODELING IN PREGNANCY}

21. Van Eijndhoven HWF, van der Heijden OWH, Fazzi GE, Aardenburg R, Spaanderman MEA, Peeters LLH, De Mey JGR: Vasodilator reactivity to Calcitonin Gene-Related Peptide is increased in mesenteric arteries of rats during early pregnancy. J Vasc Res 2003;40:344-350.

22. Somlyo AP, Somlyo AV: Signal transduction by G-proteins, rho-kinase and protein phosphatase to smooth muscle and non-muscle myosin II. J Physiol 2000;522:177-185.

23. Somlyo AP, Somlyo AV: Ca2+ sensitivity of smooth muscle and nonmuscle myosin II: modulated by $\mathrm{G}$ proteins, kinases, and myosin phosphatase. Physiol Rev 2003;83:1325-1385.

24. Novak J, Reckelhoff J, Bumgarner L, Cockrell K, Kassab S, Granger JP: Reduced sensitivity of the renal circulation to angiotensin II in pregnant rats. Hypertension 1997;30:580-584.

25. Cadorette C, Sicotte B, Brochu M, St-Louis J: Effects of potassium channel modulators on myotropic responses of aortic rings of pregnant rats. Am J Physiol 2000;278:H567-576.

26. Slangen BFM, van Ingen Schenau DS, van Gorp AW, De Mey JGR, Peeters LLH: Aortic distensibility and compliance in awake-pregnant rats. Am J Physiol 1997;272:H1260-1265. 
CHAPTER 7

GENERAL DISCUSSION 

In this thesis, we have studied various mechanisms possibly involved in the onset of early-pregnancy vasodilatation in the Wistar rat. Systemic vasodilatation in human and rat pregnancy are comparable [1] and initiate marked cardiovascular and renal changes resulting in the institution of a high-flow and low-resistance circulation. Hypertensive complications of human pregnancy are preceded by the defective development of these adaptive changes [2,3]. Therefore, unraveling the mechanisms leading to this vasorelaxation is expected to improve the insight in the etiology of hypertensive disorders of pregnancy. Today, management of these disorders is limited to symptomatic treatment and/or premature termination of pregnancy. However, better insight in the mechanisms of early vasodilatation is likely to accelerate the development of treatment modalities that may enable us to prevent, or at least delay the onset of these disorders.

Chapter 2 presents our data on hemodynamics in chronically instrumented pseudopregnant rats with and without a uterus. In both groups, cardiac output increases and total peripheral resistance decreases from day 4 postmating compared to baseline values. The observed changes resemble those in normal pregnancy and indicate that neither trophoblast nor uterus is needed for these changes to develop. It emphasizes the central role of the ovary (corpus luteum) and its hormones and not the trophoblast or uterus in triggering these changes.

Chapter 3 describes our results on reactivity to CGRP of arteries from pregnant and nonpregnant rats mounted in myographs. In mesenteric arteries of pregnant rat, CGRP elicits a significantly stronger vasodilatation. We also demonstrated that administration of $\mathrm{K}^{+}$ stimulates the release of endogenous CGRP from the arterial sensory-motor nerves. Both, this release and the CGRP content from arteries did not differ between the pregnant and nonpregnant group. These data provide evidence for a higher arterial sensitivity to CGRP in early pregnancy without a concomitant higher availability of CGRP.

Chapter 4 elaborates on our observations related to the mechanism responsible for the higher vascular response to CGRP in pregnancy. We excluded the possibility of an MMP-2dependent reduction in the CGRP inactivation as an explanation for the higher CGRP activity in pregnancy. Density of CGRP binding sites in mesenteric arteries did not differ between pregnant and nonpregnant rats. The similar arterial response in pregnant and nonpregnant rats to direct stimulation of adenylyl cyclase supports the view that enhanced coupling of CGRP receptors to adenylyl cyclase rather than an altered downstream signal-transduction pathway is responsible for the higher arterial response to CGRP in pregnancy. 
Chapter 5 presents our data on the vasodilator activity of adrenomedullin (ADM) which belongs to the same superfamily of peptides as CGRP. Vasoactive responses to this peptide of mesenteric and uterine arteries preconstricted by EFS were higher in the pregnant group. As this response did not occur in arteries preconstricted by noradrenalin, the ADM effect appears to be a prejunctional effect on perivascular sympathetic nerves. On the other hand, mesenteric arteries preconstricted by $\mathrm{K}^{+}$only responded differently to ADM in pregnancy relative to nonpregnancy after desensitization of the sensory-motor nerves by capsaicin. This provides evidence for a postjunctional mechanism, possibly orchestrated by a change in the function of the common calcitonin-receptor-like receptor.

Chapter 6 outlines our results regarding blunted vascular responses of mesenteric arteries in pregnancy to sympathetic nerve stimulation by EFS, noradrenaline and angiotensin II. These blunted responses persisted in conditions of inhibited nitric oxide synthase. Mesenteric arteries of 10-day pregnant and nonpregnant rats were morphometrically similar. The data from this study provide evidence for the concept that neither NO nor vascular remodeling contribute to the early-pregnancy vasorelaxation.

Our studies on the mechanism of vasodilatation in early pregnancy provide experimental evidence for the view that the predominance of vasodilatation in pregnancy results from a change in the response to vasodilators as well as to vasoconstrictors, with these changes taking place both at the pre- and post-junctional level.

\section{SEX STEROIDS: THE HORMONAL ENVIRONMENT IN PREGNANCY IS A PREREQUISITE FOR EARLY PREGNANCY VASORELAXATION}

Pregnancy is a condition characterized by elevated estrogen and progesterone levels of both ovarian and placental origin. Sex steroids remain elevated throughout pregnancy and play a crucial role in its normal development. Removal of the corpus luteum - the ovarian source of sex steroid production - before the so-called luteo-placental shift results in a miscarriage. Progesterone and $17 \beta$-estradiol have a wide range of effects on target cells in reproductive tissues mediated by genomic and nongenomic pathways $[4,5]$. They also play a role in the vascular function through their specific receptors in the endothelium and vascular smooth muscle cells [6-8]. Progesterone and 17ß-estradiol have vasodilator properties [9-13], which raises the question, whether pregnancy-like hemodynamic changes can be mimicked by creating an identical hormonal environment in nonpregnant animals. To our knowledge such an experimental setup in animal models has never been reported. As hormonal changes in pseudopregnant rats resemble closely those in early normal pregnant rats [14-16], the 


\section{CHAPTER 7}

pseudopregnant rat represents an elegant experimental model to study the independent contribution of luteal hormones on the early-pregnancy cardiovascular adaptation. Chapter 2 presents our data on hemodynamic changes in hysterectomized pseudopregnant rats. The observed changes are almost identical to the ones in intact pseudopregnant - and normal pregnant rats. Progesterone receptor blockade also eliminated the systemic vasodilatation in pseudopregnant rats (unpublished data). Although, we did not measure the hormonal levels in that study, this observation provides indirect support for the concept that luteal hormones play a crucial role in triggering the initial hemodynamic adaptation. From these data we concluded that luteal hormones play a critical role in creating the hormonal environment necessary for early-pregnancy vasodilatation.

\section{PERIVASCULAR NERVES: CHANGES AT THE PREJUNCTIONAL LEVEL IN PREGNANCY}

In chapter 6 we presented our data supporting a lower contractile responsiveness of mesenteric arteries during pregnancy to both noradrenaline and electrical field stimulation of its sympathetic nerves. The experimental design of this study, though, did not enable us to determine, whether the latter effects were a consequence of pre- or postjunctional sympathetic changes. Alterations in sympathetic nerve density on the one hand, and release, uptake or degradation of transmitter content, on the other hand, may be involved. Mesenteric arteries display a higher neuronal uptake of cathecholamines in late-pregnant than in nonpregnant rats [17]. However, using the same experimental setup with blockade of noradrenaline reuptake, we were unable to reproduce this effect in early pregnancy. Although, the uterus is known for its sympathetic nerve degeneration during pregnancy [18-20], there is no experimental evidence for a similar effect in the arterial wall in early pregnancy [21]. Our data presented in chapter 5 provide evidence for adrenomedullin inducing a stronger vasodilator response in arteries of pregnant than in arteries of nonpregnant rats during neurogenic constriction, but not after being preconstricted by noradrenaline. These observations support the concept that adrenomedullin inhibits the effect of sympathetic nerves at the prejunctional level. Adrenomedullin is a vasodilator peptide with both endothelium-dependent and independent vasodilator activity. One of the properties of adrenomedullin is the inhibition of noradrenaline release by adrenergic nerves [22-24]. Therefore, adrenomedullin may be indirectly involved in the early-pregnancy vasodilatation by its inhibiting effect on sympathetic nervous function.

CGRP is released from sensory-motor nerves distributed throughout the cardiovascular system. Although circulating levels of CGRP [25] and vascular sensitivity to CGRP increase in pregnancy (chapter 3), we did not find a concomitant rise in perivascular sensory-motor nerve density or CGRP content (chapter 3 ). The latter observation indicates that a 
prejunctional effect is highly unlikely in the pregnancy-related increased CGRP sensitivity and thus, opposes a role of sensory-motor nerves at a prejunctional level and of the raised circulating levels of CGRP in the early-pregnancy vasodilatation. There is experimental evidence for sensory-motor nerves and sympathetic nerves to share a common topography and to act as functional antagonists through their transmitters CGRP and Neuropeptide $Y$ [26]. Like adrenomedullin, CGRP inhibits the release of noradrenaline from sympathetic nerves [27,28]. Furthermore, in chapter 5 we described a clear rise in adrenomedullin activity in the absence of CGRP after desensitization of the sensory-motor nerves. As mentioned earlier, adrenomedullin modulates sympathetic innervation. We speculate that altered crosstalk between these neurovascular systems is involved in the early-pregnancy vasodilatation.

\section{RECEPTORS: CHANGES IN PREGNANCY}

We demonstrated that both CGRP (chapter 3) and adrenomedullin (chapter 5) elicit increased vasodilator responses in mesenteric arteries of pregnant rat. Our data suggest that at least part of this effect is due to postjunctional changes. We also noticed that pregnancy did not change the vasodilator response of the post-receptor transduction pathway of CGRP, which implies that the higher sensitivity to vasodilators in pregnancy results from a change at the receptor level. CGRP and adrenomedullin use calcitonin receptor-like receptor (CRLR), which can both function as a CGRP - and as an ADM receptor, depending on the coupling to so-called receptor-activity-modifying proteins (RAMP's). CRLR may either bind to RAMP to form the CGRP-A receptor, or to $\mathrm{RAMP}_{2}$ or $\mathrm{RAMP}_{3}$ to form the ADM receptor [29,30]. In mesenteric arteries of pregnant rats, mRNA levels of RAMP ${ }_{1}$ increase gradually from early pregnancy onward [31] as opposed to CRLR, which does not change until day 18 , to increase sharply afterwards [31]. These observations are in line with our data of unchanged CGRP arterial binding sites by day 10 of pregnancy relative to the pre-pregnant condition. The regulation of CRLR-RAMP coupling is still poorly understood. Studies in endothelial cell lines indicate that interaction between RAMP's can lead to competition between the different RAMP types [32]. Whether such dynamic interaction plays a role in the increased vasodilator responsiveness to CGRP in pregnancy is unsettled. In rat uterus ADM receptors are upregulated during pregnancy [33]. However, it is unknown, whether such effect can be found in arteries. In chapter 5, we described the pregnancy-dependent stronger relaxation of mesenteric arteries in response to adrenomedullin in the absence of endogenously released CGRP. This finding could indicate that changes in receptor coupling modulated by changes in coupling to RAMPs are responsible for the increased relaxing responses to both adrenomedullin and CGRP in pregnancy. The role of the CGRP-receptor component (RCP) in 
this context is still unclear. The RCP allows direct coupling of the CGRP receptor to the intracellular signalling pathway $[34,35]$. Recently, it was demonstrated that human pregnancy is associated with an increased myometrial mRNA expression of CGRP-RCP [36]. We speculate that early pregnancy is a state with increased receptor coupling modulated by changes in RCP and/or RAMP. Reproductive steroids, changes in the levels of CGRP and/or adrenomedullin, but also interaction between the RAMPs are potential mechanisms responsible for these changes.

In chapter 6, we describe reduced vasoconstrictor responsiveness to both electrical field stimulation and noradrenaline. There is no evidence for pregnancy-induced changes in vascular $\alpha_{2}$ or $\beta$-adrenergic receptors [37]. Animal studies on this subject are scarce and provide conflicting results with both increased [38] or unchanged [39,40] levels of arterial $\alpha_{1}$ adrenergic receptors. Therefore, experimental evidence supporting a change in the adrenergic receptors or their coupling to G-proteins being responsible for the early-pregnancy vascular relaxation is lacking. Meanwhile, a pregnancy-induced fall in the ratio of angiotensin-1 (vasoconstriction) and angiotensin-2 receptors (vasodilatation) is thought to explain the lack of response to infused angiotensin II in the pregnant uterine artery [41]. As a matter of fact, in the renal cortex of pregnant rats this lower ratio is well documented. Finally, inhibition of angiotensin II by relaxin is also documented $[42,43]$. Together with the recently provided evidence for a relaxin ligand-receptor system in renal and mesenteric arteries of rats [44] this presents another potential candidate in the regulation of arterial function in pregnancy.

The studies incorporated in this thesis did not identify a single factor responsible for the early-pregnancy vasodilatation. Instead, they support the concept of a complex pattern of changes in different vasoactive systems. These changes are summarized in a cartoon at the end of this chapter. Estrogen and progesterone seem to provide the endocrine environment essential for these vascular changes to evolve. The studies brought together in this thesis unravel some of the mechanisms responsible for these changes. However, many questions remain unanswered and further research is needed to fill in the question marks in the diagram. 


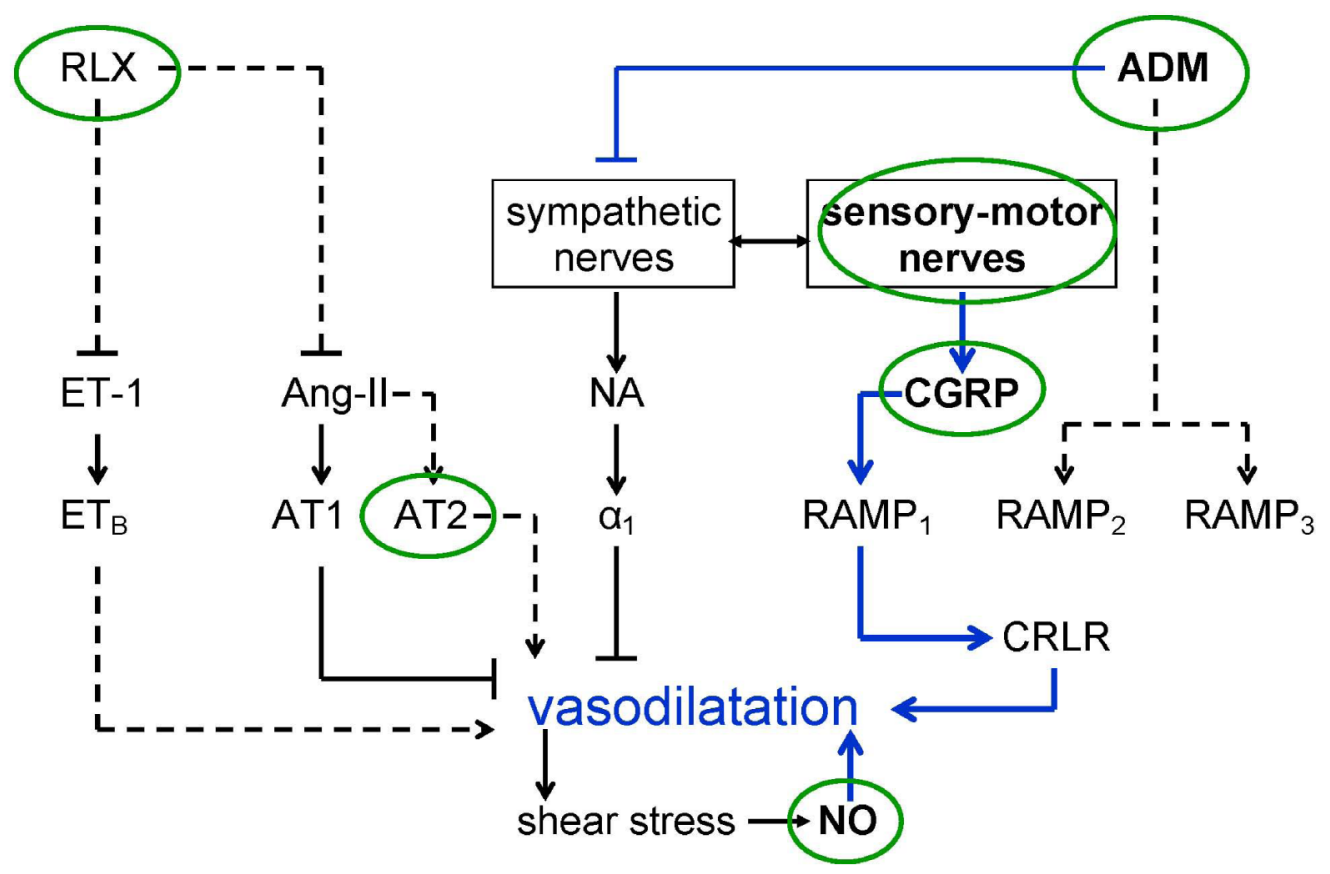

Figure. A schematic diagram of potential (dotted lines) and established (black and blue - this thesis lines) effects of different vasoactive factors and their receptors on vasodilatation in pregnancy. Relaxin (RLX), ADM (adrenomedullin), CGRP (calcitonin gene-related peptide) ET-1 (endothelin 1), Ang II (angiotensin II), NA (noradrenalin), NO (nitric oxide). 


\section{CHAPTER 7}

\section{REFERENCES}

1. Slangen BFM, Out ICM, Verkeste CM, Peeters LLH: Hemodynamic changes in early pregnancy in chronically instrumented conscious rats. Am J Physiol 1996;270:H1779-1784.

2. Duvekot JJ, Cheriex EC, Pieters FAA, Menheere PPC, Schouten HJA, Peeters LLH: Maternal volume homeostasis in early pregnancy in relation to fetal growth restriction. Obstet Gynecol 1995;85:361-367.

3. Spaanderman MEA, Willekes C, Hoeks AP, Ekhart THA, Aardenburg R, Courtar DA, van Eijndhoven HWF, Peeters LLH: Maternal nonpregnant vascular function correlates with subsequent fetal growth. Am J Obstet Gynecol 2005;192(2):504-512.

4. Revelli A, Massobrio M, Tesarik J: Nongenomic actions of steroid hormones in reproductive tissues. Endocr Rev 1998;19(1):3-17.

5. Katzenellenbogen BS: Mechanisms of action and cross-talk between estrogen receptor and progesterone receptor pathways. J Soc Gyn Investig 2000;7(1):S33-37.

6. Rupnow HL, Phernetton TM, Shaw CE, Modrick ML, Bird IM, Magness RR: Endothelial vasodilator production by uterine and systemic arteries. VII. Estrogen and progesterone effects on eNOS. Am J Physiol 2001;280(4):H1699-H1705.

7. Simoncini T, Mannella P, Fornari L, Caruso A, Willis MY, Garibaldi S, Baldacci C, Genazzani AR: Differential signal transduction of progesterone and medroxyprogesterone acetate in human endothelial cells. Endocrinology 2004;145(12):5745-5756.

8. Byers MJ, Zangl A, Phernetton TM, Lopez G, Chen DB, Magness RR: Endothelial vasodilator production by ovine uterine and systemic arteries: ovarian steroid and pregnancy control of ERalpha and ERbeta levels. J Physiol 2005;565(1):85-99.

9. Rosenfeld CR: Responses of reproductive and nonreproductive tissues to 17beta-estradiol during ovine puerperium. Am J Physiol 1980;239(5):E333-E339.

10. Naden RP, Rosenfeld CR: Systemic and uterine responses to angiotensin II and norepinephrine in estrogen-treated nonpregnant sheep. Am J Obstet Gynecol 1985;153(4):417-425.

11. Magness RR, Rosenfeld CR: Local and systemic estradiol-17ß: effects on uterine and systemic vasodilation. Am J Physiol 1989;E536-E542.

12. Davis LE, Magness RR, Rosenfeld CR: Role of angiotensin II and alpha-adrenergic receptors during estrogen-induced vasodilation in ewes. Am J Physiol 1992;263(5): E837-E843.

13. Omar HA, Ramirez R, Gibson M: Properties of a progesterone-induced relaxation in human placental arteries and veins. J Clin Endocrinol Metab 1995;80(2):370-373.

14. De Greef WJ, Dullaart J, Zeilmaker GH: Serum concentrations of progesterone, luteinizing hormone, follicle stimulating hormone and prolactin in pseudopregnant rats: effect of decidualization. Endocrinology 1977;101:1054-1063.

15. Atherton JC, Bu'lock D, Pirie SC: The effect of pseudopregnancy on glomerular filtration rate and salt and water reabsorption in the rat. J Physiol Lond 1982;324:11-20.

16. Garland HO, Atherton JC, Baylis C, Morgan MRA, Milne CM: Hormone profiles for progesterone, estradiol, prolactin, plasma renin activity, aldosterone and corticosterone in two strains of rats: correlation with renal studies. J Endocrinol 1987;113:435-444.

17. Crandall ME, Keve TM, McLaughlin MK: Characterization of norepinephrine sensitivity in the maternal splanchnic circulation during pregnancy. Am J Obstet Gynecol 1990;162(5):1296-1301.

18. Brauer MM, Chávez-Genaro R, Llodrá J, Richeri A, Scorza MC: Effects of chronic oestrogen treatment are not selective for uterine noradrenaline-containing sympathetic nerves: a transplantation study. J Anat 2000;196(3):347-355.

19. Lobos E, Gebhardt C, Kluge A, Spanel-Borowski K: Expression of nerve growth factor (NGF) isoforms in the rat uterus during pregnancy: accumulation of precursor proNGF. Endocrinology 2005;146(4): 1922-1929. 


\section{GENERAL DISCUSSION AND SUMMARY}

20. Chávez-Genaro R, Lombide P, Anesetti G: A quantitative study of rat uterine sympathetic innervation during pregnancy and post partum. Reprod Fertil Dev 2006;18(5):525-531.

21. Aukes AM, Bishop N, Godfrey J, Cipolla MJ: The influence of pregnancy and gender on perivascular innervation of rat posterior cerebral arteries. Reprod Sci 2008;15(4):411-419.

22. Charles CJ, Rademaker MT, Richards AM, Cooper GJ, Coy DH, Jing NY, Nicholls MG: Hemodynamic, hormonal, and renal effects of adrenomedullin in conscious sheep. Am J Physiol 1997; 272(6):R2040-R2047.

23. Fujioka H, Okamura T, Toda N: Inhibition by adrenomedullin of amine release from adrenergic nerves in dog mesenteric arteries. Eur J Pharmacol 1999;385(2-3):155-161.

24. Akiyama S, Hatanaka Y, Hobara N, Honghua J, Kosugi K, Takayama F, Kawasaki H: Effect of adrenomedullin on adrenergic vasoconstriction in mesenteric resistance arteries of the rat. J Pharmacol Sci 2005;99(3):264-271.

25. Gangula PRR, Wimalawansa SJ, Yallampalli C: Pregnancy and sex steroids enhance circulating calcitonin gene-related peptide concentrations in rats. Hum Reprod 2000;15:949-953.

26. DeMey JG, Megens R, Fazzi GE: Functional antagonism between endogenous neuropeptide $Y$ and calcitonin gene-related peptide in mesenteric resistance arteries. J Pharmacol Exp Ther 2008;324(3): 930-937.

27. Kawasaki H, Nuki C, Saito A, Takasaki K: Role of calcitonin gene-related peptide-containing nerves in the vascular adrenergic neurotransmission. J Pharmacol Exp Ther 1990;252(1):403-409.

28. Takenaga M, Kawasaki H: Endogenous calcitonin gene-related peptide suppresses vasoconstriction mediated by adrenergic nerves in rat mesenteric resistance blood vessels. Eur J Pharmacol 1999; 367(23):239-245.

29. McLatchie ML, Fraser NJ, Main MJ, Wise A, Brown J, Thompson N, Solari R, Lee MG, Foord SM: RAMPs regulate the transport and ligand specificity of the calcitonin-receptor-like receptor. Nature 1998;393:333-339.

30. Thota C, Gangula PRR, Dong YL, Yallampalli C: Changes in the expression of calcitonin receptor-like receptor, Receptor Activity-Modifying Protein (RAMP) 1, RAMP2, and RAMP3 in rat uterus during pregnancy, labor and by steroid hormone treatments. Biol Reprod 2003;69:1432-1437.

31. Yallampalli C, Kondapaka SB, Lanlua P, Wimalawansa SJ, Gangula PRR: Female sex steroid hormones and pregnancy regulate receptors for Calcitonin Gene-Related Peptide in rat mesenteric arteries, but not in aorta. Biol Reprod 2004;70:1055-1062.

32. Muff R, Leuthäuser K, Bühlmann N, Foord SM, Fischer JA, Born W: Receptor activity modifying proteins regulate the activity of a calcitonin gene-related peptide receptor in rabbit aortic endothelial cells. FEBS Lett 1998;441(3):366-368.

33. Thota C, Yallampalli C: Progesterone upregulates calcitonin gene-related peptide and adrenomedullin receptor components and cyclic adenosine 3'5'-monophosphate generation in Eker rat uterine smooth muscle cell line. Biol Reprod 2005;72(2):416-422.

34. Evans BN, Rosenblatt MI, Mnayer LO, Oliver KR, Dickerson IM: CGRP-RCP, a novel protein required for signal transduction at calcitonin gene-related peptide and adrenomedullin receptors. J Biol Chem 2000;275:31438-31443.

35. Prado MA, Evans-Bain B, Dickerson IM: Receptor component protein (RCP): a member of a multiprotein complex required for G-protein-coupled signal transduction. Biochem Soc Trans 2002;30:460464.

36. Goharkay N, Lu J, Felix JC, Wing DA: Expression of calcitonin gene-related peptide-receptor component protein (CGRP-RCP) in human myometrium in differing physiological states and following misoprostol administration. Am J Pernatol 2007;24(8):497-500.

37. Pantuck CB, Smiley RM: Longitudinal study of beta- and alpha-adrenergic receptor properties during human pregnancy. Am J Obstet Gynecol 1997;177(1):234-242. 


\section{CHAPTER 7}

38. Fallgren B, Bjellin L, Edvinsson L: Effect of pregnancy and sex steroids on alpha 1-adrenoceptor mechanisms in the guinea-pig uterine vascular bed. Pharmacol Toxicol 1988;63(5):375-381.

39. Guenther AE, Conley AJ, Van Orden DE, Farley DB, Ford SP: Structural and mechanical changes of uterine arteries during pregnancy in the pig. J Anim Sci 1988;66(12):3144-3152.

40. Shaul PW, Magness RR, Muntz KH, DeBeltz D, Buja LM: Alpha-1-adrenergic receptors in pulmonary and systemic vascular smooth muscle. Alterations with development and pregnancy. Circ Res 1990; 67(5):1193-1200.

41. Sullivan JA, Rupnow HL, Cale JM, Magness RR, Bird IM: Pregnancy and ovarian steroid regulation of angiotensin II type 1 and type 2 receptor expression in ovine uterine artery endothelium and vascular smooth muscle. Endothelium 2005;12(1-2):41-56.

42. Debrah DO, Conrad KP, Jeyabalan A, Danielson LA, Shroff SG: Relaxin increases cardiac output and reduces systemic arterial load in hypertensive rats. Hypertension 2005;46(4):745-750.

43. Failli P, Nistri S, Mazzetti L, Chiappini L, Bani D: Effects of relaxin on vascular smooth muscle and endothelial cells in normotensive and hypertensive rats. Ann NY Acad Sci 2005;1041:311-313.

44. Novak J, Parry LJ, Matthews JE, Kerchner LJ, Indovina K, Hanley-Yanez K, Doty KD, Debrah DO, Shroff SG, Conrad KP: Evidence for local relaxin ligand-receptor expression and function in arteries. FASEB J 2006;20(13):2352-2362. 

CHAPTER 8

SAMENVATTING 



\section{CHAPTER 8}

In de vroege zwangerschap treden indrukwekkende veranderingen op in de bloedsomloop, nierfunctie en vochthuishouding bij de moeder. Hoewel de exacte betekenis van deze hemodynamische aanpassingen niet bekend is blijkt een gestoord verloop hiervan te leiden tot ernstige zwangerschapscomplicaties zoals intra-uteriene groeivertraging en preeclampsie.

De hemodynamische veranderingen worden vooraf gegaan door een voor de zwangerschap specifieke, systemische vaatverwijding. Inzicht in het mechanisme dat verantwoordelijk is voor deze vaatverwijding kan een belangrijke bijdrage leveren aan het onderzoek naar de oorzaak van de maternale hypertensieve complicaties tijdens de zwangerschap. Doel van dit proefschrift is de exploratie van mogelijke factoren die verantwoordelijk zouden kunnen zijn voor de systemische vaatverwijding in de vroege zwangerschap. Omdat de voor de zwangerschap specifieke hemodynamische aanpassingen in de mens en de rat sterk overeenkomen is de rat een geschikt proefdier voor dit onderzoek. Voor de studies beschreven in dit proefschrift werd zowel gebruik gemaakt van een in vivo model als van geïsoleerde arteriën van de rat.

In hoofdstuk 1 wordt een literatuuroverzicht gegeven van mogelijk factoren die een rol zouden kunnen spelen bij het ontstaan van de systemische vaatverwijding in de vroege zwangerschap. Op basis van dit overzicht werden de volgende vragen geformuleerd:

- Is het voor de zwangerschap karakteristieke hormonale milieu, wat in de vroege zwangerschap bepaald wordt door steroïden van luteale oorsprong, noodzakelijk voor de inductie van de systemische vaatverwijding?

- Spelen de krachtige vaatverwijders CGRP en ADM onder invloed van deze steroïden een rol bij het ontstaan van de systemische vaatverwijding?

- Is de verminderde contractiele respons van arteriën op verschillende vaatvernauwers, die gevonden wordt aan het einde van de zwangerschap, ook een factor in de vroege zwangerschap? En speelt NO of een veranderde morfometrie van de vaatwand een rol in dit proces?

Hoofdstuk 2 beschrijft de hemodynamische aanpassingen in schijnzwangere ratten met en zonder uterus. In beide groepen wordt vanaf dag 4 van de schijnzwangerschap een toename gezien van het hartminuutvolume en een afname van de perifere vasculaire weerstand. Deze veranderingen zijn vergelijkbaar met de hemodynamische veranderingen in de gewone zwangere rat. Aangezien de hormonale veranderingen in de vroege zwangerschap en schijnzwangerschap van de rat vrijwel identiek zijn, is het aannemelijk dat zowel de trophoblast als de uterus niet nodig zijn voor het ontstaan van de systemische vaatverwijding 
in de zwangerschap. Moederlijke hormonen afkomstig van de ovaria (corpus luteum) lijken daarentegen cruciaal voor deze hemodynamische aanpassingen.

De studie beschreven in hoofdstuk 3 laat zien dat kleine arteriën afkomstig uit het mesenterium van zwangere ratten een sterkere vaatverwijding laten zien na toediening van CGRP dan arteriën van niet zwangere ratten. Tevens wordt aangetoond dat $\mathrm{K}^{+}$de afgifte van CGRP uit sensore motor zenuwen in de vaatwand stimuleert. Zowel deze afgifte als het totale gehalte van CGRP in de arteriële vaatwand laat geen verschil zien tussen de zwangere en niet zwangere groep. Deze gegevens tonen aan dat bepaalde arteriën in de vroege zwangerschap gevoeliger zijn voor CGRP zonder dat er meer CGRP beschikbaar is.

In hoofdstuk 4 wordt de studie beschreven waarin mogelijke mechanismen, die verantwoordelijk zouden kunnen zijn voor de toegenomen gevoeligheid voor CGRP in de zwangerschap, verder worden onderzocht. Er wordt aangetoond dat er geen verminderde afbraak van CGRP door MMP-2 in de zwangerschap plaats vindt. Tevens blijkt het aantal CGRP receptoren in mesenteriale arteriën niet te verschillen tussen de zwangere en niet zwangere groep. Directe stimulatie van adenylyl cyclase door forskoline geeft een vergelijkbare arteriële vaatverwijding in beide groepen. Deze bevinding maakt het waarschijnlijk dat de grotere gevoeligheid voor CGRP in de zwangerschap verklaard kan worden door veranderingen ter hoogte van de CGRP-receptor en niet door veranderingen in de signaal transductie voorbij dit niveau in de gladde spiercellen van de vaatwand.

In hoofdstuk 5 worden de resultaten beschreven van de vaatverwijdende activiteit van $\mathrm{ADM}$ in de zwangerschap. Kleine arteriën werden in de myograaf gestimuleerd door elektrische prikkels waardoor de sympatische zenuwen worden geactiveerd. De afname van de vaatvernauwing ten gevolge van deze prikkels na toediening van ADM was groter in de zwangere groep. Dit verschil werd niet gezien als de vaatvernauwing werd geïnduceerd door rechtstreekse toediening van noradrenaline. Derhalve lijkt dit effect van ADM het resultaat te zijn van een effect op de sympatische zenuwen. Als de arteriën tot vernauwing worden gebracht door $\mathrm{K}^{+}$wordt ook een toename van de activiteit van ADM gezien in de zwangere groep. Deze toename treedt echter alleen op nadat de sensore motor zenuwen zijn kapot gemaakt door capsaicine. Dit toont aan dat ADM ook op het niveau van de gladde spiercel een toename van activiteit laat zien, mogelijk door veranderingen in de functie van de gemeenschappelijke receptor van ADM en CGRP.

In hoofdstuk 6 wordt de afgenomen vasculaire activiteit van mesenteriale arteriën van zwangere ratten na stimulatie van de sympatische zenuwen en na toediening van 


\section{CHAPTER 8}

noradrenaline en angiotensine II. Deze afgenomen activiteit ten gevolge van de zwangerschap bleef ook bestaan na onderdrukking van NO synthase. Verder bleek de morfometrie van de kleine arteriën van het mesenterium niet te verschillen tussen zwangere en niet zwangere ratten. Deze studie toont aan dat de afgenomen vasculaire activiteit van verschillende vaatvernauwers in de zwangerschap niet het gevolg is van veranderde werking van $\mathrm{NO}$ of door morfometrische veranderingen van de arteriële vaatwand.

Concluderend is er niet slechts één factor aan te wijzen die verantwoordelijk is voor de systemische vaatverwijding in de vroege zwangerschap. Veel meer is er sprake van een complex samenspel van verschillende, soms elkaar tegenwerkende, en op verschillende niveaus in de vaatwand aangrijpende factoren die bijdragen aan deze hemodynamische aanpassing in de zwangerschap. Steroïden afkomstig van de ovaria zijn in ieder geval cruciaal en lijken het hele proces van vaatverwijding te dirigeren. Enerzijds is de gevoeligheid van sommige arteriën voor de krachtige vaat verwijder CGRP toegenomen, anderzijds is er sprake van een verminderde contractiele respons op sympatische prikkeling. Dit laatste mogelijk onder invloed van ADM. De verminderde contractiele respons op andere vaatvernauwers lijkt niet te worden bepaald door het endotheel of structurele morfometrische veranderingen van de vaatwand. Verder onderzoek is noodzakelijk om de exacte rol en de onderlinge verbanden tussen de verschillende factoren die een rol spelen bij de systemische vaatverwijding in de vroege zwangerschap te ontrafelen. 



\section{Dankwoord}

Het heeft even geduurd maar uiteindelijk is het wetenschappelijk onderzoek waarmee ik gestart ben tijdens mijn tijd in Maastricht, afgerond in de vorm van dit proefschrift. Dit was waarschijnlijk nooit gelukt zonder de steun en het geduld van velen. Hoewel ik inmiddels in een nieuwe fase van mijn leven zit met nieuwe wetenschappelijke uitdagingen, zijn de herinneringen aan de samenwerking met hen die betrokken zijn bij de totstandkoming van dit proefschrift nog altijd goed. Ook tijdens mijn huidige werkzaamheden in Zwolle heb ik veel steun ondervonden bij het afronden van dit werk. In het bijzonder wil ik de volgende mensen bedanken:

Dr. L.L.H. Peeters, beste Louis, de laatste jaren heb ik niet alleen veel bewondering gekregen voor je creativiteit en kennis van de zwangere vrouw, maar ook voor je geduld en je immer positieve instelling. Als inspirator van vele onderzoekers en begeleider van een groot aantal promovendi durf ik te stellen dat Maastricht in vele opzichten te klein is voor jou.

Prof. dr. J.G.R. De Mey, beste Jo, als "vreemde gynaecologische eend in de farmacologische bijt" heb ik me altijd een welkome gast gevoeld in jouw laboratorium. Dat de samenwerking tussen twee heel verschillende disciplines tot mooie resultaten kan leiden bewijst dit proefschrift. Jouw grote kennis van de farmacologie en vermogen ingewikkelde zaken op een eenvoudige wijze aan een buitenstaander duidelijk te maken hebben daar in belangrijke mate toe bijgedragen.

Prof. dr. J. de Haan, beste Jelte, voor goed wetenschappelijk onderzoek is een goed wetenschappelijk klimaat nodig. Eerst als opleider, later als directeur van GROW was je als geen ander in staat de juiste voorwaarden hiervoor te creëren. Het doet me groot genoegen dit werk onder jouw promotorschap te mogen afronden.

De leden van de beoordelingscommissie: Prof. dr. G.G.M. Essed (voorzitter), Prof. dr. J. Glatz, Prof. dr. P.W. de Leeuw en Prof. Dr. H.A.J. Struijker Boudier wil ik bedanken voor de moeite die zij hebben genomen om dit proefschrift te beoordelen.

Marijke Sanders en Brigitte Slangen, beste Marijke en Brigitte, jullie beiden hebben op geheel eigen wijze geholpen bij mijn eerste stappen op het gebied van het dierexperimenteel 
onderzoek. De verschillende technieken die nodig waren bij de in vivo experimenten en de myograaf studies had ik mij zonder jullie hulp nooit eigen kunnen maken.

Alle medewerkers van de afdeling farmacologie en toxicologie, maar in het bijzonder Gregorio Fazzi en Ger Janssen, wil ik bedanken voor de hulp bij de verschillende experimenten in het laboratorium. Om eens een tijd buiten het ziekenhuis in zo'n geheel andere omgeving te mogen werken, heb ik als bijzonder inspirerend ervaren. Hartelijk dank daarvoor.

Mijn lotgenoten binnen het PERIM, Robert Aardenburg, Audrey Coumans, Dorette Courtar, Olivier van der Heijden en Marc Spaanderman wil ik bedanken voor de mooie tijd in Maastricht en vooral ook tijdens de gezamenlijk bezochte congressen.

Thea Schenk, beste Thea, dank voor je hulp bij de laatste loodjes, de snelheid waarmee jij op zeer secure wijze dit proefschrift hebt opgemaakt vind ik nog steeds verbazingwekkend. Leny van Ingen, beste Leny, al zoveel jaren verbonden aan onze maatschap gynaecologie. Vanzelfsprekend heb je ook aan dit werk, en dan vooral bij de distributie je steentje bijgedragen. Bedankt.

Mijn paranimfen Ben Cohlen en Jan den Boon, beste Ben, als fietsmaatje richting werk en schoolplein brengen we ongemerkt heel wat tijd samen door. De vele voor- en nabeschouwingen van werk en andere dagelijkse beslommeringen en de gedeelde passie voor chips en Cola vormen een goede basis om jou als paranimf aan mijn zijde te hebben.

Beste Jan, met ons gezamenlijk aandachtsgebied, hebben we de laatste jaren heel wat uur samen aan de operatietafel, tijdens besprekingen en op congres doorgebracht. Ik merk dat ik nog steeds veel van je kan leren. De laatste jaren wordt duidelijk dat we met de urogynaecologie iets moois aan het opbouwen zijn in Zwolle. Dat jij mijn paranimf bent is hiervan het logische gevolg, en ongetwijfeld een voorbode van wat er op wetenschappelijk gebied gaat volgen.

Maatschap Zwolse Vrouwenartsen, beste Bas, Ben, Gerald, Hans, Harm, Henk, Jan, Jeroen, Jim, Joke, Mieke en Walter, door de moed waarmee we de laatste jaren veranderingen hebben doorgevoerd zijn we uitgegroeid tot een geweldige club. Een maatschap die iedere dag weer grensverleggend durft bezig te zijn, en dat bevalt prima. Hartelijk dank voor jullie steun en belangstelling in de afgelopen jaren. 
Lieve vader en moeder, eindelijk is het dan klaar. De vaardigheden die je nodig hebt om een proefschrift te schrijven worden natuurlijk grotendeels op jonge leeftijd door je ouders meegegeven. Dus ook jullie mogen trots zijn op dit werk.

Lieve Marieke, het is natuurlijk onzinnig om op deze plaats iets op te schrijven wat al vaak is uitgesproken. Toch doe ik het nog een keer: je weet dat je samen met de kinderen de allerbelangrijkste in mijn leven bent en dat ik dankbaar ben voor alles wat we samen hebben.

Tenslotte, lieve, lieve Roos en Thijs, iedere dag verwonder ik me over jullie creativiteit, fantasie en scherpzinnigheid. Daarom zijn jullie echt de allerleukste mensen die ik ken en leer ik elke dag heel veel van jullie. Ik beloof jullie nog veel meer leuke dingen samen te gaan doen en nog heel veel samen te genieten. 



\section{Curriculum vitae}

Hugo van Eijndhoven werd op 30 januari 1967 geboren te Delft. Na het doorlopen van het atheneum op het Rhedens Lyceum in Velp, begon hij in 1985 met de studie geneeskunde aan de Rijksuniversiteit Groningen. Na afronding hiervan volgde tussen 1993 en 1996 assistentschappen gynaecologie in het Weezenlanden ziekenhuis in Zwolle en het Canisius ziekenhuis in Nijmegen. In 1996 werd gestart met de opleiding tot gynaecoloog in het Academisch Ziekenhuis Maastricht (opleiders prof. dr. J. de Haan en prof. dr. J.L.H. Evers). De opleiding werd afgerond in het Maxima Medisch Centrum Veldhoven (opleiders prof. dr. H.A. Bröllman en prof. dr. G. Oei). De studies beschreven in dit proefschrift werden grotendeels verricht tijdens zijn opleiding op het laboratorium van de afdeling farmacologie van de Rijksuniversiteit Limburg.

Vanaf juli 2003 is hij werkzaam als gynaecoloog in de Isala klinieken Zwolle, waar hij zich geheel niet in overeenstemming met dit proefschrift vooral bezig houdt met de bekkenbodem gynaecologie. 